\title{
COMPARATIVE MUTAGENESIS OF HUMAN CELLS IN VIVO AND IN VITRO
}

\author{
William G. Thilly
}

Professor of Applied Biology and Civil Engineering Director, M.I.T. Center for Environmental Health Sciences Cambridge, MA 02139

May 1992

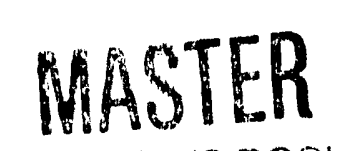

DISTRIBUTION OF THIS DOCUMENT IS UNLIMITED 


\section{Scientific Progress Report and Proposal}

\section{DISCLAIMER}

This report was prepared as an account of work sponsored by an agency of the United States Government. Neither the United States Government nor any agen y thereof, nor any of their employees, makes any warranty, express or implied, or assumes any legal liability or responsibility for the accuracy, completeness, or usefulness of any information, apparatus, product, or process disclosed, or represents that its use would not infringe privately owned rights Reference herein to any sperific commercial product, process, or service by trade name, trademark, manufacturer, or otherwise does not necessarily constitute or imply its endorsement, recommendation, or favoring by the United States Government or any agency thereof. The views and opinions of authors expressed herein do not necessarily state or reflect those of the United States Government or any agency thereof. 


\section{PROLOGUE}

An MIT provost once asked me to come to lunch with a potential donor. When the alum asked what I was doing I said I was trying to develop a reliable way to measure mutations in human cell culture. Our esteemed provost interrupted with a crack implying this wasn't a suitable goal for a "real scientist". I was "just a toolmaker". From his mouth to God's ears! In this renewal proposal are described three independent physical toois to identify and measure point mutations at the frequencies they seem to appear in real people. My lab has been working toward this goal since January 1984 when we first learned about Fischer and Lerman's use of cooperative melting equilibria in denaturing gradient gel electrophoresis. We figured DGGE would have the resolving power to let us select mutants en masse and thus overcome the immense labor and statistical problems attendarit on all "clone by clone" approaches. That turned out to be currect and our method combining DGGE and Hi Fi PL'R can work for just about any selectable gene sequence. Alex Kat's results with 8 separate sequences in the human hprt gene are offered here as evidence of the truth of this broad assertion.

However, we are not satisfied with studying mutition in cell cultures, bacterial or human. As Charlie Heidelbeger used to say "Cells don't get cancer, people do". Thus we are not using our general technology for selectable genes except as a part of training program for new researchers. Instead, for the past four years grad students and post-docs have devised means to measure point mutations without reference to phenotypic change. They have made segnificant progress as I hope the descriptions of their new technologies convey to you. We think we now have several ways to measure point mutations as they occur in animals and humans. We give as an example application of our MAMA procedure to discover that $\mathrm{c} \cdot \mathrm{H}$-ras rat mammary mutations arise in untreated animals during puberty and that $\mathrm{c}-\mathrm{H}$-ras mammary tumors following $\mathrm{MNU}$ treatment come from these previously - existing uninduced early developmental mutations.

Central to this proposal is our theory that mutational spectra in human tissies should reveal important information about the causes of mutation in humans. One criticism of this hypothesis is the "every mutagen does its bit" view of how human cells are mutated. Real environmental mixtures - soot, cooked food, tobacco products etc. - are complex and contain multiple mutagens. As a consequence some people think mutations in human isells will have complex overlapping spectra that will be noninformative. Our own laboratory experiences have tought that exposure to mixtures reveals the effect of a "most important mutagen". From moldy peanut meal, (aflatoxin $\mathrm{B}_{1}$ ), from turbulent combustion flames, (cyclopenta [c,d] pyrene), from the old Olc'smobile deisel, (1-nethlyphenanthrene), and so forth we have consistently been able to ascribe the mutagenicity of a mixture in forward mutation assays to one or two components. Thus I expected that complex mixtures would yield the mutational spectrum of a "most important mutagen", not an uninterpretable complex set of mutations. In this report Dr. Lata Shirnamé-More show's that the aqueous extract of smokeless tobacco, another very complex chemical mixture, does indeed yield a simple mutational spectrum in human TK-6 cells. Thus our primary argument has not yet been invalidated by observation. Our rationale for direct studies of human tissues by mutational spectrometry is strengthened.

A very important part of our DOE OHER sponsored research has been the intense but less expensive theoretical effort to create a unified theory relating mutations in somatic cells to the timing and rate of appearance of human cancers. In our early thinking it appeared likely that the time of cancer appearance should depend on when the first post conception oncomutation arose in a particular human organ. I struggled for a few years to fit an " $n$ " nuclear mutation model to fit this 
data. The main problem was that the probability of most cancer deaths in humans rises exponentially but remains very low until age $47-50$ and then rises linearly at least through age 85 . But no combination of nuclear mutations would produce this behavior if mutation rates remain constant.

\section{"Non sunt multiplicandum entia praeter necessitatem".}

Since simple combinations of nuclear mutations were not sufficient to describe the age dependence of cancer, and since reports by Albertini and Morley showed constant mutation rates in $\mathrm{T}$ cell hprt, it was necessary to hypothesize another entity.

The simplest addition seemed to be a recessive mitochondrial oncomutation. Because there are many copies of the mitochondrial genome, many successive cell divisions would be necessary to express a recessive phenotype.

When we did the arithmetic for nuclear oncomutations followed or preceded by a mitochondrial oncomutation which requires multiple divisions to express a recessive phenotype, the model fit the human cancer death curve fairly well. This theory is put forward in explicit terms in this proposal. It is specifically shown that many cancers fit the expectation of one mitochondrial and one nuclear oncomutation. Cancers of the stomach, lower intestine and bladder fit the expectation of one mitochondrial and two nuclear oncomutations.

We propose two major kinds of experiments using our technology to measure point mutations in vivo. 1. Continue our studies of mutational spectra in animal tissues and human $T$ cells as well as certain experiments in human B cell lines. 2. Begin the study of the kinds, rates and timing of nuclear and mitochondrial mutations during fetal, postnatal and adult life in experimental animals and humans.

\section{TECHNOLOGY TO MEASURE MUTATIONS}

\section{A. SPECIALIZED SYSTEMS FOR GROWING HUMAN CELLS.}

\section{High density human B cell fermentors.}

In order to study mutation one must have enough mutants to permit statistically reproducible results. We have put special emphasis on this matter beginning with our initial development of human B cell lines mutation assays (Thilly et al 1976), the introduction of microtiter plate human cell mutation assays (Furth et al 1981) and statistical analysis of single cell mutation assays in single short exposures (Leong et al 1985) and in long term - low dose studies, (Oller, 1989). Most recently we have combined the work of our group's biochemical engineers with mutation assay protocols. Using a novel means to increase oxygen transfer to large cultures we have been able to expose $10^{10}$ human $B$ cells simultaneously and thus create more than $2 \times 10^{4}$ hprt ${ }^{-}$mutants in a single population even when induced mutant fractions were as low as $10^{-5}$ and survival was 0.2 (Oller et al 1989).

The reason for needing $10^{10}$ cells yielding $\geq 2 \times 10^{4} \mathrm{hprt}^{-}$surviving mutants arises from our desire to study mutational spectra as a series of "hotspots" each comprising $1 \%$ or more of the induced hprt mutants. $1 \%$ of $2 \times 10^{4}$ is 200 initial surviving mutants. The $95 \%$ confidence limits based on numerical variance alone is $200 \pm 2 \sqrt{200}$ or $200 \pm 28$. This $\pm 14 \%$ uncertainty for $1 \%$ hotspots has been observed in our actual studies with BPDE (Keohavong and Thilly, 1992 in 
press) and MNNG (Ling and Thilly, manuscript in preparation) and furnishes us with an acceptable degree of precision for comparing spectra among mutagens.

Emphasis on mutant number and the need for precision in mutational spectrometry is critical for development of the field. In the April 1992 issue of Mutation Research, for instance, a paper refers to a collection of 33 mammalian cell mutants in a 100 bp sequence as a "high-density mutational spectrum" for ethylmethyl sulphonate (EMS). In contrast, Coulondre and Miller (1977) examined 635 induced mutants distributed over 95 base pairs in the E.coli lac I gene and compared that spectra to some 960 mutants induced by MNNG. Using $c^{2}$ testing we find that the Coulondre and Miller's EMS and MNNG spectra to be significantly different at the $99 \%$ confidence level despite the fact that the same kinds of mutations were induced, chiefly GC ...> AT at the same positions. When we used half the number of mutants without changing the relative distributions, the same analysis did not reveal a significant difference at the $95 \%$ confidence limit. This example taught us that the "density" of mutations distributed over base pairs in a spectrum was going to have to approach or exceed ten mutational events / bp if we were going to be serious about using the data to distinguish among mutagens of similar chemistry or to carefully test hypotheses about mutational mechanisms or public health issues. None of the subsequent publications using Miller's lac I system or other "clone by clone" experiments approach the numerical precision of the Coulondre and Miller work. Few workers have recognized its importance. Most are content to group their data into "mutation - type sets" and declare 2 or 3 identical mutants in a set to be a "hot-spot".

This problem arises because researchers are unfamiliar with the "Bonferroni inequality" in anaiysis which should be applied in this content because mutational spectra experiments scan any of a large number of base pairs. Most researchers look for any particular mutation which occurs more than once. This is like the well known problem of being in a room with 30 people and discovering that there are nearly always a couple of people with the same birthday. If one asked how many people were born on May $i$ the chances of finding one would be $30 / 365$, of two (30/ $365)^{2}$ and so forth. But when the question becomes the chance of two people sharing any same birthday the odds are much higher. Professor Will Rand (Tufts University) is working with us on a manuscript for a special issue of Mutation Research which we hope will provide a useful and simple definition of "hotspot" and provide researchers with an analytical approach to (a) test any mutational spectra for non-randomness and (b) permit pairwise statistical comparisons of mutational spectra using the reasonably familiar $c^{2}$ method.

An immediate need for this degree of precision and analytical rigor arises from the proposed thesis work of Jia Chen and David Katz. Both of them propose exploring dose and dose rate phenomena in human cells. In the past we have used $t \mathrm{k}^{-/}$and hprt mutant assays in long term low dose studies (Penman et al, 1983; Liber et al, 1985; Oller et al, 1989; Danheiser et al, 1989; Rastogi et al, 1991), in which a doubling dose for any mutagen could be defined in a 20 day exposure period.

However, these earlier studies involved counting all $6 \mathrm{TG}^{\mathrm{R}}$ or $\mathrm{F}_{3} \mathrm{TdR} \mathrm{R}^{\mathrm{R}}$ phenotypic mutants for which 200 not 20,000 mutational events were required. The proposed experiments using ordinary cell cultures would require handling triplicate six liter cultures for twenty days. This requirement arises from the desire to work at induced mutation rates within a factor of five of the spontaneous tk and hprt mutation rates of $10^{-7}$ per cell division (Penman et al, 1983). Such a prodigious effort is beyond the patience of nearly all investigators, (theoretically) and all investigators (practically) I've tried to talk into doing it. 
Happily, we report here a new device incorporating a series of our laboratory's advances in $\mathrm{pH}$ control, 02 provision, and cell separation which make it fairly easy to work with TK-6 cells at $\geq 10^{7}$ cells $/ \mathrm{ml}$ while maintaining a rapid growth rate. At $10^{7}$ cells $/ \mathrm{ml}, 10^{10}$ cells requires only 1 liter and medium change occurs continuously with a simple pump or gravity feed. Triplicate studies at this scale are routinely performed by our cell technology students. Furthermore, long term low dose studies have $100 \%$ survival fractions so one can have about $10^{10} \times 10^{-7}=1000$ spontaneous hprt- mutants per day. Given a 24 hour doubling time one notes that $1 \%$ spontaneous hotspot mutations would arise at 10 per day and 200 separate events would have occurred over 20 days. For induced mutations arising at three times the sponianeous rate one would expect to be able to measure the mutation rate of a $1 \%$ hotspot of $3 \times 10^{-9}$ mutations / generation with $95 \%$ confidence limits of 2.2 and $3.8 \times 10^{-9}$. (Oller et al, 1989). The development of this culture system for TK-6 cells and all other suspension grown mammalian cells will permit relatively facile studies of mutational spectra at low mutagen dose rates. Since human tissues experience exposure to low mutagen concentrations over long periods of time the need to determine low dose spectra in human cells is an essential bridge to interpretation of human tissue mutational spectra.

\section{RESEARCHER REPORT}

\section{High Density Cell Culture for Long Term Low Dose Studies}

\section{Michael Tyo, Amy Smith, and Claudia Buser, Research Assistants}

To facilitate our ongoing studies of mammalian cells in culture, we developed a novel cell separator which utilizes a series of nested cones to achieve cell separation. Placing one cone inside another defines a region between them consisting of an annular space which increases in crosssectional area with increasing height. The fluid velocity decreases with increasing height, permitting the cells to settle and return to the culture vessel. This separator permits us to grow cells at a high density (greater than $10^{7} \mathrm{cell} / \mathrm{s} / \mathrm{ml}$ ) while preventing the depletion of essential amino acids and carbohydrates. Figure 1 shows the design of the nested conical cell separator attached to the top of a $250 \mathrm{ml}$ bioreactor. A key point is that after achieving maximum cell density, exponential growth of the cells is maintaired (newly dividing cells = cells lost from the separator). 


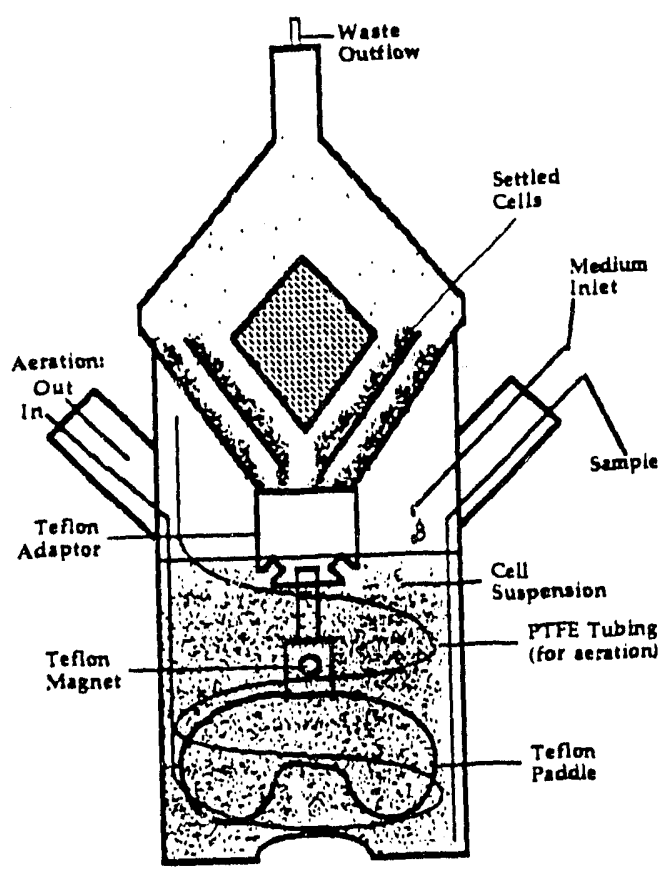

TK6 cells were grown using fructose as a carbohydrate source to avoid the production of excessive lactate (2). Cultures were initiated by iroculating the bioreactor with exponentially growing cells at about $5 \times 10^{5}$ cells $/ \mathrm{ml}$. Perfusion was begun at 1 volume per day and increased. Figure 2 shows the results of three simultaneous cultures of Sp2/0 cells. The viable cell density exceeded $10^{7}$ cells $/ \mathrm{ml}$ for each culture. The cell density was kept constant by means of continuous removal of excess cells, since the cells grew exponentially throughout the experiment. Two of the cultures were maintained at hgh density for more than 40 days. 
Figure 2.

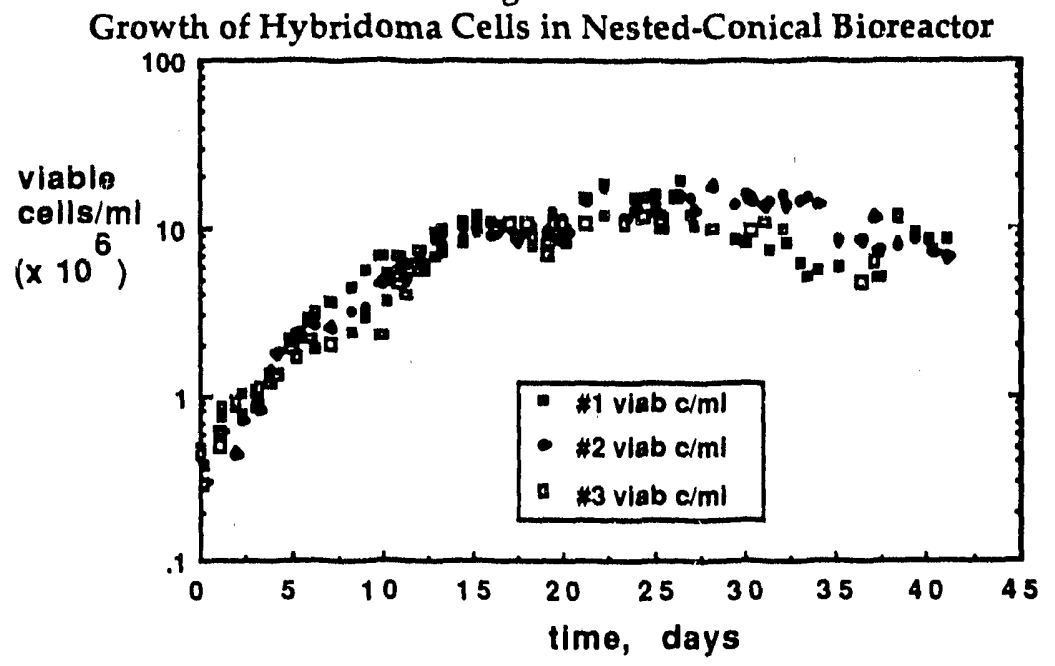

Figure 3 presents the results of a preliminary experiment with human TK-6 lymphoblastoid cells. This work was done by David Gebala. The cells quickly grew to a density of over $10^{7}$ viable cells $/ \mathrm{ml}$.

Figure 3.

Growth of human TK-6 cells in Nested-Conical Bioreactor

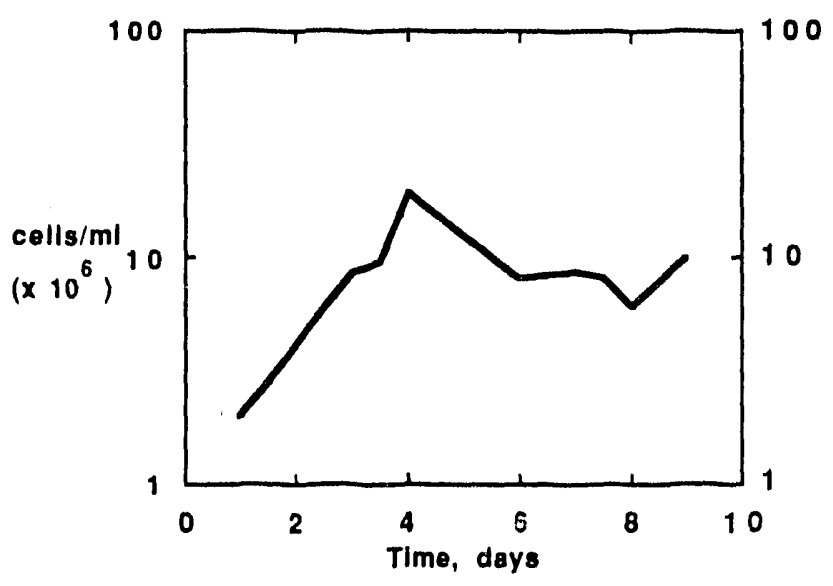




\section{Continuous Expansion of Human $\mathrm{T}$ Cells Through 15 Generations.}

In our 1989 DOE proposal we recognized that one could sample human T-cells from donors and identify hprt ${ }^{-}$mutants in selected clones. However, the low frequency $\left(\leq 10^{-5}\right)$ would require isolation of cells from one liter of blood to achieve the desired precision of a mutational spectrum (Albertini et al, 1982; Morley et al, 1982) Thus we proposed to set up mutation assays for mitochondrial DNA sequence changes to take advantage of the several thousand gene copies per cell which would reduce the necessary blood volume to less than $1 \mathrm{ml}$.

However, measurement of mutational spectrum in a blood cell sample (in progress) would yield the mutations arising from replication errors, reaction with cell generated endogenous mutagens and reactions with mutagenic chemicals entering the cell. In order to discover the kinds of mutations arising from replication error and reaction with endogenous cellular mutagens, we proposed to devise a means to expand small human $T$ cell populations through sufficient generations to permit observation of a reproducible "spontaneous" mutational spectrum.

$\begin{array}{lll}\text { All Mutations = } & \text { Replication Error } & + \\ & \text { Induction By } & \text { "Spontaneous" } \\ & \text { Endogenous Cellular } & \\ \text { Mutagens } & \\ & + \\ & \text { Induction By } & \\ & \text { Endogenous Extracellular } & \\ & \text { Mutagens } \\ & + \\ & \text { Induction By } \\ & \text { Exogenous } \\ & \text { (Environmental) Mutagens }\end{array}$

For any 100 bp sequence this again implied a desire to permit 20,000 separate mutations to occur. We expected a "spontaneous mitochondrial mutation" rate of $2 \times 10^{-9} /$ bp division (20 times nuclear hprt selected hprt mutation rate). Our present measurements indicate 10,000 mitochondrial copies per $T$ cell growing in vivo. Thus for $100 \mathrm{bp}$ we expect $(100)(10, \cdots)$ $\left(2 \times 10^{-9}\right)=2 \times 10^{-3}$ "spontaneous" mitochondrial mutations per cell division. In the expansion of $100 \mathrm{~T}$ cells to $10^{7}$ we would expect the number of independent mutations to be: $\frac{1}{\ln 2}\left(2 \times 10^{-3}\right)\left(10^{3}\right) \cong 3 \times 10^{4}$. Such an expansion has been achieved for the $\mathrm{T}$ cell samples from healthy human donors by Mr. John Hanekamp in the course of his thesis research (Appendix 2 (IA). With $50 \mathrm{ml}$ unstirred cultures at $5 \times 10^{5}$ cells $/ \mathrm{ml}$, the final $10^{7}$ celi number is achieved in a single flask. By combining mutational spectra from 3 independent flasks errors due to "jackpots" can be eliminated. This should permit accurate and reproducible recognition of $1 \%$ hotspots of 300 mutations each. 
Figure 2 (I-A) demonstrates the efficacy of his cell growth procedure. By 21 days the desired $10^{5}$ fold growth has been achieved.

T-CELL GROWTH CURVES

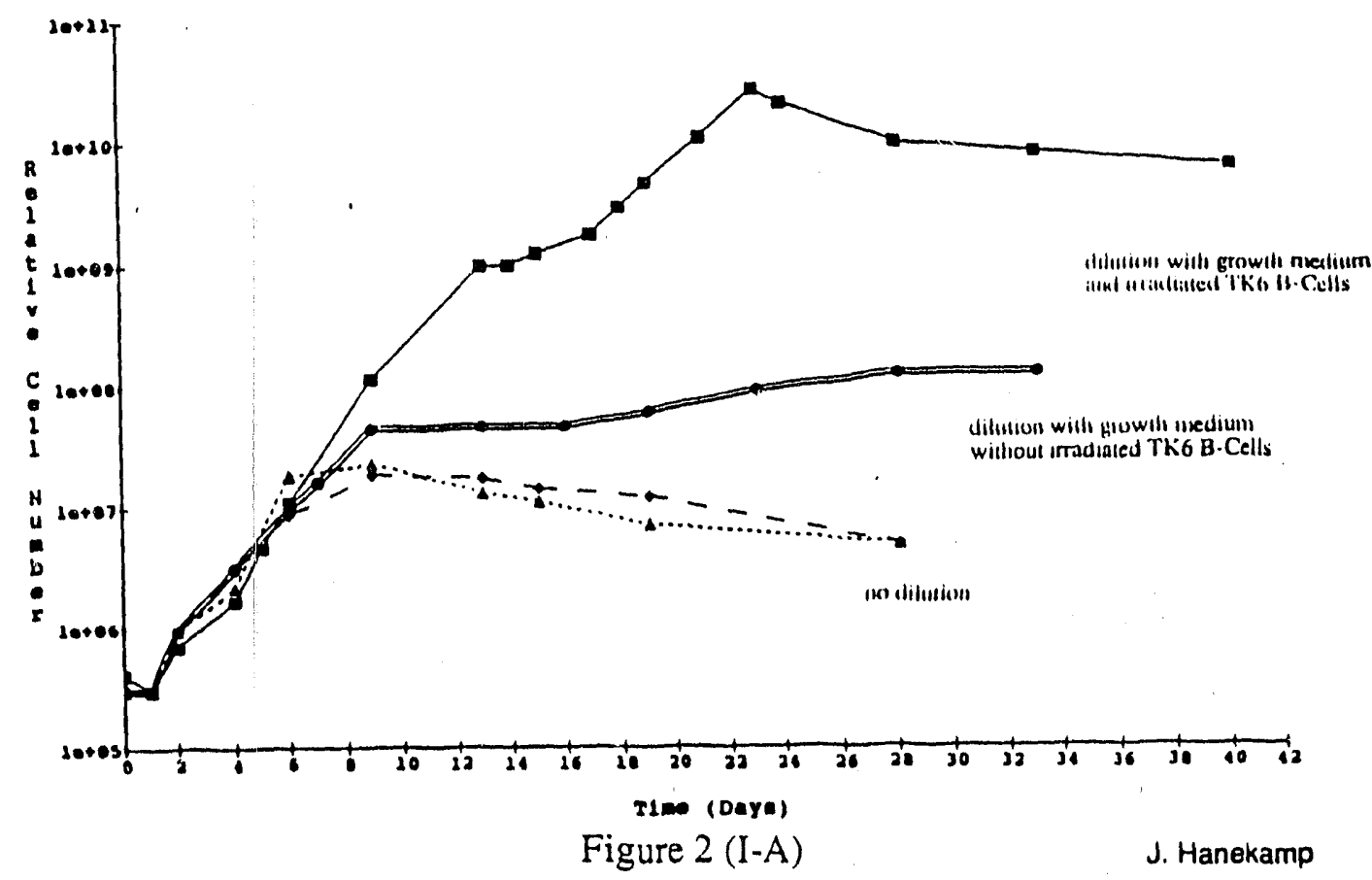

Mr. Hanekamp's studies have shown that eventual growth cessation is accompanied by concomitant loss of cellular $\Pi$-2 and transferrin receptors. Study of antigens expressed by the cells during expansion shows that the HIA-DR Class II, Leu 2A (CD8), Leu 4 (CD3) and Leu 5B (CD2) antigens are expressed by the cells undergning expansion. Cells expressing Leu $3 A$ (CD4), Leu $11 \mathrm{~A}$ (CD16) and Leu 12 (CD19) are not expanded in this process. Tentatively, we conclude that neutrophils (Leu 11A) and helper T cells (Leu 3A) do not undergo rapid growth but cytotoxic $T$ cells (Leu 2A) do. A draft manuscript describing observations on these cultures for more than 150 days is appended (Appendix 2 (I-A), Hanekamp and Thilly, 1992).

Four healthy donors' $T$ cell populations have been expanded in this way and the DNA is ready for analysis. By examining the mutational spectra in several mitochondrial sequences (see Section II-B) we expect to be able to compare the actual set of mutations acquired in a lifetimi in vivo (average donor age $=30 \mathrm{yrs}$.) to the set arising in 21 days of growth in vitro.

This study is a direct test of the null hypothesis that mutations arising in human $T$ cells are caused primarily by the spontaneous mutation pathway. Mr. Hanekamp's accomplishment also permits the exposus e of small T cell samples to low doses of environmental chemicals or mixtures. Should the in vivo spectra suggest some primary cause of mutation, such as tobacco smoke, experiments testing a hypothesis about a specific causation are now possible. In this way the important advances of Albertini's and Morley's laboratories in clonal growth of T cells for mutation assays may be translated into a reliable means to observe in vitro mutational spectra in freshly isolated T cell samples. Each donor becomes in a sense his or her own negative and positive control in experiments aimed at diagnosing the causes of the mutational spectrum found in a particular donor. 
We have progressed with the development of B cell in vitro technology so that we have sufficient cell numbers to study mutational spectra including dose rate effects in single copy nuclear genes. This we cannot do for T cells in ordinary blood samples. However, we have worked out a means to expand fresh $T$ cells sufficiently to be able to observe an in vitro mitochondrial mutational spectrum and compare it to the in vivo spectrum of any donor. Cells numbers therefore are no longer the limiting technological problem. The tough remaining problems lie in the analyses of DNA.

\section{B. MEASUREMENT AND SEQUENCE DETERMINATION OF MUTATIONS IN DNA.}

\section{Overview}

Both experimental aims of our research: measurement of a mutational spectrum in human tissue and determination of the timing of said mutations during human life require that we be able to measure specific point mutations. Since we cannot grow cells of most human tissues to select mutants we need technology that allows us to count mutant DNA sequences accurately without reference to phenotypic change.

The sensitivity required for such technology has two aspects - the number and the fraction of mutants in the sample studied. In general, to achieve a numerical precision of $\pm 20 \%$ samples must contain 100 or more specific mutants such as a GC to TA transition in the $41 \mathrm{st}$ bp of the third exon of the hprt gene. However, if these 100 mutant sequences are mixed with $10^{8}$ normal copies then we require a method which allows us to count mutants at a fraction of $10^{-6}$. What kind of mutant fractions do we expect in human tissues? These expectations define the sensitivity required for our technology to be successful.

To date we have used the mutant fractions in human T cell hprt' assays first reported ' ${ }^{-}$ Albertini in Vermont and Morley in Australia. Roughly speaking they found the hprt' fractions to be about $5 \times 10^{-6}$ in young adults; this estimate is in close agreement with fractions seen for red blood cell glycophorin A null mutations using flow cytometric methods need reference to glycophorin A (Langlois et al 1985). Morley's group has recently reported T cell point mutant fractions for specific HLA alleles to be two or three times higher (Grist et al, 1992). Of course both $T$ cells and erythrocytes arise from the same stem cell populations and their average rates of mutation may be higher or lower than in other tissues.

Using an hprt mutant fraction of $5 \times 10^{-6}$ permits estimation of the unit mutant fraction of $5 \times 10^{-6} / 10^{3}=5 \times 10^{-9}$ mutants $/ \mathrm{bp}$. We use $10^{3} \mathrm{bp}$ as an estimate of target size because the number of base pairs in hprt involved in hprt mutants includes the $654 \mathrm{bp}$ of the reading frame, some 300 bp of mRNA splicing sequences and no doubi a few unmapped mutations in or about the promoter region.

However a mutational hotspot comprising $10 \%$ of the hprt- mutants, would have a mutant fraction of $5 \times 10^{-6} / 10=5 \times 10^{-7}$ at a single base pair. Such intense hotspots have been seen by us for MNNG, ICR-191 and recently with smokeless tobacco extract. Each $1 \%$ hotspot such as more commonly seen with PAH, UV light or $\mathrm{x}$-rays in human $\mathrm{B}$ cell lines would have a mutant fraction of $5 \times 10^{-8}$. For single copy genes our goal is therefore to be able to measure specific mutants at $5 \times 10^{-8}$ and higher. Obviously this means that a tissue sample would have to contain 200 specific 
mutants $/ 5 \times 10^{-8}=4 \times 10^{9}$ mutant cells. This is about a liter of blood (WBC) or about $14 \mathrm{gms}$ of parenchymal tissue of most organs. We have not devised an approach to process tissue in these guantities which would have to be obtained either at autopsy or, in limited cases, at surgery. The steps to do such experiments would involve scaling up gentle DNA isolation systems to handle several grams of cells, scaling up such steps as restriction enzyme digestion and mutant sequence isolation procedures. Existing procedures described below would then appear to have the sensitivity to accurately count 200 mutant copies.

One way to get around this problem of a large copy number requirement encumbered by a large cell number requirement is to use multicopy sequences. Examples we are exploring are the nuclear rRNA genes (400 copies / cell) mitochondrial genome ( $10^{4}$ copies / cell). In this report we err phasize the mitochondrial genome but equivalent results have been obtained with nuclear rRNA sequences in TK-6 cells (Carielio, N. unpublished observations).

A 400 copy sequence reduces the number of cells needed to get 200 copies of a specific $1 \%$ mutant present at a fraction of $5 \times 10^{-8}$ from $4 \times 10^{9}$ to $10^{7}$. This number of cells represents $2.5 \mathrm{ml}$ of whole blood WBC's and about $33 \mathrm{rgm}$ of parenchymal tissue. A $10^{4}$ copy mitochondrial sequence reduces this cell requirement even further: $0.1 \mathrm{ml}$ of blood and less than $2 \mathrm{mgm}$ of tissue. Of course we have no present reliable estimate of the actual mutant fractions in the rRNA genes of the nucleus (nucleolus) or in the mitochondria. Our assumption is that nuclear rRNA mutant fractions will be about the same as nuclear hprt mutant fractions but we won't know for sure until we make the measurements.

With regard to mitochondria we work on the assumption that mutation rate will be considerably higher than in the nucleus, as has been observed in yeast mutagenesis. Alan Wilson's work established a ten fold higher evolutionary mutation rate for mitochondrial relative to nuclear sequences (Brown et al, 1979). For calculation purposes we have assumed that human mitochondrial mutant fractions per base pair will be 10 times higher than we find in nuclear genes. This would be around $5 \times 10^{-5}$ for $100 \mathrm{bp}$ with the equivalent of $1 \%$ and $10 \%$ hotspots arising at frequencies of $5 \times 10^{-7}$ to $5 \times 10^{-6}$. If this turns out to be a reasonably accurate guess we could be dealing with mutational spectra from very small tissue samplcs for human mitochondrial genes.

$$
4 \times 10^{4} \text { cells }=4 \times 10^{8} \text { copies }=\frac{200 \text { copies of a } 1 \% \text { hotspot }}{5 \times 10^{-7}}
$$

There is a key difference between selecting for forward $6 \mathrm{TG}^{\mathrm{R}}$ null mutations in a single copy gene like hprt and selecting for any and all point mutants with physical methods as we employ in our work: the difference is that the set of mutants which is selected by 6 thioguanine resistance is a subset of the total mutant set. How much smaller depends on the cause of mutation. For the intercalating agent ICR-191 which causes frameshifts in bacterial and human cells alike, the sets of selected and unselected mutants in the reading frame would be almost identical. Our studies of "spontaneous" mutations in B cell culture and $x$-ray induced mutations show that single to oligodeletion mutations predominate. Thus the "spontaneous" and $\mathrm{x}$-ray induced $6 \mathrm{TG}$ mutants in hprt would also be expected to closely approximate the total set. Alkylating agents like MNNG which cause predominately GC-AT mutations in the hprt reading frame and splice sites would represent an opposite extreme in which many cryptic base pair substitutions would be expected to make the total hprt mutant set significantly larger than the $6 \mathrm{TG}^{\mathrm{R}}$ mutant subset. However, these considerations do not influence the estimate of necessary sensitivity for in vivo human tissue mutation assays. There may be mutational hotspots that would be cryptic under selection 
conditions but there is no reason to suppose that they would arise at individual frequencies higher or lower than observed for hotspots yielding the hpr" phenotype.

In summary our goals for our past and future work are and hive been:

Precision: $200 \pm 28$ mutant copies of a particular point mutant Sensitivity: $5 \times 10^{-8}$ for nuclear sequences, $5 \times 10^{-7}$ for mitochondrial sequences.

The next three sections discuss four specific technologies which we are employing to develop n:eans io measure the kinds, positions and frequencies of point mutants in human cells and tissues.

i. Denaturing oradient gel electrophoresis. This method originally developed by Fischer and Lerman (1983) has served us well. Using the cooperative equilibria of DNA helix melting it has permitted us to separate all point mutations in a given ioc bp sequence from wild iype sequences. We report here some important improvements in the use of this technique so that only one part per thousand of original wild type sequences are admixed with the desired mutant sequences in our preparations. This advance is due principally to the work of Mr. John Hanekamp a graduate student supported by this grant.

ii. High Fidelity DNA amplification (HiFi PCR). The simple but effective strategy of DNA amplification has the limitation common to all amp'ifiers of "noise". In this case the most common PCR procedure - million fold amplification with the thermostable Taq DNA polymerase - produces products in which the majority contain one or more mutations induced during amplification. We have spent several years addressing this and have com: up with a number of ways to ameliorate the difficulty. Chiefly through the work of Prof. Phouthone Keohavong and lately by Drs. Lucy Ling and Ahmad Chaudhry we have been able to define amplification conditions for the thermolabile $\mathrm{T} 7$ DNA polymerase and the thermostable Pfu polymerase which decrease amplification noise twenty fold relative to Taq. Much remains to be done in this area and the research is being carried out by Professor Keohavong at the University of Pittsburgh.

iii. MAMA mismatch amplification mutation assay. In this process devised by graduate student, Ms. Rita Cha, allele - specific amplification conditions have been devised so that specific mutant frequencies as low as $5 \times 10^{-6}$ are routinely measured in cell and tissue samples.

iv. Restriction enzyme digestion. While in our early work we used restriction digestion followed by gel separation simply as a means to reduce the toral DNA mass containing our sequences, Dr. Gengxi Hu of has defined conditions for two restriction enzyines, KpnI and Eagl, which cut DNA with a residue of less than $5 \times 10^{-5}$ of the wild type sequences. Ways to extend and apply this advance are part of our proposal.

\section{Denaturing Gradient Gel Electrophoresis and High Fidelity PCR.}

In this process the cooperative equilibrium between a helical and melted DNA sequences is used to separate DNA sequence is used to separate DNA sequences of different melting temperatures, Tm. It was long known (Scheraga and Poland, 1970) that DNA sequences exhibited cooperative melting equilibria. When means to estimate numerically the enthalpy and the entropy of these reactions were developed they permitted calculation of the Tm for any DNA sequence to 
within $\pm 0.1 \mathrm{C}$. Stuart Fischer a graduate student of Leonard Lerman's at S.U.N.Y. Albany proposed and demonstrated a means to separate sequences of slight Tm differences by pulling them in an electric field into a polyacrylamide gel containing an ascending gradient of urea and formomide (Fischer and Lerman, 1983). His special technical inovation was to use contiguous short DNA sequences of significantly different Tm's. The higher Tm domain (clamp) would remain in helical form at temperatures and urea - formamide concentrations that converted the lower $\mathrm{Tm}$ domain to a fully melted condition. This combination of a melted sequence clamped by a helical sequence markedly decreased the velocity of migration in the gel field relative to the fully helical molecule. Thus these molecules essentially "focussed" on the gels. One simply "tagged" the sequences with ${ }^{32} \mathrm{P}$ and used an autoradiogram or Phosphorimager ${ }^{T M}$ to locate focussed bands for excision and DNA sequencing.

This approach was extremely attractive to our laboratory because it seemed to us that it could be applied to the definition of mutational spectra in any DNA sequence in any tissue. We reasoned that boiling and reannealing tissue derived DNA sequences would by mass action force all point mutants to form heteroduplexes with wild-type DNA and thus be easily separated from wild type homoduplexes, and, in most cases, from each other. (Thilly et al, 1985). Fortunately this has turned out to be the case (Cariello et al, i988; Cariello et al, 1990; Keohavong et al, 1989a; Keohavong et al, 1989b; Thilly et al, 1989; Keohavong et al, 1991; Oller et al, 1992; Keohavong et al, 1992). We have a fairly simple way of looking at the hotspot point mutational spectum of almost any DNA sequence in a selectable gene. In the case of stucies of the hprt gene we first treat enough cells to produce the desired 20,000 separate hprt mutations among the cells suiviving treatment. These populations grow for : $x$ days post treatment to express the $6 \mathrm{TG}^{\mathrm{R}}$ phenotype. $6 \mathrm{TG}$ is added and over the riext 10 days ot so the $6 \mathrm{TG}^{\mathrm{R}}$ mutants increase exponentially until their growth is apparent (>105 live cells $/ \mathrm{ml}$ ). DNA from some $10^{6} 6 \mathrm{TG}^{\mathrm{R}}$ cells is the substrate for amplifying the desired sequence. If naturally contiguous high and low $\mathrm{Tm}$ domains exist, PCR primers defining the sequences are used. If not, then an artificial high Tm domain is incorporated into one primer so that the cellular sequence becomes the low Tm domain in which mutants can be detected. The use of Lerman's improvements in the Poland algorithms for calculating Tm are indispensable in this process. Trial and error approaches are wasteful and expensive.

By end - labelling PCR primers the mutant - containing heteroduplex bands created are easily separated and identified on a gradient denaturing gel. Bands are excised, reamplified and rerun on subsequent denaturing gradient gels to obtain pure mutant homoduplex bands for Sanger DNA sequencing. (See Appendix Keohavong and Thilly, 1992, for an explicit description of this approach in its present form).

Key reconstruction experiments must be performed to discover if any mutant fraction estimate has been effected by the more rapid growth of a particular mutant cell clone (similar to Albertini's finding of expanding $T$ cell hprt populations in humans) or by an artifact of PCR amplification known as "allelic preference". Absent such bias the amount of $32 \mathrm{P}$ in a mutant band on DGGE relative to total $32 \mathrm{P}$ is the estimate of mutant fraction for the specific mutant it represents in the cell population sample. Using this procedure allows reliable detection and enumeration of mutants as low as $0.5 \%$ of the hprt mutant fractions. In the case of Oller's study of spontaneous hprt- mutations, she used the combination of 6TG selection and DGGE - HiFi PCR to detect, count and identity $1 \%$ hotspots existing at mutant fractions of $4 \times 10^{-8}$ and mutant numbers as low as 50 in multiple 3 liter TK-6 cell cultures. In terms of mutation rate, the Oller experiments detected reproducible point mutational hotspots arising at $10^{-9}$ mutations / cell generation or $1 \%$ of 
the hprt forward mutation rate of $10^{-7} 6 \mathrm{TGR}$ mutations / cell generation. (See Appendix Oller et al, 1992).

Obviously, the combination of high density cell culture technology 6TG selection and DGGE + HiFi PCR in its present form could be applied by our laboratory to publish a whole series of papers describing mutational spectra in TK- 6 and other human cells.

We have chosen not to do so.

The technology described is used as a training exercise for new researchers and by using different mutagens over a few years we should get enough of this kind of information without making it an important but unchallenging aim of our research. Instead, we prefer to face the fact that TK-6 cells, though human, ain't humans. We propose to push on and find a usable procedure to find, count and identify mutations in human cells and tissues without benefit of phenotypic selection for mutant cells.

We can't even rely on $6 T G$ selections for human $T$ cell mutants in human blood samples from which so much has been learned about the kinds of hprt mutants which arise. The reasons are tvo fold. Phenotypic variation among mixed $T$ cells populations can lead to their numerical increase or decrease as a function of specific immune stimulation or unknown factors of their physiology (Nicklas et al 1989). Secondly, there are a lot of cells in the human body which are not $T$ cells, cannot be grown in quantity ex corpora and from which most human tumors and all heritable mutations arise. The only way to find out what is happening in numan somatic and germinal cells in terms of genetic change is to measure the genetic changes. That is what our work and proposals are all about.

That said, we return to the problems of measuring specific mutants at frequencies as low as $5 \times 10^{-8}$ for nuclear genes or $5 \times 10^{-7}$ for mitochondrial genes. The 1991 combination of DGGE and Hi Fi PCR in the hands of an "average" researcher had a limit of detection of about $5 \times 10^{-3}$ for specific point mutants. Paragons have worked as low as $10^{-3}$. The reasons are two fold (i) PCR noise and (ii) failure to separate a large enough fraction of wild type sequences from the mutant DNA sequences on a first DGGE pass.

The problem may be illustrated by imagining a mixture of $10^{9}$ wild type copies of the sequence we wish to study and $5 \times 10^{-7} \times 10^{9}=500$ copies of a particular point mutant. We first isolate the DNA by anion exchange elution methods, cleave it with a suitable restriction en ryme and isolate the fraction containing our desired fragment using an ethanol precipitation step. We elute this DNA, boil it briefly and allow the reannealing process to convert the 500 mutant homoduplex fragments to 1000 mutant / wild type heteroduplexes. We load this mixture on a denaturing gradient gel using a temperature of $60 \mathrm{C}$ and a urea - formamide gradient.

What we would like to have is $10^{3}$ heteroduplex molecules in two small bands and $10^{9}$ wild type homoduplexes well separated on the gel: 


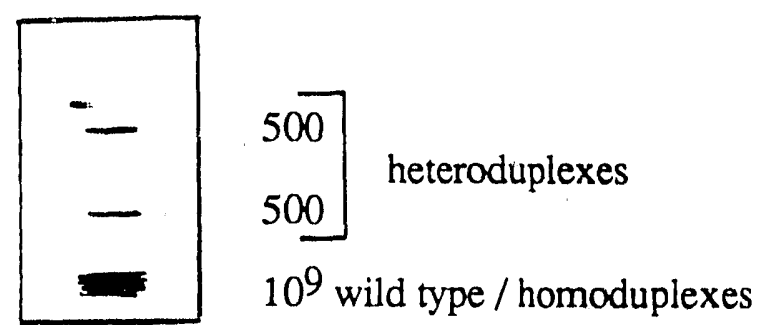

Instead what we get is:

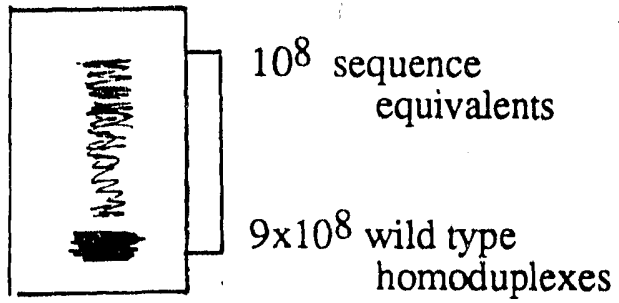

For some reason the process has allowed about $10 \%$ of the wild type DNA to end up where the mutant heteroduplexes should be. The credit for discovering the sources of this horrendous noise belongs to graduate student John Hanekamp. Hanekamp has found that the $12-18$ hours period of DNA separation on DGGE at $60 \mathrm{C}$ led to approximately $5 \%$ of the original DNA focussing in the "mutant heteroduplex" region of the gel. When he reduced the separation temperature to $40 \mathrm{C}$ using higher urea / formamide concentrations the total noise was halved. He also found that the DNA handling steps of DEAE cellulose concentration followed by ethanol precipitation accounted for the bulk of the remaining noise. Finally he found about $1 \%$ of the wild type DNA was non - specifically adsorbed to the gel. By replacing the original protocol with a protocol eliminating these problems, using a $90^{\circ}$ shift gel to separate non - specific gel binding DNA from mutant heteroduplexes and by using as a redox buffer, $\mathrm{Mr}$ Hanekamp has reduced this wild type DNA contaminant to somewhat less than $0.1 \%$ of the original sample. (See Report Researcher below).

Returning to the example of studying 500 mutants among $10^{9}$ wl'd type copies we believe we now have a means to isolate our 1000 mutant / wild type heteroduplexes in the presence of no more than $10^{-3} \times 10^{9}=10^{6}$ wild type homoduplex copies. Applying HiFi PCR to this mixture results in $5 \times 10^{8}$ mutant copies and $10^{12}$ wild type copies. From the PCR process the amplification would produce

$\begin{array}{ll}10^{12} & \text { [copies] } \\ 10^{2} & \text { [base pairs] } \\ 2 \times 10^{-5} & \text { [Pfu polymerase error rate] } \\ 20 & \text { [doublings to yield } 10^{6} \text { fold increase] } \\ 4 \times 10^{10} & \text { PCR noise copies }\end{array}$

Pfu polymerase creates about 20 noise bands on DGGE. In this case each would contain about $2 \times 10^{9}$ copies, approximately 4 times the intensity of the two mutant heteroduplex bands we would be seeking.

Close, but not good enough. This example was worked out to show exactly where we are now in our procedural development of phenotype independent mutational spectrometry. If instead of the thermostable Pfu polymerase we use the thermolabile T4 DNA polymerase which has an 
error rate of less than $5 \times 10^{-6}$ our signal to noise ratio would improve by at least four fold. We think that either of several thermostable DNA polymerases which we have found to produce mainly AT to GC mutations may be amenable to increasing fidelity by simple reduction in the concentration of the misincorporated dNTP's. Alternately, the work of Keohavong in progress with T4 DNA polymerase and auxiliary proteins may result in a manual amplification procedure which repays the extra labor with greatly increased fidelity.

\section{RESEARCHER REPORT}

\section{DNA Damage Caused By Handling Procedures Resulting In DGGE Noise}

\section{John Stephen Hanekamp}

Research Assistant

\section{Introduction}

In a double stranded DNA molecule, any chemical modification of either strand's low melting domain will cause a significant drop in $\mathrm{T}_{\mathrm{m}}$ and result in the modified duplex focusing on a denaturing gradient gel as if it were a point mutant heteroduplex. Because the opposite strand would ordinarily not contain a damaged site, that strand would easily be amplified by PCR and constitute a source of noise using DGGE to obtain mutational spectra.

Such chemical reactions could occur at any time prior to or during DGGE separation. They may even occur after the DNA has focused and be detected only when the focused band is analysed on a second DGGE.

In order to reduce the background noise to a practical minimum I have studied the effects of DNA isolation procedures and the present DGGE protocol itself to discover steps leading to artifactual focusing in the mutant heteroduplex region of our gels.

Cariello et al, (1988) had already shown that the common practice of "visualizing" DNA bands with ethidium bromide and brief transillumination with $314 \mathrm{am}$ light caused photochemical reactions with a large fraction of the DNA in a polyacrylamide gel band. Exposure of DNA in this way was eliminated from our protocols in 1986. Further, early studies showed us that deliberately depurinating DNA with heat and mild acid, while decreasing DNA available for PCR, did not result in new mutant bands after PCR. Similar experiments were performed for laboratory lights, and no new mutant bands appeared after PCR of irradiated DNA.

However, now we have a different problem. It is that the presence of a chemically reacted "Watson" strand automatically results in an unmodified "Crick" strand. If these are sufficiently numerous, amplification results in sufficient noise from PCR to obscure signals from true mutants at frequencies common to human cells and tissues. 
I therefore considered the effects of;

a) laboratory light

b) 60C temperature used in DGGE

c) urea, formanide in the denaturing gel

d) dissolved oxygen

e) DNA concentration and ethanol precipitationin a series of iterative experiments to separate these variables.

I further considered the possibility that normal DNA d'ıplexes might nonspecifically adsorb to polyacrylamide.

\section{Background}

Environmental factors and chemicals have been shown to affe the integrity of DNA. Ultraviolet light (UV), present in fluorescent light, has been shown to cause the formation of thymine dimers (Gentil et al, 1989), (Mitchell et al, 1992), (Matsunaga et al, 1991). Heat has been shown to produce apurinic sites (AP sites) (Gentil et al, 1989). Ethanol has been shown to reduce the melting temperature of DNA, allowing for contaminants in the ethanol solution, such as acetaldehyde, to form adducts with the DNA (Rajasinghe et al, 1990). In the presence of oxygen, such as oxygen radicals, DNA can be oxidized (Devasagayam et al, 1991). Dithiothreitol (DTT) has be shown to be an oxygen scavenger, reducing the presence of reactive oxygen species in solution, therefore reducing the damage to DNA by oxygen (Devasagayam et al, (1991, and (Held et al, 1991).

\section{Results}

Significant noise on a DGGE results when DNA is subjected to any of the following conditions; fluorescent light during handling, elution from polyacrylamide with DEAE cellulose/ethanol precipitation, and running of the DGGE at a temperature of 60C. Phosphorimager ${ }^{\mathrm{TM}}$ analysis of the amount of noise above the wild type homoduplex when these conditions are not controlled range from 5-20\% of duplex DNA. See Figure 1 (I-B-2).

The noise observed above the wild type homoduplex can be due to chemical modifications, nonspecific adsorption to the gel matrix, or a combination of both. In order to determine this distribution, the entire lane from the loading well to the wild type homoduplex was cut out, turned 90 degrees and layered on top of another DGG and run. The original wild type homoduplex focuses as a single peak. Modified DNA complexes or mutant heteroduplexes contained in the noise region of the original DGGE focus on a 45 degree angle to the wild type. Nonspecifically adsorbed DNA contained in the noise region of the original DGG focuses on a horizontal line at the level of the wild type homoduplex. Finally, a combination of chemically adducted/modified DNA and nonspecifically adsorbed DNA to the gel matrix is again found in the vertical region above the wild type homoduplex dot. The noise in the vertical region above the wild type homoduplex is created during the two dimensional DGG run itself! Refer to Figure 2 (I-B-2).

The results of this simple experiment showed that a significant amount of the DNA was damaged during the hardling procedures prior to running on the DGG, that significant damage arose on the gel itself, and that nonspecific adsorption was also a contribution to overall noise. Refer to Table 2 (I-B-2) for quantitative Phosphorimager ${ }^{\text {TM }}$ data. 


\section{DGGE}
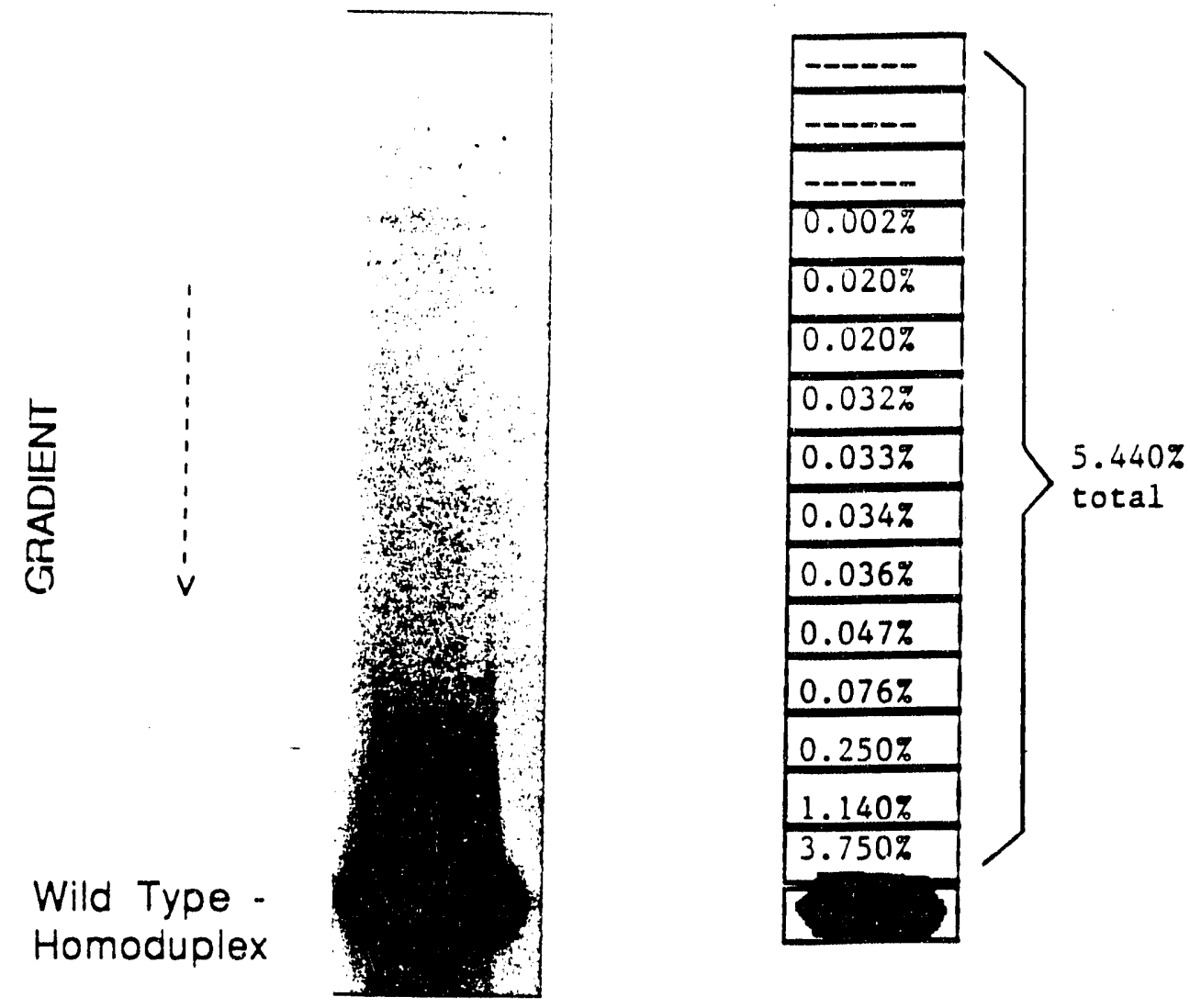

J. Hanekamp

Left figure: TK6 mitochondrial DNA (CW7, J2). DGGE conditions; 0$50 \%$ denaturant, $12.8 \%$ polyacrylamide/bis $(37.5: 1), 60^{\circ} \mathrm{C}$ tank, 150 volts for 18 hours. Right figure: Phosphorimager analysis of DGGE. Each block calculated as percent of wild type homoduplex block. A block half width represents a six sigma standard deviation from peak intensity of wild type homoduplex.

figure 1 . 


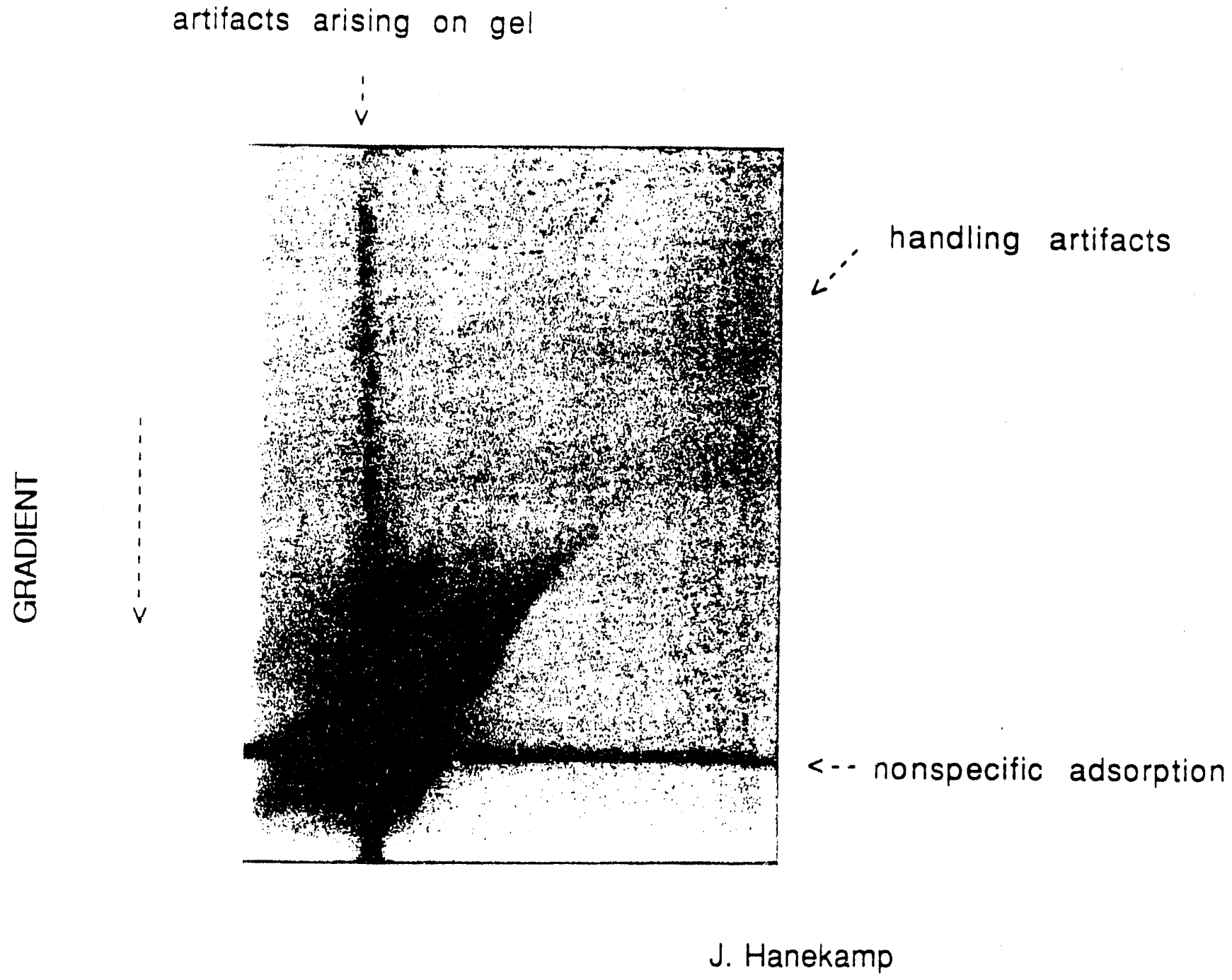

TK6 mitochondrial DNA (CW7,J2). DG UE conditions; 0-50\% denaturant, $12.8 \%$ polyacrylamide/bis $(37.5: 1), 600 \mathrm{C}$ tank, 150 volts for 18 hours.

$$
\text { iigure } 2 \text {. }
$$




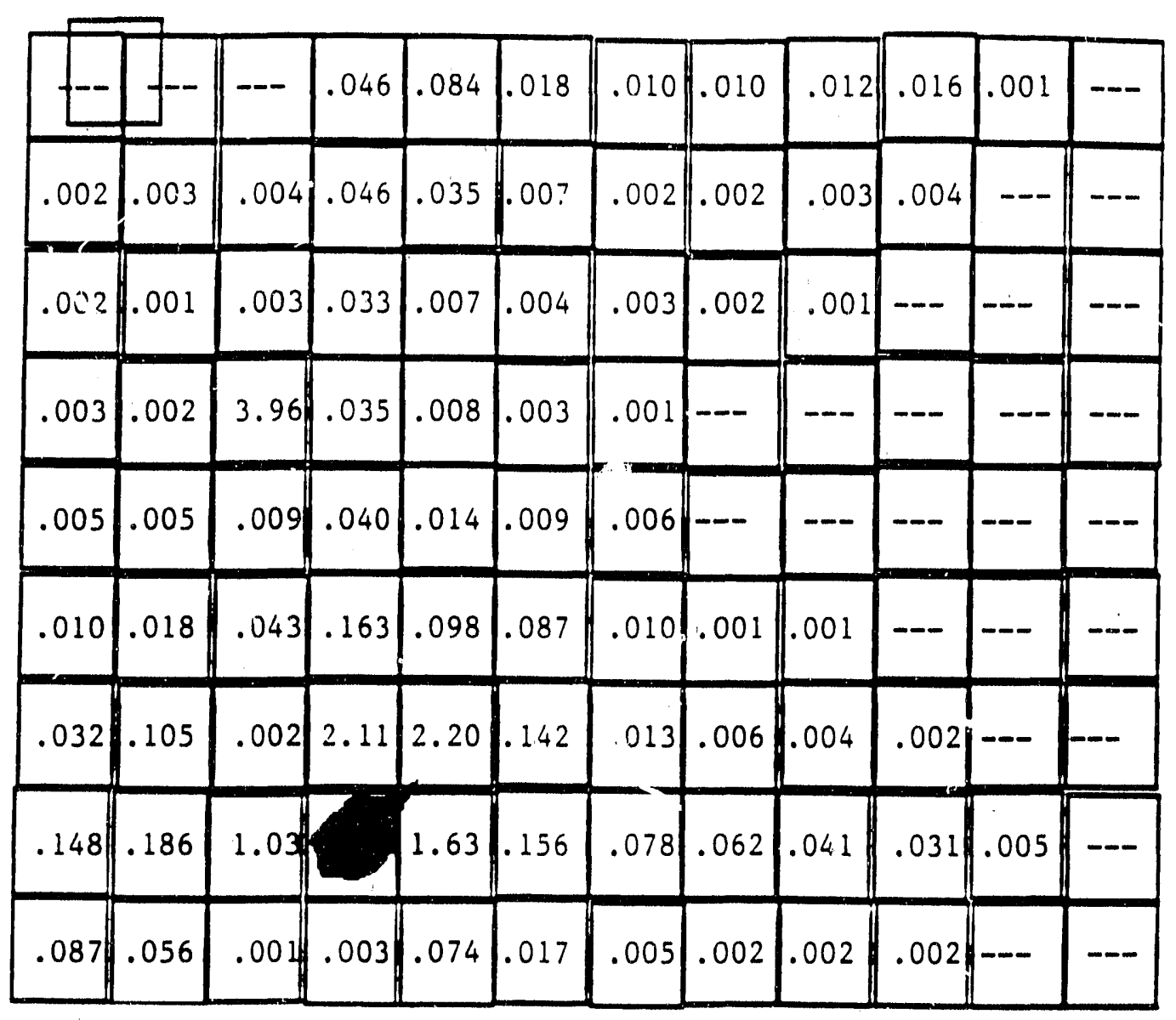

J. Hanekamp

Phosphorimager analysis of two dimensional DGGE. Each block calculated as percent of wild type homoduplex block. A block half width represents a 6 sigma standard deviation from peak intensity of wild type homoduplex.

table 2. 
The use of DEAE cellulose in the elution of DNA from a gel followed by ethanol precipitation damaged the DNA. Phosphorimager ${ }^{\mathrm{TM}}$ analysis shows that the noise induced on a DGG by DEAE cellulose elution/ethanol precipitation is between 5-8\%. Refer to Figure 3 (I-B-2).

DNA is damaged by heat. Under usual DGG conditions, the DGG is run for 10-20 hours at a temperature of $60 \mathrm{C}$. Under these conditions, significant damage to the DNA occurs. A significant reduction in the heat induced damage can be achieved by reducing the exposure of DNA to heat by running of the DGG at $40 \mathrm{C}$. Refer to Figure 4 (I-B-2).

The DNA is damaged in the presence of fluorescent light. This damage is not as significant as the heat damage yet important since all damage is cumulative during the handling process. Refer to Figure 5 (I-B-2).

In addition to DNA damage induced by handling procedures, DNA damage in the form of chemical adducts/modifications appears to also occur during the movement of the DNA through the DG gel matrix. The addition of dithiothreitol (DTT) to the gel matrix prior to polymerization further decreases the noise as measured by Phosphorimager ${ }^{\mathrm{TM}}$. Refer to Figure 6 (I-B-2).

Significant decreases in the handling - induced DNA damage have been achieved with appropriate changes in protocols: avoid fluorescent light, substitute of horizontal gel elution/Millipore spin filtration columns for DEAE cellulose gel elution/ethanol precipitation, add dithiothreitol (DTT) to the DG gel matrix, and run of the DGG at a temperature of $40 \mathrm{C}$ instead of $60 \mathrm{C}$. Phosphorimager ${ }^{\mathrm{TM}}$ analysis of the noise above the wild type homoduplex under these conditions is less than $1 \%$. Refer to Figure 7 (I-B-2).

With these changes in protocol the heteroduplex region still contained approximately 0.5 $1.2 \%$ of the loaded DNA, a fraction nearly fully attributable to nonspecific gel binding. We thus employed to the 90 degree second DGG procedure of Figure 2 (I-B-2) and achieved removal of most of this material. See Figure 8 (I-B-2). Quantitative analysis of the remaining DNA (cpm) in the "heteroduplex rectangle" shown, revealed less than $0.1 \%$ of the total DNA counts. Refer to Table 8 (I-B-2).

This is the key to our proposed improvements and applications. Now $1 \times 10^{9}$ starting wild type copies and $1 \times 10^{3}$ mutant copies can be fractionated so that only $1 \times 10^{6}$ wild type copies are mixed with the fully recovered mutant copies.

\section{Capillary Denaturing Gel_Electrophoresis}

Another approach which involves the work of Dr. Konstantin Khrapko and is supported by a grant from NIEHS is to use the capillary gel electrophoretic technology developed by Professor Barry Karger at the Barnett Institute, Northeastern University. Together, Dr. Karger's group and ours have demonstrated that we can achieve separations of mutants and wild type DNA sequences as on standard DG gels. By using fluorescein labelled primers or full length probes we can count sequences by laser induced fluorescence on these capillary columns at only a few hundred molecules in a peak. Dr. Khrapko is now working full time on this approach and with his collaborators at the Barnett Institute have achieved the desired resolution in reconstruction experiments using 40C. (May 1992): 


\section{DGEE}

LANES

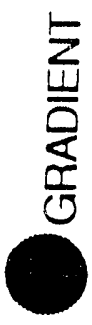

$7.6 \%$ of wild type
A

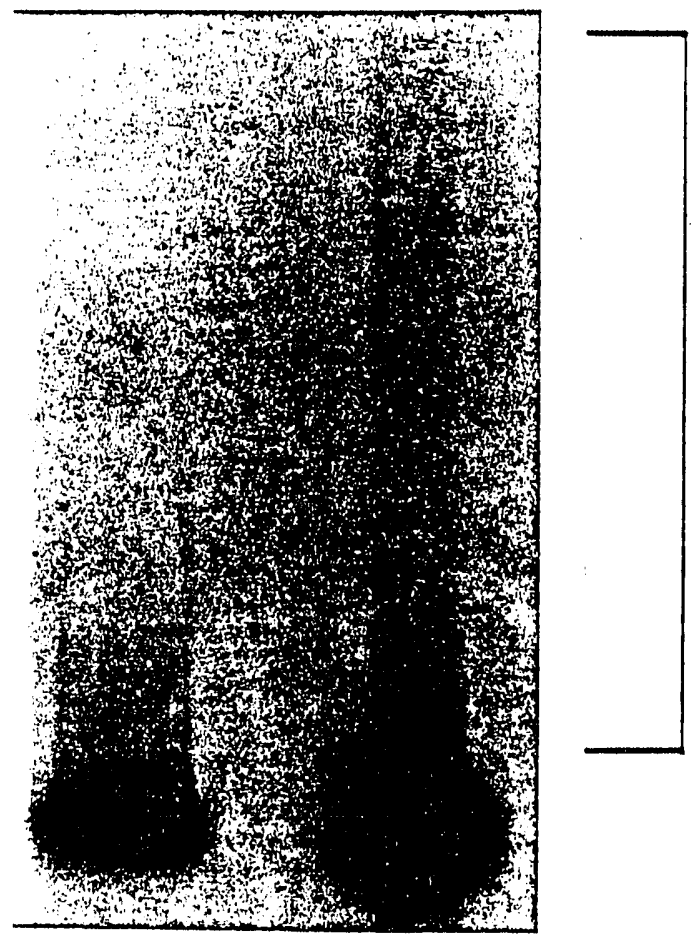

$2.4 \%$ of wild type

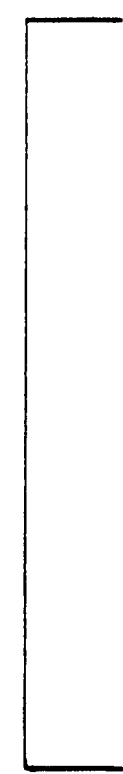

J. Hanekamp

TK6 mitochondrial DNA (CW7,J2). DGGE conditions; 0-50\% denaturant, $12.8 \%$ polyacrylamide/bis $(37.5: 1), 600 \mathrm{C}$ tank, 150 volts for 18 hours. Lane $A_{;}$TK6 DNA elution with DEAE cellulose/ethanol precipitation prior to DGGE, Lane $B$; TK6 DNA run on DGGE from gel block without prior elution with DEAE cellulose/ethanol precipitation.

figure 3. 


\section{DGGE}

LANES

A B C D $E$

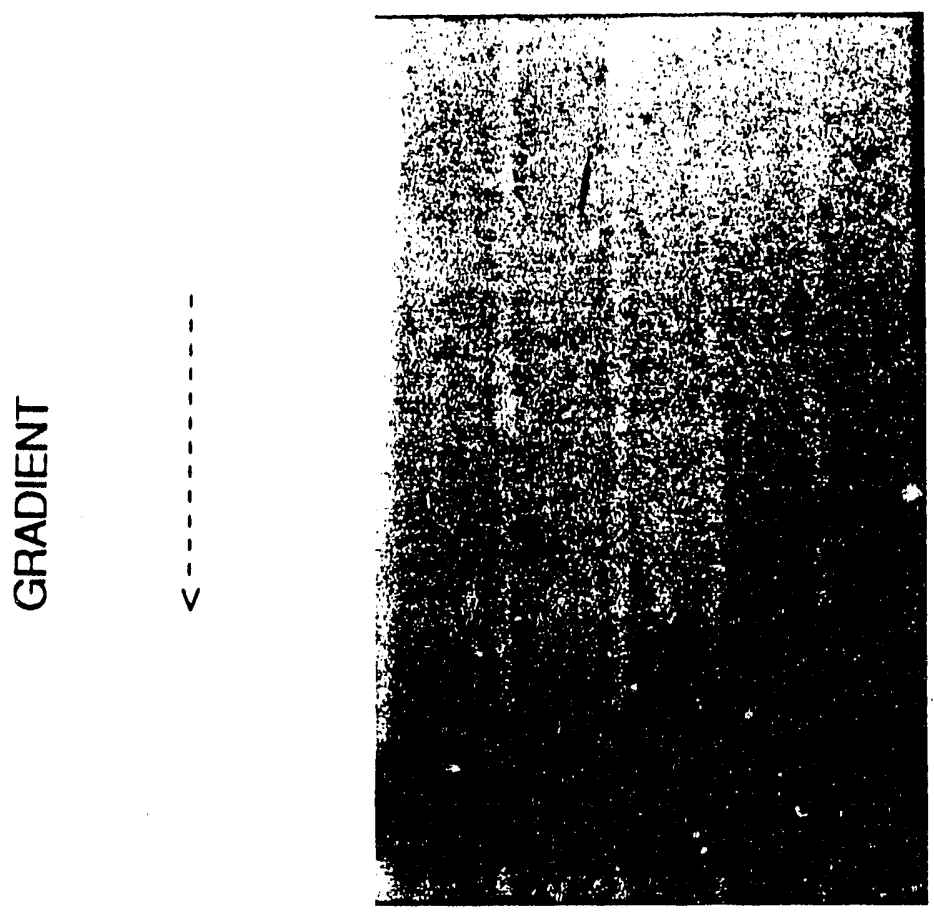

J. Hanekamp

TK6 mitochondrial DNA (CW7,J2) in $\mathrm{ddH}_{2} \mathrm{O}$. Lane $\mathrm{A}$; control at $-20{ }^{\circ} \mathrm{C}$, lane $\mathrm{B} ; 40^{\circ} \mathrm{C}$ for 24 hours, lane $\mathrm{C} ; 400 \mathrm{C}$ for 48 hours, lane $\mathrm{D} ; 600 \mathrm{C}$ for 24 hours, lane $\mathrm{E} ; 600 \mathrm{C}$ for 48 hours. DGGE conditions; $0-50 \%$ denaturant, $12.8 \%$ polyacrylamide/bis $(37.5: 1), 600 \mathrm{C}$ tank, 150 volts for 18 hours.

note- these samples were subjected to DEAE cellulose elution/ethanol precipitation prior to DGGE run and show the $\sim 6 \%$ noise from this source. 


\section{DGX}

LANES

$\frac{\sum}{\frac{1}{0}}$

$A \quad B \quad C \quad D \quad E \quad F \quad G$

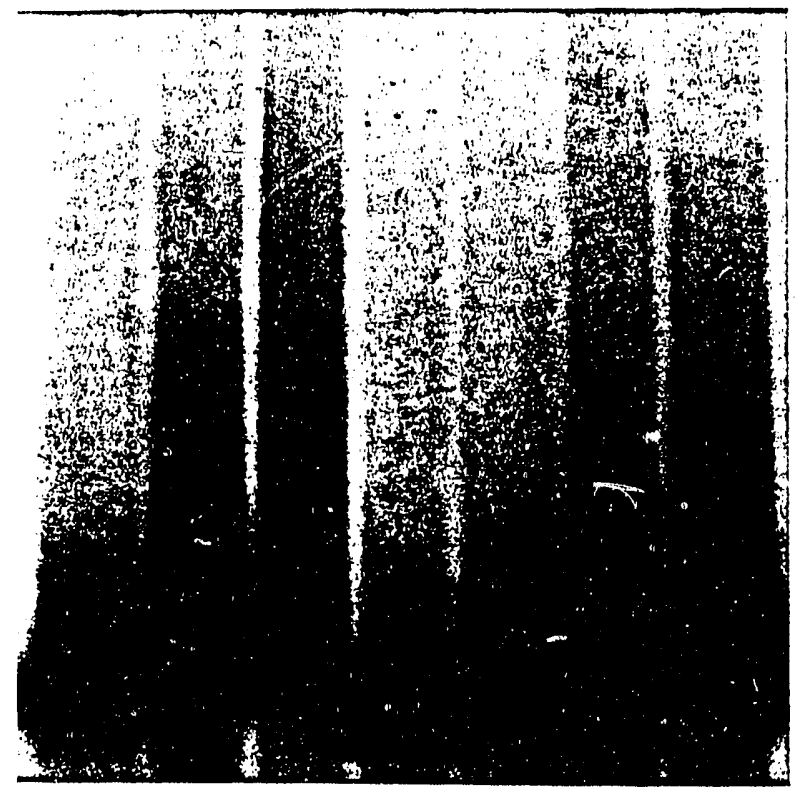

J. Hanekamp

TK6 mitochondrial DNA $(\mathrm{CW} 7, \mathrm{~J} 2)$ in $\mathrm{ddH}_{2} \mathrm{O}$. Lane $\mathrm{A}$; control in dark at $-200 \mathrm{C}$, lane $\mathrm{B} ; 1.0 \mathrm{~cm}$ from fluorescent iight for 24 hours, lane $\mathrm{C}$; $1.0 \mathrm{~cm}$ from fluorescent light for 48 hours, lane $D ; 5.0$ feet from fluorescent light for 24 hours, lane $E ; 5.0$ feet from fluorescent light for 48 hours, lane $F ; 1.0 \mathrm{~cm}$ from fluorescent light in blue eppendorf tube for 24 hours, lane $G ; 1.0 \mathrm{~cm}$ from fluorescent light in blue eppendorf tube for 48 hours. DGGE conditions; $0-50 \%$ denaturant, $12.8 \%$ polyacrylamide/bis $(37.5: 1), 600 \mathrm{C}$ tank, 150 volts for 18 hours.

note- these samples were subjected to DEAE cellulose elution/ethanol precipitation prior to DGGE run and show the $\sim 6 \%$ noise from this source. 


\section{DOCE}

\section{LANES}

$3.6 \%$ of wild type
A

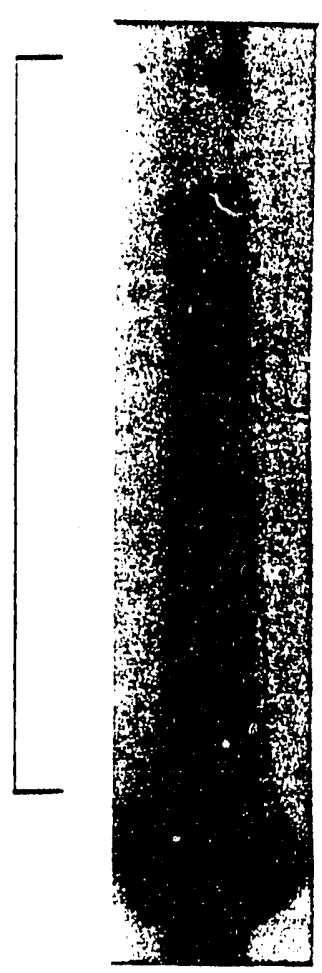

B

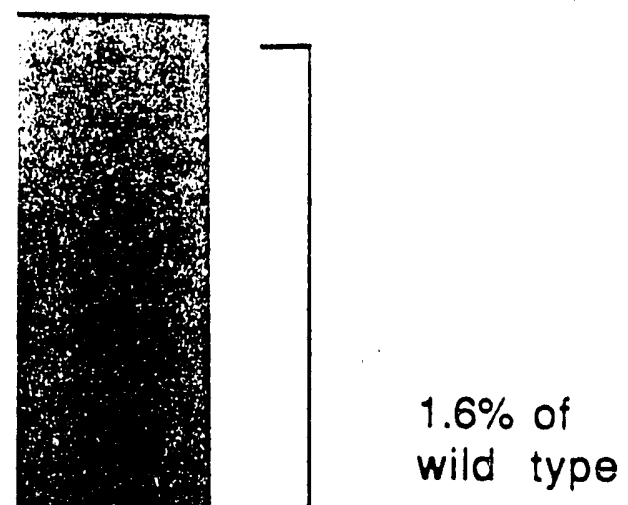

K. Khrapko

TK6 nuclear DNA (P1 ,P4). Lane $A$; without dithiothreitol, lane $B$; with dithiothreitol. DGGE conditions; $15-35 \%$ denaturant, $12.8 \%$ polyacrylamide/bis $(37.5: 1), 60^{\circ} \mathrm{C}$ tank, 150 volts for 16 hours.

figure 6. 


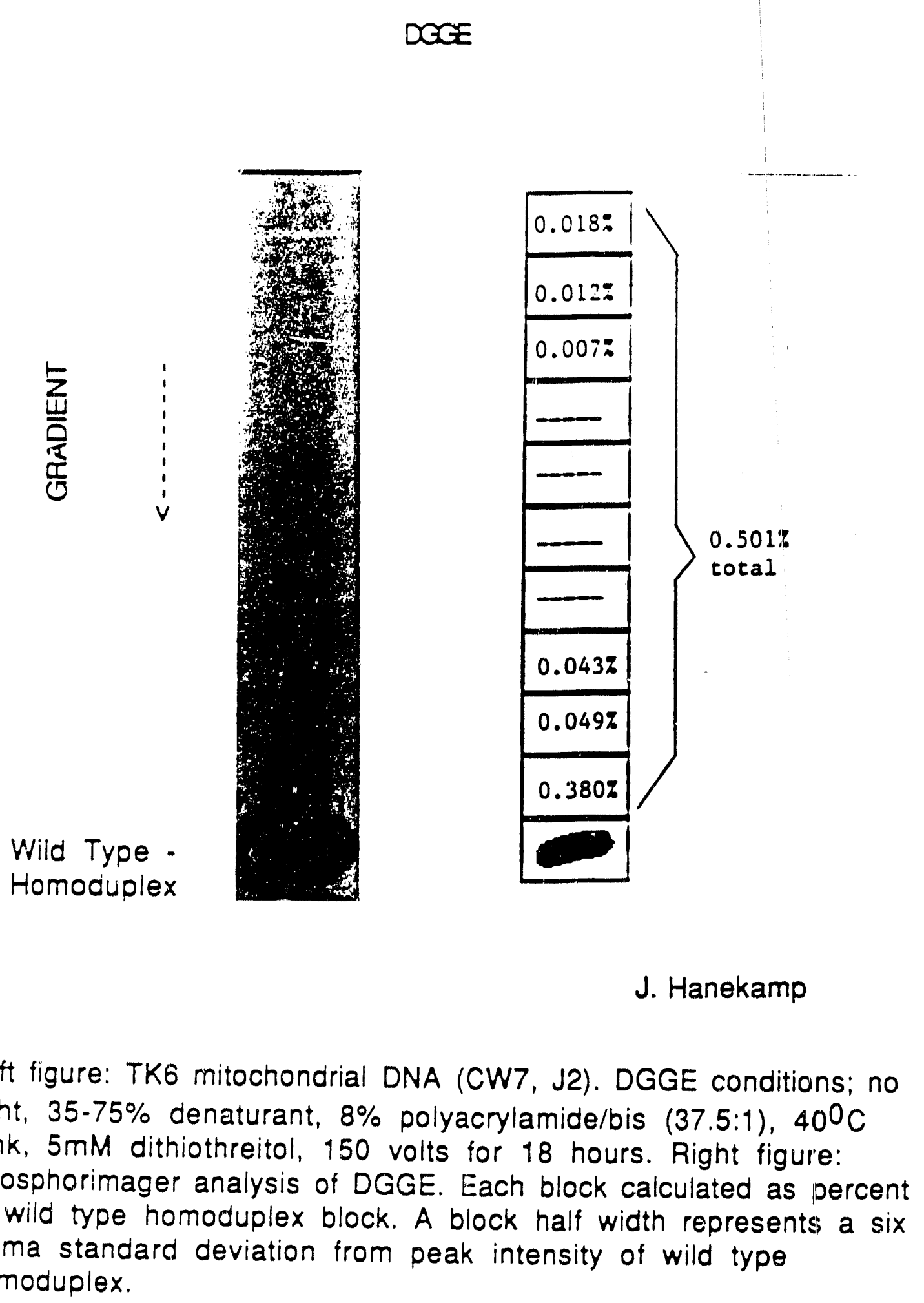

figure 7. 


\section{TWO DIMENSIONAL DGGE}

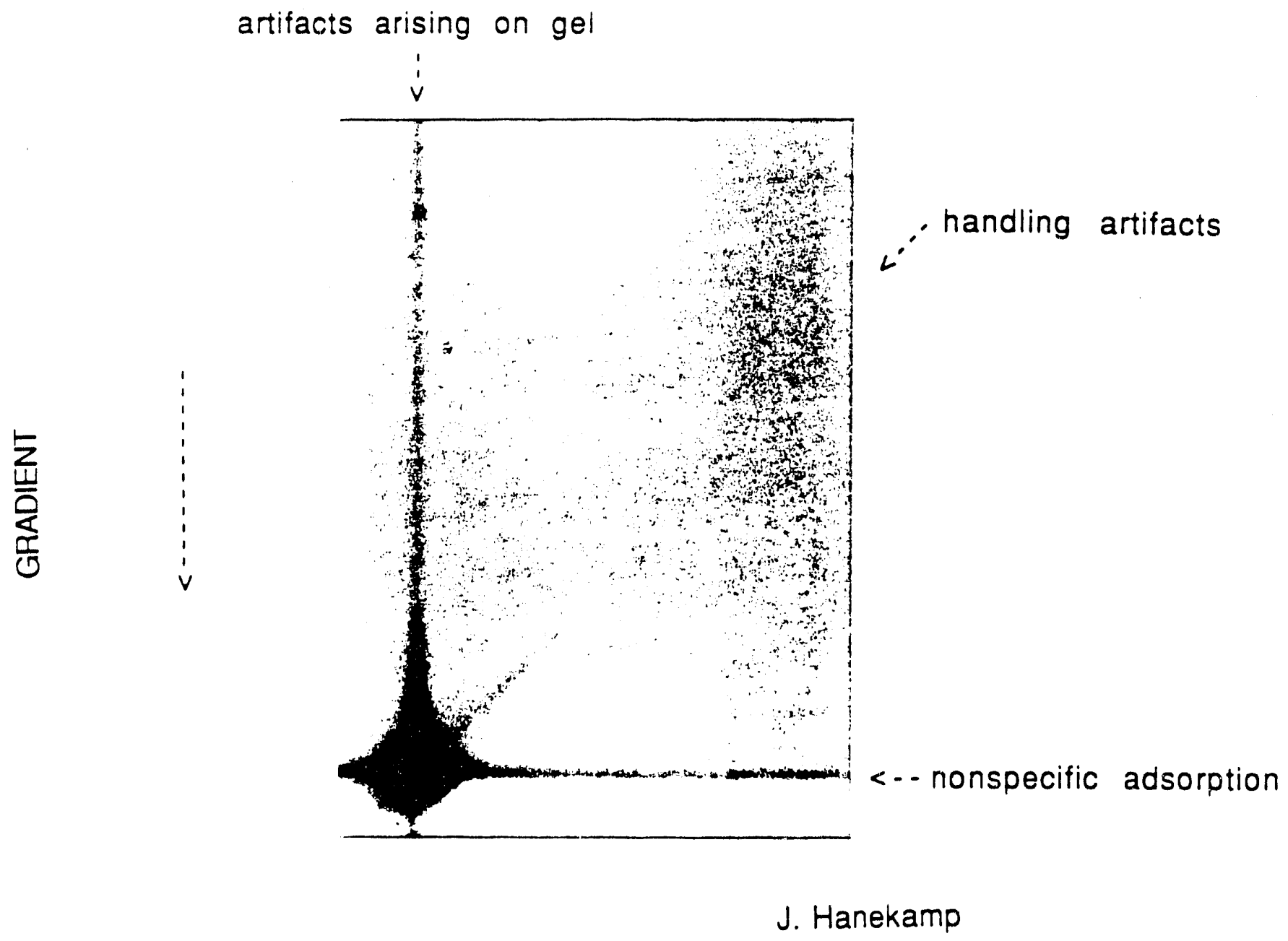

TK6 mitochondrial DNA (CW7,J2). DGGE conditions; no light, 35-70\% denaturant, $8 \%$ polyacrylamide/bis $(37.5: 1), 400 \mathrm{C}$ tank, $5 \mathrm{mM}$ dithiothreitol, 150 volts for 18 hours.

figure 8 . 


\begin{tabular}{|c|c|c|c|c|c|c|c|c|}
\hline-- & .150 & -- & --- & -- & -- & -- & - & $-f$ \\
\hline .026 & .120 & .010 & --- & -- & -- & -- & -- & -- \\
\hline .045 & .152 & .014 & -- & -- & -- & -- & -- & -- \\
\hline .030 & .095 & .014 & -- & -- & - & -- & - & - \\
\hline .024 & .077 & .010 & -- & .009 & -- & - & -- & - \\
\hline .010 & .078 & .014 & .009 & .011 & .015 & .010 & - & -- \\
\hline .014 & .082 & .020 & .018 & .079 & .022 & .076 & .018 & .018 \\
\hline .018 & .100 & .033 & .028 & .030 & .034 & .031 & .027 & .027 \\
\hline .030 & .270 & .07 & .047 & .024 & .044 & .040 & .038 & .036 \\
\hline .097 & 1.17 & .200 & .063 & .057 & .058 & .054 & .058 & .055 \\
\hline 1.33 & 0 & .780 & .180 & .120 & .140 & .140 & .150 & .140 \\
\hline .100 & .330 & .067 & .029 & .024 & .028 & .028 & .036 & .037 \\
\hline
\end{tabular}

J. Hanekamp

Phosphorimager analysis of two dimensional DGGE. Each block calculated as percent of wild type homoduplex block. A block half width represents a 6 sigma standard deviation from peak intensity of wild type homoduplex.

table 8 . 
To communicate the potential value of capillary gels we ask you to consider the previous hypothetical example in which 500 mutant sequences were admixed initially with $10^{9}$ wild type sequences. Using Hanekamp's improvements these 500 mutants would be separated on a two dimensional DGGE in the presence of no more than $10^{6}$ wild type sequences $(0.1 \%)$. If we can get these $10^{6}+500$ molecules on a temperature controlled capillary column we should be able to separate the wild type and heteroduplex peaks and count the molecules in the litter. An alternate strategy for mitochondrial studies would be to use as many as $10^{7}$ cells (1011 copies) so that recovery from gels and interface with the capillary system could be more easily achieved. Note that this process, if it works, eliminates PCR entirely from mitochondrial mutational spectrometry.

\section{SUMMARY: DGGE + HiFi PCR TECHNOLOGY}

Protocol for mutants using phenotypic selection plus DGGE and Hi Fi PCR.

Demonstrated detection limit:

$$
\begin{aligned}
& 4 \times 10^{-8} \text { hprt } \text { mutants } \\
& \text { wild type copies of hprt } \\
& \text { Oller et al (1992) }
\end{aligned}
$$

Proposed goal:

No further research required. Limit sufficient for studies in all genes and cultured cell types.

Limitations:

Not useful in human or animal tissues.

Protocol for mutants without phenotype selection with DGGE and HiFi PCR.

Demonstrated detection limit: $\quad 5 \times 10^{-3} \quad$ (average worker)

Proposed goal: $\quad 5 \times 10^{-7} \quad$ (mitochondrial mutational spectra)

Means to goal:

1. Reduction of DNA reaction products and removal of nonspecific binding

$$
\begin{aligned}
& \approx 5 \times 10^{-6} \\
& \approx 5 \times 10^{-7}
\end{aligned}
$$

2. With $10 x$ reduction of PCR noise using improved protocol for

thermostable DNA polymerases

Limitations:

Labor intensive.

\section{MAMA: Mismatch Amplification Mutation Assay.}

MAMA is a means to measure specific point mutations accurately and rapidly in any genomic DNA sample. It uses the same equipment and enzymes used in PCR. One assay or 100 
assays can thus be completed in one working day. We think MAMA is hot stuff. The procedure has already been demonstrated to have a sensitivity of somewhat less than $10^{-5}$ mutants / wild type copies directly in rat tissues. It is based on some unexpected features of allele specific PCR. Ms. Rita Cha, a Ph.D. candidate, wanted to focus her research on known point oncomutations and selected the G -..-> A transition in the twelfth codon of the H-ras gene. The wild type sequence of h-ras 12th codon is GGA and in a wide variety of animal and human tumors the mutant sequence is GAA. The analytical question was how to measure the sequence - GAA - as a small fraction of wild type - GGA - sequences.

The most obvious way was to try, as others have tried, to make a PCR primer which has a 3' mismatch with the wild type and a perfect match with the mutant. Despite the use of a wide range of conditions - temperature, time, dNTP concentrations, ionic strength - no differential in PCR efficiency was obtained in this way between the wild and mutant alleles. The product DNA from single 3' mismatched primers contained the primer sequence demonstrating that the amplification did not proceed via exonucleolytic removal of the mismatch base.

Ms. Cha then reasoned that if single 3' mismatches in PCR primers amplified as well as perfectly matched primers then a single mismatch with the mutant would also amplify well. Several such primers were tried and they amplified her mutant GAA sequence as well as the perfect match primer.

Next she devised primers in which a single mismatch existed at the ultimate or penultimate 3' prime base for the GAA sequence but for which two mismatches existed for the wild type sequence. [Unnoticed by her at the time (Newton et al, 1989); (Kwok et al, 1990), had reported this valuable observation earlier but had not developed a mutation assay of sensitivity sufficient for in vivo mutation studies]. By varying reaction conditions. She found a means to detect mutants admixed with wild type sequences at frequencies as low as $5 \times 10^{-6}$ simply by amplifying a genomic DNA sample with the double mismatch primer. This work has been accepted for publication in PCR Methods (Cha et al, (1992a) and the manuscript is included in the Appendix. Her application of MAMA to discover that the $\mathrm{H}$-ras mutations of rat mammary tumors in MNU treated animals occurred prior to MNU treatment is described in Section III and a manuscript under review is also included in the Appendix (Cha et al, 1992b).

In this section on technology to measure mutations independent of phenotype MAMA deserves special attention. The basic concept is that for any single base change - substitution, there autonatically exist a set of 12 separate PCR primers which produce a double mismatch for the wild type and a single mismatch for the specific mutant sequence. If any one of them gives the desired allele - specific amplification then one has a MAMA for that mutation.

In tests of five potentially suitable primers Ms. Cha found four to be suitable for quantitative MAMA. Dr. Richard Okinaka (Los Alamos National Laboratory) has successfully applied MAMA to a single base pair deletion mutation in exon 3 of hprt of TK- 6 cells (personal communication). Dr. Alex Kat of our laboratory has successfully used MAMA to measure a specific MNNG induced GC to AT mutation recently Ms. R. Cha and Dr. Z. Jin of Prof. Helmut Zarbl's laboratory have created a sensitive MAMA for an oncogenic neu mutant. It should be obvious to those skilled in the art that MAMA sensitivity would be greatly extended whenever the mutation of interest also changes a restriction site. A high proportion of wild type sequences could then be destroyed prior to MAMA using restriction digestion. 


\section{MAMA in Mutational Spectrometry}

Of special significance is that MAMA may be used in looking for specific mutational spectra. Consider the hypothesis that a particular chemical is responsible for most mutants induced in a human organ such as aflatoxin $B_{1}$ in human livers. Using cytochrome $\mathrm{P} 450$ expressing human cell cultures one could use the DGGE + HiFi PCR approach to determine several prominant hotspot for aflatoxin $B_{1}$ in a mitochondrial or nuclear rRNA sequence. One could then create a specific MAMA primer for each of the several aflatoxin hotspots. Using these reagents one should be able to quickly assay for all of the hotspots in a large number of autopsy specimens and discover whether or not the expected aflatoxin mutational spectrum exists in livers of persons exposed to that fungal toxin. Of course, prior to human application the parallel experiment would be performed in experimental animals; this example is given as an illustration of a simple means to provide technology for mutational spectrometry in human population studies once a mutational spectrum has been established in human cells by the more demanding DGGE + HiFi PCR technology.

\section{HUMA and Other Possibilities}

Dr. Gengxi Hu decided to reexamine the use of restriction enzymes in mutation assays independent of phenotype. He knew that molecular biologists reported uncut fractions of at least $10^{-2}$ in restriction digests and that "6-cutters" could detect mutations only in the restriction site. But he reasoned that in the mitochondrial genome there were would be an average of 4 sites for any 6 cutter and a set of 5 " 6 cutters" would thus yield a target of $4 \times 6 \times 5=120$ bp as target sequences in the $16 \mathrm{~kb}$ mitochondrial sequence. By judicious choices this could yield a fair variety of local sequences.

His first observations have been made with Eag I (CGGCCG) and Kpn I (GGTACC) enzymes using the conditions generally reported to yield $95-98 \%$ cutting efficiency. Choosing a sequence in the mitochondrial rRNA gene he has found that he can reduce the uncut wild type sequences to less than $5 \times 10^{-5}$ in the total human cell DNA preparation. The only variation from standard protocols apparent in his approach is the use of somewhat higher restriction enzyme concentrations.

The experiment was simple. Cellular DNA from $10^{5}$ cells containing $10^{9}$ mitochondrial sequences was subjected to his conditions of restriction enzyme digestion. The digested DNA was found to contain approximately $5 \times 10^{5}$ uncut sequences by quantitative PCR with primers which amplified a 115 bp sequence containing the Eag I and Kpn I sites. This PCR product mixture was then restricted again by Eag I or Kpn I enzymes and found to contain a 10\% fraction which was cut and a $90 \%$ fraction uncut. Thus the number of copies after the first restriction digest was calculated to be $(0.10)\left(5 \times 10^{5}\right)=5 \times 10^{4} 5 \times 10^{4} / 10^{9}$ original copies $=5 \times 10^{-5}$ uncut copy fraction, an unexpected result which appears to open a new technical pathway to measuring point mutations in tissue DNA. 


\section{High Efficiency Restriction Digestion With EagI And KpnI}

\section{Dr. Gengxi Hu \\ Postdoctoral Associate}

Restriction digestion of DNA is generally reported to result in an uncut residuum of greater than $1 \%$. However, in my predoctoral studies in Shanghai my experiments seemed to result in lower uncut residua. On coming to this laboratory at MIT I decided to use its techniques for measuring low numbers of DNA moleculs to measure the extent of the digestion reactions with precision. I hypothesized that if my restriction digests were really as efficient as they seemed they could be used as the basis of another approach to identifying and counting rare point mutations.
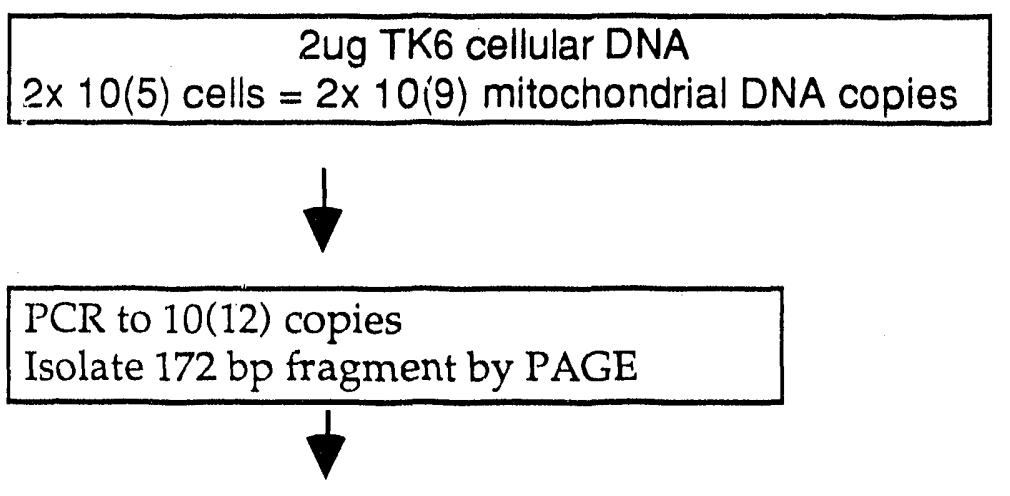

\section{Take $4 \times 10(11)$ copies}

Digest with KpnI

$$
\text { or EagI }
$$

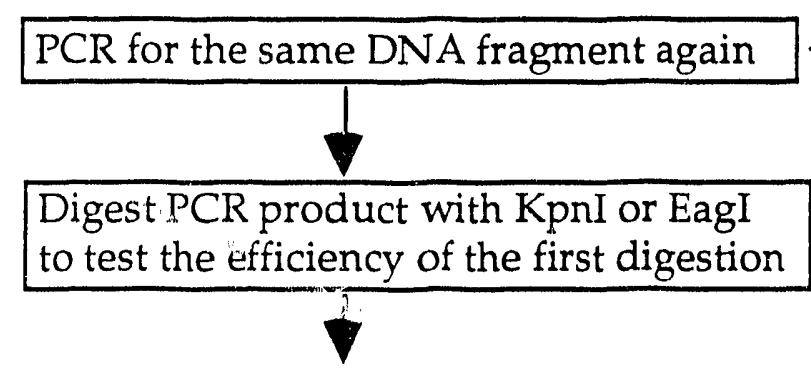

For both of the KpnI ant EagI digested samples, $10 \%$ of the total PCR product can be cut and $90 \%$ can not.

Uncut wild type DNA copies/Total original wild type DNA copies r. ropies from PCR $\times \%$ of uncut / amplifi. fold $\times$ total copies for digestion $=2 \times 10(12) \times 0.1 / 10(5) \times 4 \times 10(11)$ $=5 \times 10(.5)$ 
As part of his continuing research Dr. Hu has cloned and sequenced the uncut sequences in his whole cell DNA preps and found a variety of sequences which appear to be, on the basis of frequency, nuclear copies of mitochondrial sequences. The sequence differences between these nuclear integrants are, however, marked (about 16 mutations / $100 \mathrm{bp}$ ) and should not represent a serious noise problem in the measurement of single point mutations in true mitochondrial sequences. Experiments in progress are using cosmid libraries of "nuclear" human DNA and human cells lacking mitochondria kindly provided to us by Dr. Michael King of Columbia University. Already several putative nuclear mutant sequences have been found intact in the DNA taken from fresh $\mathrm{T}$ cell preparations of human blood samples eliminating the possibility that the nuclear sequences arose in the culture"s of the W1 - L2 and derived TK- 6 cell lines.

\section{Proposed use of HUMA in direct measurement of mitochondrial DNA mutational spectra:}

Using our goal of being able to measure hotspot point mutations at frequencies of $5 \times 10^{-7}$ and above in human mitochondrial DINA preparations we may now numerically explore how HUMA could be performed. Beginning with $10^{9}$ mitochondrial copies (about $10^{5}$ cells) one would restrict them with Eag I or Kpn I.

We would expect that of our wijld type sequences $10^{9} \times 5 \times 10^{-5}$ would remain uncut serving as our "noise" of $5 \times 10^{4}$ copies. However our "signal" is $5 \times 10^{-7} \times 10^{9}=500$ copies. Signal / noise is $500 / 50,000$ or 1 "

If we amplify these uncut cop. with one primer containing a clamp sequence we would have $10^{12}$ total copies of which $10^{10}$ would be our particular mutant. The PCR noise (Pfu polymerase) would arise from all $100 \mathrm{bp}$ of the domain but would total only $5 \times 10^{10} \mathrm{PCR}$ noise copies distributed over about 20 Pfu PCR noise hotspots of about $2.5 \times 10^{9}$ copies each. Thus any Eag I or KpN I restriction site mutation at a frequency of $5 \times 10^{-7}$ would be easily observed using our standard PCR + DGGE protocol. [The nuclear sequences have been eliminated in the PCR step by choosing a primers which will amplify only the true mitochondrial sequences].

Dr. Hu is in the process of studying all 16,569 bp of the human mitochondrial genome to define suitable $100 \pm 20$ bp regions containing by chance 6 cutter restriction sites which would lend themselves to an assay outlined below. This very recent finding that restriction digests could so easily be driven to such high efficiency was of course another technological surprise similar to the demonstration of specificity available in MAMA last year. Other combinations such as HUMA + MAMA, DGGE followed by HUMA or MAMA and the ever present possibility of interfacing with mutant separations by capillary gel electrophoresis are actively being discussed and planned.

If we first eliminated the nuclear - mitochondrial sequences by isolating mitochondrial DNA as $10^{9}$ supercoiled plasmids and then digested them with Eag I, for instance, we would have $5 \times 10^{4}$ total copies in which any of 18 base pair substitutions or $12 \pm 1$ bp additions / deletions could occur. If any did occur at a frequency of $5 \times 10^{-7}$ (our target) it would be present at 500 copies. Simply by increasing the original cell number to $10^{6}\left(10^{10}\right.$ mitochondrial copies) we could obtain 5000 specific mutant copies in $5 \times 10^{5}$ total copies. By using fluorescein - labeled, DGGE - purified probes for this sequence, we would, in a simple boiling and reannealing step, have a sample ready for separation and detection on our existing capillary gel system. 


\section{HU-mutation assay: principle, technique and potential applications}

\section{Dr. Gengxi Hu \\ Postdoctoral Associate}

The demonstration that either KpnI or EagI, six cutter restriction enzymes, cleaved DNA so that only $5 \times 10^{-5}$ of the wild type restriction sites were uncut can serve as the basis for a highly selective and sensitive mutation assay.

The concept of a HU-mutation assay is based on the high efficiency restriction digestion and high fidelity PCR. By digesting wild type DNA, only the mutant copies having mutations on the recognition site of the enzyme will remain undigested and therefore be PCR-amplified. To describe the details of the proposed techniques, I will assume a cell population containing a $5 \times 10^{-7}$ mutant fraction at one bp on a 6-bp restriction site of its mitochondrial DNA. This is abcut the same as the mutation fractions we expect in the human body.

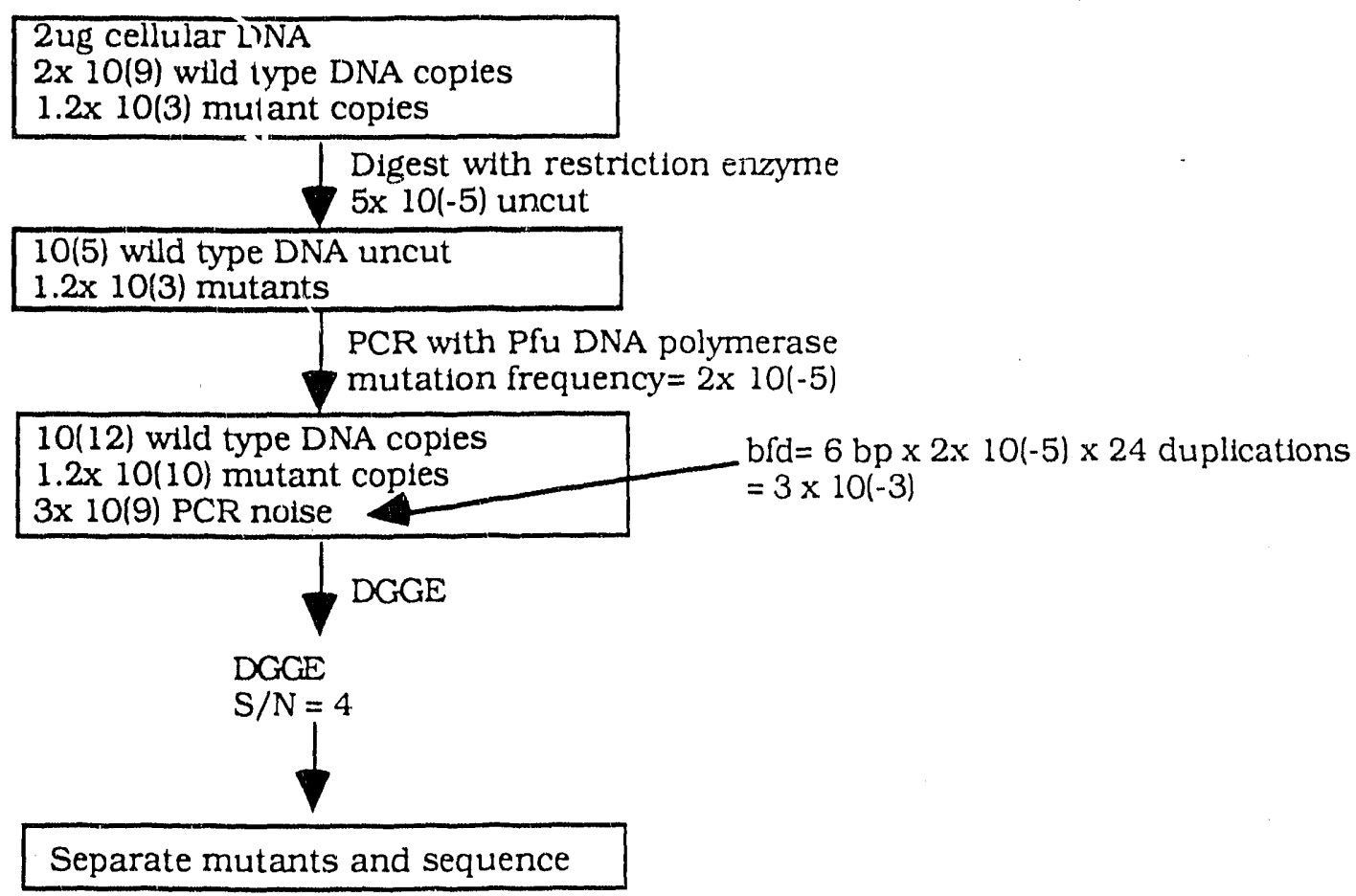

HUMA when used for several genoriic sites could be used to establish the mutational spectra of various mutagens. Its potential sensitivity recommends it as a possibility to detect the mutations in a living human body for an estimate of the risk for heritable diseases and tumors, or to check the possible exposure to mutagens. It could also be applied in theoretical research such as mutation mechanisms, DNA modifications, mitochondrial segregation, and so on. Since it is developed at 
the end of January, 1992, four mitochondrial DNA-like sequences, which could be nuclear pseudogenes, have been detected in the cultured human B-lymphocyte cell line TK6.

\section{MUTATIONAL SPECTRA IN HUMAN CELLS AND TISSUES A. hprt}

This gene for which Waclaw Szgbalski devised both forward and reverse selection systems in 1958 has been a good friend to all of us who have studied mammalian cell mutagenesis. Many laboratories have contributed to knowledge of hprt particularly Tom Caskey's which sequenced the whole gene including introns and extensive 3' and 5' flanking regions. In the interests of brevity we will not review this long and productive history of hprt.

Soon after reading Fischer and Lerman's 1983 paper on gradient denaturing gel electrophoresis, we asked Lenny Lerman for his program for calculating Tm, plugged it into a VAX and looked at the hprt cDNA sequence which Caskey had just determined. Exon 3 stood out as having just what we thought we needed for DGGE, a naturally occurring high melting domain of $84 \mathrm{bp}$ next to a $100 \mathrm{bp}$ low melting domain. Fortunately, the discovery (rediscovery) of DNA amplification came along in late 1985. We found DGGE admirably adaptable to the study of PCR, (Keohavong et al, 1989a); (Keohavong et al, 1989b). By 1990 we had shown that we could use DGGE + HiFi PCR to observe and measure mutational spectra in hprt exon 3 (Cariello et al, 1990); (Keohavong et al, 1991), and have two manuscripts in press that teach the hprt technology in its present form. It yields mutational spectra as reproducible as the experimenter may require and sensitive enough for the study of spontaneous mutation in human cell culture. (Keohavong and Thilly, 1992; Olier and Thilly, 1992).

This basic approach:

(a) Treat a sufficiently large number of cells so that $2 \times 10^{4} 6 \mathrm{TG}^{\mathrm{R}}$ surviving mutants result. e.g. $2 \times 10^{4} \div\left(\right.$ Survival Fraction $=0.2 \times$ Mutant Fraction $\left.=10^{-4}\right)=10^{9}$ cells treated.

(b) Grow these cells exponentially with daily dilution for nine generations (6 days) for expression of the $6 \mathrm{TG}^{\mathrm{R}}$ phenotype.

(c) Add 6TG to mass culture and wait for overgrowth of $6 \mathrm{TG}^{\mathrm{R}}$ population. This takes 6 10 days depending on the $6 \mathrm{TG}^{\mathrm{R}}$ mutant fractions which may range from a background of $10^{-6}$ to an induced fraction as high as $10^{-4}$ or $10^{-3}$.

(d) Carry out HiFi PCR directly on $10^{6} 6 \mathrm{TG}^{\mathrm{R}}$ cells (or on isolated DNA) for the desired fragment.

(e) Purify amplified fragments on PAGE, reamplify with nested primers simultaneously labeling with $32 \mathrm{P}$ in the $\mathrm{PCR}$ primer. Use an engineered high melting domain clamp if necessary, PAGE purify PCR products.

(f) Perform DGGE. Analyze pattern of bands quantitatively using Phosphorimager ${ }^{\mathrm{TM}}$. Calculate intensity of each band relative to wild type band. 
(g) Excise each visible band, PCR, carry out repetitive steps to isolate mutant homoduplexes and sequence by Sanger dideoxy technique.

(h) Display data as frequency vs. sequence position and kind of mutation.

Since our last competitive renewal we have published the fruits of our first efforts:

\section{MNNG (TK-6 exon 3)}

2. ICR-191

3. ultraviolet light
Cariello et al (1990)

(Appendix)

ibid.

Keohavong et al (1991)

(Appendix)

and have in press two papers describing:

4. benzopyrene diolepoxide

Keohavong and Thilly (1992)

(Appendix)

plus one paper nearly ready for submission:

5. spontaneous mutation

Oller and Thilly (1992)

(Appendix)

6. $\mathrm{H}_{2} \mathrm{O}_{2}$

ibid.

7. 02

ibid.

8. X-rays

Okinaka et al, (1992)

(Appendix)

All of these studies were performed in the human B cell line TK- 6 and the sequence studied was the 184 bp of hprt exon 3.

Dr. Alexandra Kat has extended our technology to hprt exons 2, 4, 5, 6, 7, 8, and 9 plus $436 \mathrm{bp}$ of intron flanking regions using the TK-6 derived MNNG resistant MT-1 cell line (Goldmacher et al, 1986).
9. MNNG (MT-1 cells, exons 2-9)
Dr. Alexandra Kat Thesis.
(Manuscript in preparation)
10. MNNG (TK-6 cells, exons 2-9)
Dr. Lucy Ling.
(Manuscript in preparation)

Presented here in a series of brief reports prepared by the researchers in training. Each one works on a particular mutagen. People get trained and our hprt mutational spectra library grows.
11. Benzo( $\alpha)$ pyrene (MCL-5 cells.)
Dr. Ahmad Chaudhry 
12. Fluoranthene diol epoxide

13. Styrene oxide

14. Ethylene oxide

15. Chromate (VI) $\left(\mathrm{K}_{2} \mathrm{Cr}_{2} \mathrm{O}_{7}\right)$

16. Radon daughters

17. Smokeless tobacco extract
Peter Southam

Dr. Konstantin Khrapko

Hilary Coller

Jia Chen

David Katz

Dr. Lata Shirnamé-More

Figure 1 (II-A) the recently completed thesis work of Dr. Alexandra Kat is a good example of the facility by which almost any sequence in a selectable gene can be studied by the DGGE + HiFi PCR technology.

Kat set out to look at spectra in as much of the hprt gene as possible. When she was finished she had defined PCR primers that permitted her to perform DGGE analysis of point mutations in exons $2,3,4,5,6,7,8$ and 9 along with extensive tracts of splice site regions.

Using the MNNG resistant TK-6 derived MT-1 cell line (Goldmacher et al, 1986) treated with MNNG or grown exponentially without treatment she obtained the mutational spectra for $589 / 654$ bp in exons +436 bp of flanking sequences $=1025 \mathrm{bp}$.

Figure 2 (II-A) shows one of the pleasant surprises that came from study of the - 18 bp exon 5 which yielded two strong hotspots noted as "a" and "b" on the heteroduplex bands in the figure. Figure 3 (II-A) shows the mutational spectrum for the entire set in untreated MT-1 cells. Of all $6 \mathrm{TGR}$ mutants, fully $55 \%$ were accounted by 13 hotspots distributed over some $1025 \mathrm{bp}$. Because MT-1 cells are approximately twenty - fold mutator relative to the parent TK- 6 line, the study of MT-1 spontaneous mutation was much less arduous than that described by (Oller and Thilly 1992), for TK-6 cells (See Appendix 2 (II-A)) in which a forward hprt" mutation rate was only $10^{-7}$ mutations per generation. Notably none of the MT-1 spontaneous hotspots was a GC ---> AT transition. Two frame shifts, two GC to TA transversions, one AT to TA transversion and $4 \mathrm{AT}$ to GC transversions comprise the set. In exon 3 of the TK-6 parent line Oller found two frameshifts and no base pair substitutions. Thus MT-1 and TK- 6 spontaneous hotspot mutations were two independent sets indicating that the mutator phenotype of MT-1 cells results in mutations at sites which have very low mutation rates in the parent TK-6 line. For example the rate of mutation for the AT --.-> TA transversion in exon 3 of MT-1 cells is approximately $2.5 \times 10^{-7}$ per cell generation and, given the limits of detection in Oller and Thilly (1992) no greater than $2 \times 10^{-10}$ in TK-6 cells.

Figure 4 (II-A) displays the same data set for MNNG treated MT- 1 cells. Here $36.5 \%$ of all $6 \mathrm{TGR}^{\mathrm{R}}$ mutants are accounted in 13 hotspots distributed in the $1025 \mathrm{bp}$ examined. 12 of these hotspots are GC to AT transitions, one in the flanking region of exon 4 is an AT -..-> GC transition. (The sequences of the two exon 8 hotspots have now been determined). Obviously the spontaneous and MNNG mutations are different sets given the absence of GC -...> AT in the spontaneous set. Figure 5 (II-A) shows the two sets together clearly illustrating the independence of the two mutational spectra with regard to the position of mutations. Figure 6 (II-A) shows the 


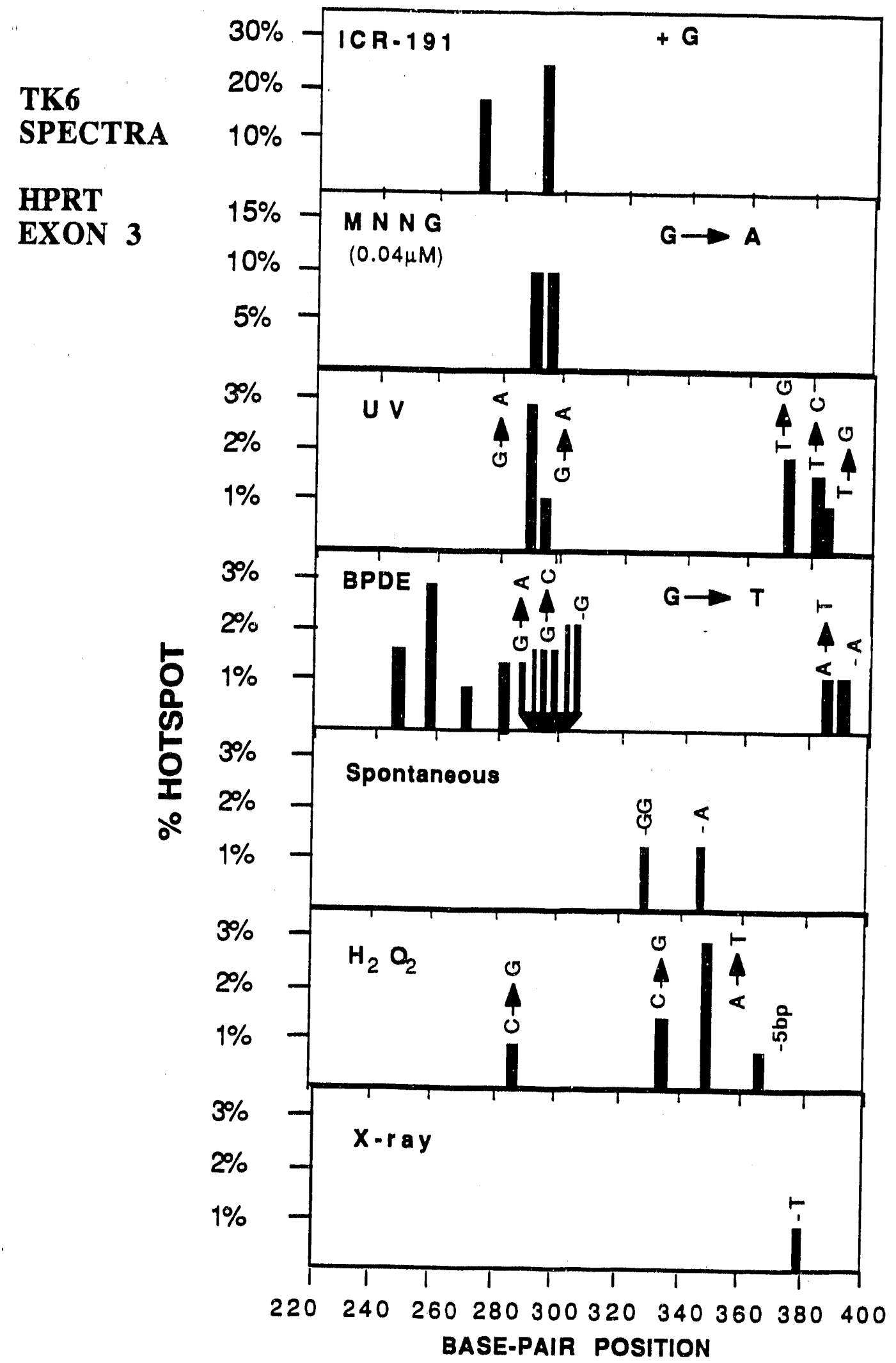

Figure 1 (II-A) 
EXON 5 6TG R MT-1 POPULATIONS

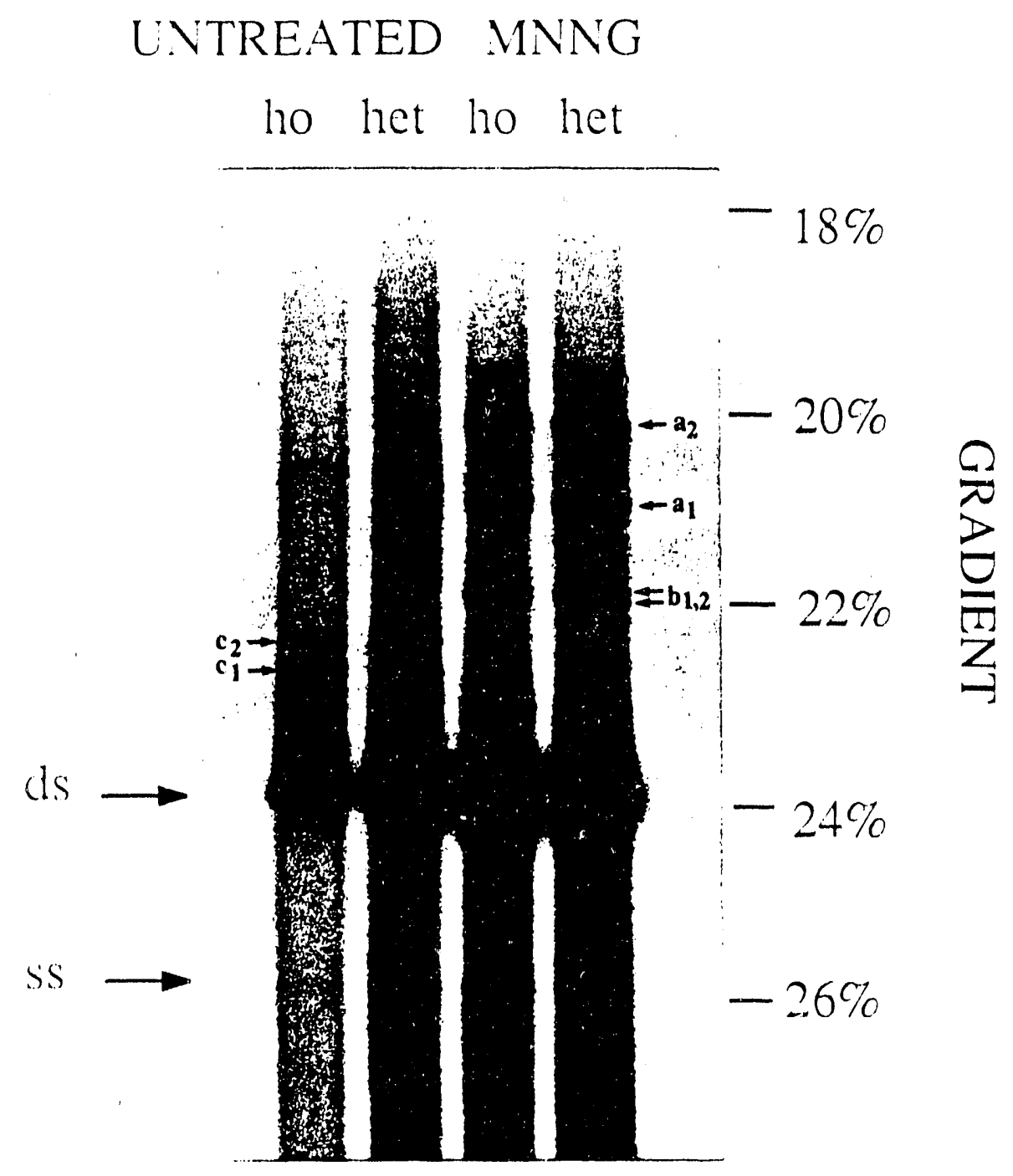

Figure 2 (II-A) 


\section{UNTREATED HOTSPOTS IN THE HPRT CODING REGION AND FLANKING INTRONS}

\begin{tabular}{|c|c|c|c|c|}
\hline $\begin{array}{l}\text { NO OF } \\
\text { HOTSPOT }\end{array}$ & & $\begin{array}{l}\text { PEACENT OF } \\
\text { POPULATION }\end{array}$ & NATURE & $\begin{array}{l}\text { EXON SIZEJ } \\
\text { BP SCANNED }\end{array}$ \\
\hline EX 2 & 2 & $5 \%$ & $\underset{\cdot G}{G . C} \rightarrow$ T.A & $107 / 71$ \\
\hline EX 3 & 5 & $32 \%$ & $\begin{aligned} A . T & \rightarrow T . A \\
T . A & \rightarrow G . C \\
A . T & \rightarrow G . C \\
& +G\end{aligned}$ & $184 / 184$ \\
\hline
\end{tabular}

EX4 $00 \%$

$66 / 66$

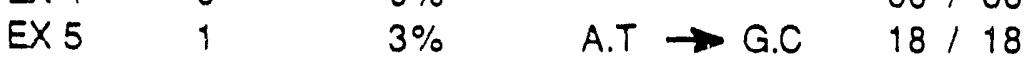

EX $6 \quad 0 \quad 0 \%$

$83 / 83$

EX $7 \quad 1$

$5 \%$

$T . A \rightarrow G . C$

$47 / 42$

EX $8-3$

$8 \%$

A.T $\rightarrow$ G.C

$77 / 77$

G.C $\rightarrow$ T.A

EX9 1

$2 \%$

A.T $\rightarrow$ G.C

$48 / 48$

$42 \%$ of 6 TG $R$ alterations in

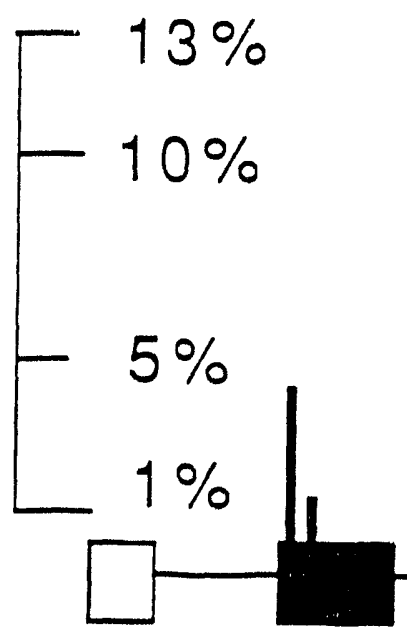

$89.6 \%$ of the coding region

$13 \%$ of 6 TG $R$ alterations

in flanking intron sites

1

2

3

4

Distribution

Figure 3 (II-A) 


\section{MNNG HOTSPOTS IN THE HPRT CODING REGION AND FLANKING INTRONS}

\begin{tabular}{|ccccc|}
\hline $\begin{array}{c}\text { NO OF } \\
\text { HOTSPOT }\end{array}$ & $\begin{array}{c}\text { PERCENTOF } \\
\text { POPULATION }\end{array}$ & NATURE & $\begin{array}{c}\text { EXON SIZE } \\
\text { BP SCANNED }\end{array}$ \\
\hline EX2 & 3 & $4.5 \%$ & G.C $\rightarrow$ A.T & $107 / 71$ \\
EX3 & 2 & $20.0 \%$ & G.C $\rightarrow$ A.T & $184 / 184$ \\
EX 4 & 1 & $0.5 \%$ & A.T $\rightarrow$ G.C & $66 / 66$ \\
EX 5 & 2 & $5.5 \%$ & G.C $\rightarrow$ A.T & $18 / 18$ \\
EX6 & 1 & $2.0 \%$ & G.C $\rightarrow$ T.A & $83 / 83$ \\
EX7 & 1 & $3.0 \%$ & G.C $\rightarrow$ A.T & $47 / 42$ \\
EX8 & $2 *$ & $6.0 \%$ & $\ldots \ldots \ldots .$. & $77 / 77$ \\
EX9 & 1 & $1.0 \%$ & G.C $\rightarrow$ A.T & $48 / 48$ \\
\hline
\end{tabular}

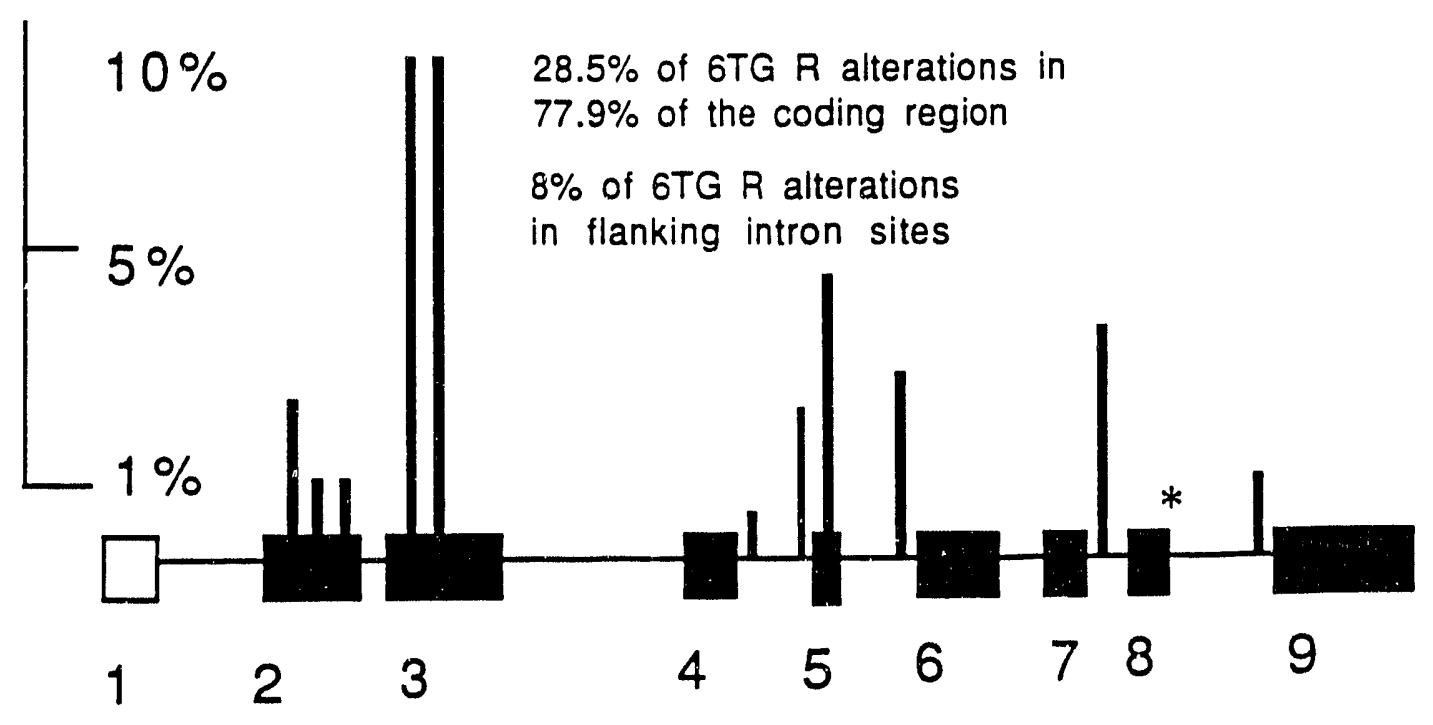

\section{Distribution of Hotspots}

Figure 4 (II-A) 
$(+) \perp \forall \leftarrow-0$

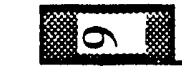

$0 \cdot 0-1 \cdot \forall$

焉

0

$(+) \perp \forall<-00$

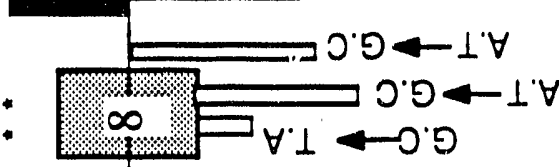

으

世

安

号

ช.

늘

$\leftarrow 2$

II

I

0

z

$\sum$ क

\section{$(+) \perp \forall<-0.0-0$ 的}

$(+) \perp \forall-0 \cdot 0$

$(-) 0 \cdot 0 \leftarrow \perp^{\prime} \forall$

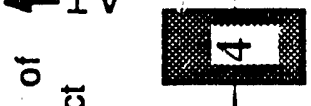

$5 \leftarrow \forall \perp$
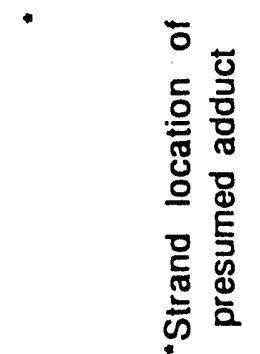

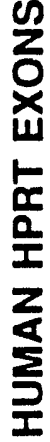

$(+) 1 \forall-0 \cdot 0$ $(+) \perp \forall \leftarrow \circ \cdot 0$

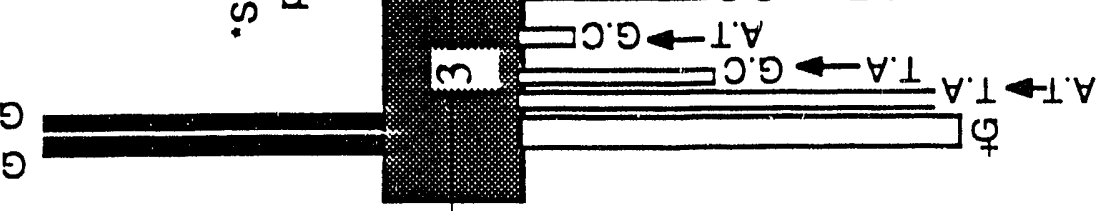

(-) $\perp \cdot \forall \leftarrow 0 \cdot$

(-) $\perp \forall \leftarrow-0$ (+) $1 \forall \leftarrow-0$

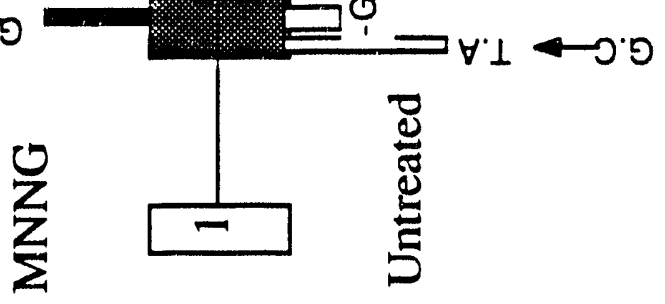

Figure 5 (II-A) 


\section{SEQUENCE CONTEXTS FOR MNNG HOTSPOTS}

\begin{tabular}{|c|c|c|c|c|c|c|}
\hline HOTSPC & & NT 6TG R & & SURROUNI & ING & SEQUENCE \\
\hline$G \rightarrow A$ & bp 132 & $2.5 \%$ & $5^{\prime}$ & ACCAG & G & TTATG $3^{\prime}$ \\
\hline$G \rightarrow A$ & bp 140 & $1 \%$ & $5^{\prime}$ & ATCAA & G & GTCAT $3^{\prime}$ \\
\hline$G \rightarrow A$ & bp 159 & $1 \%$ & $5^{\prime}$ & GATTA & G & GTATG $3^{\prime}$ \\
\hline$G \rightarrow A$ & bp 294 & $10 \%$ & $5^{\prime}$ & CAAGG & G & GGGCT $3^{\prime}$ \\
\hline$G \rightarrow A$ & bp.297 & $10 \%$ & $5^{\prime}$ & GGGGG & G & CTATA $3^{\prime}$ \\
\hline $\mathrm{G} \rightarrow \mathrm{A}$ & -15 ex 5 & $1.5 \%$ & $5^{\prime}$ & TTCTA & $\mathrm{G}$ & AATGT $3^{\prime}$ \\
\hline$G \rightarrow A$ & bp 485 & $4 \%$ & $5^{\prime}$ & ATGTG & G & AAGTA $3^{\prime}$ \\
\hline$G \rightarrow A$ & $\begin{array}{ll}-5 & 3 \\
3^{\prime} & \mathrm{ex}\end{array}$ & $3 \%$ & $5^{\prime}$ & TGTAA & G & TGAAT $3^{\prime}$ \\
\hline$G \rightarrow A$ & $165^{\prime} \operatorname{ex} 9$ & $1 \%$ & $5^{\prime}$ & TTTCT & G & GATTT 3 \\
\hline
\end{tabular}

Figure 6 (II-A) 
sequence context of the MNNG induced GC -..-> AT hotspots in MT-1 cells. As has been seen in E.coli using Jeffrey Miller's lac I system the context Purine - Guanine is most frequently observed (Coulondre and Miller 1977). Our data for human cells mutated by ICR-191, MNNG benzopyrene diol epoxide and ultraviolet light show a remarkable similarity in sequence contexts for hotspots between E.coli and human cells. Furthermore, no statistically significant variation has arisen between our studies with hprt using DGGE + HiFi PCR and human cell studies such as in Veronica Maher's laboratory using clone by clone analysis). Kat's work also provides a look at mRNA splice site mutations as seen in Figure 7 (II-A)).

Work by Dr. Lucy Ling has traced the MNNG induced mutational spectra in more exons and flanking sequences in the TK-6 parent line. Although sequencing of the hotspots is still in progress Figure 8 (II-A) shows the remarkable difference between the "isogenic" MT-1 and TK-6 cells' mutational spectra in exon 3 alone. While the hotspots arising in TK- 6 cells at the second and third G's in a run of $6 G^{\prime}$ s, the MT-1 hotspots are at the third and sixth G's. All three GC -..$>$ AT mutations eliminate a glycine - glycine motif and give rise to $6 \mathrm{TG}$ Rutants. Other TK-6 vs MT-1 differences in MNNG induced spectra include the absence of all three MT-1 exon 2 hotspots in TK- 6 cells while TK- 6 hotspots not seen in MT-1 have shown up, too!

Figure 9 (II-A) shows the reproducibility of the general approach using exon 3 as an example (MNNG, TK-6 cells). Figure 10 (II-A) shows the results for exon 5; Figure 11 (II-A) shows exon 8. Here four independent 6 liter cultures were treated once with MNNG to produce a $6 \mathrm{TG}^{\mathrm{R}}$ mutant fraction of only $2 \times 10^{-5}$ but resulting in some 24,000 separate MNNG mutations per culture. It is this emphasis on numerical analysis before doing experiments, boring to most of our colleagues and, too frequently, to our reviewers, that permits this degree of reproducibility. In the current instance a hotspot mutation comprising only $0.5 \%$ of the $6 \mathrm{TG}^{\mathrm{R}}$ total would have arisen some 120 times in the initial treatment.

The amount and kinds of alkylated base products are the same in lines TK- 6 and MT-1 which differ $10^{3}$ fold in MNNG sensitivity. Both TK-6 and MT- 1 cells are deficient in $0^{6} \mathrm{Me}$ guanine methyl transferase. Of all the alkylated base products only $3 \mathrm{Me}$ - adenine is removed by either cell line. By analogy to mismatch deficient E.coli we have suggested that MT-1 cells have a deficient mismatch repair system (Goldmacher et al 1986). The appearance of spontaneous base pair substitutions hotspots in MT-1 but not TK- 6 is consistent with this idea.

Our work on BPDE (which should appear soon in PNAS) similarly demonstrates the marked reproducibility of the general approach (Appendix 1 (Il-A). This paper also contains two extremely important tests for bias in estimating the hotspot mutant frequencies: differential growth of a particular mutant during cell culture and differential amplification of a particular mutant during PCR.

Growth advantage / disadvantage is tested by growing a treated population for the minimum 6 and then 10 more days after treatment before selecting with 6TG. If any mutant type has an average growth rate $5 \%$ greater or lower than the culture average, this will result in a DGGE band which significantly changes between days 6 and $16 ;(0.95)^{10}=0.6,(1.05)^{10}=1.6$. Similarly it we take a small sample of our initial PCR product and amplify it $10^{3}$ fold more we can detect a deviation from the average PCR efficiency of $\pm 5 \%$ by a relative doubling or halving of a particular hotspot band on the denaturing gel autoradiogram. To our certain knowledge no test for such biases have been performed in previous mutational specrra studies going back to Benzer and Freese. Dick Albertini's demonstration of the more rapid growth of hprt mutants is the in vivo equivalent of selective advantage and warns us all of the need for greater vigilance. The PCR bias 


\section{TG R ALTERATIONS IN EXON FLANKING REGIONS OF HPRT}

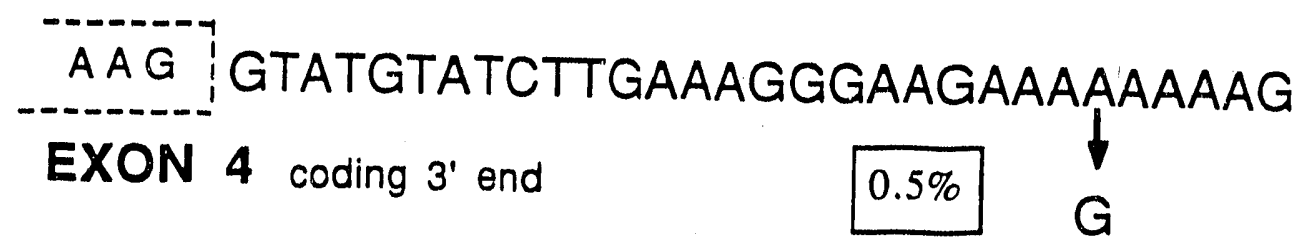

M N N G

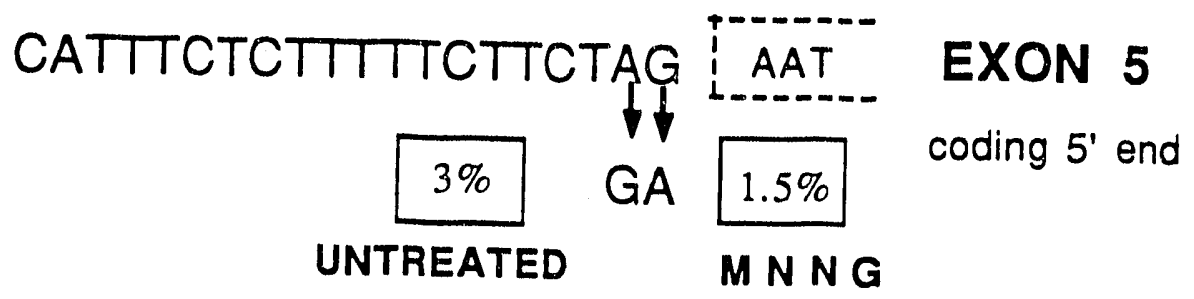

TITAAAGCTATGCAATGTCTTCTITITTGAAAG GAT $2 \%$

EXON 6 coding 5 ' end

M N N G
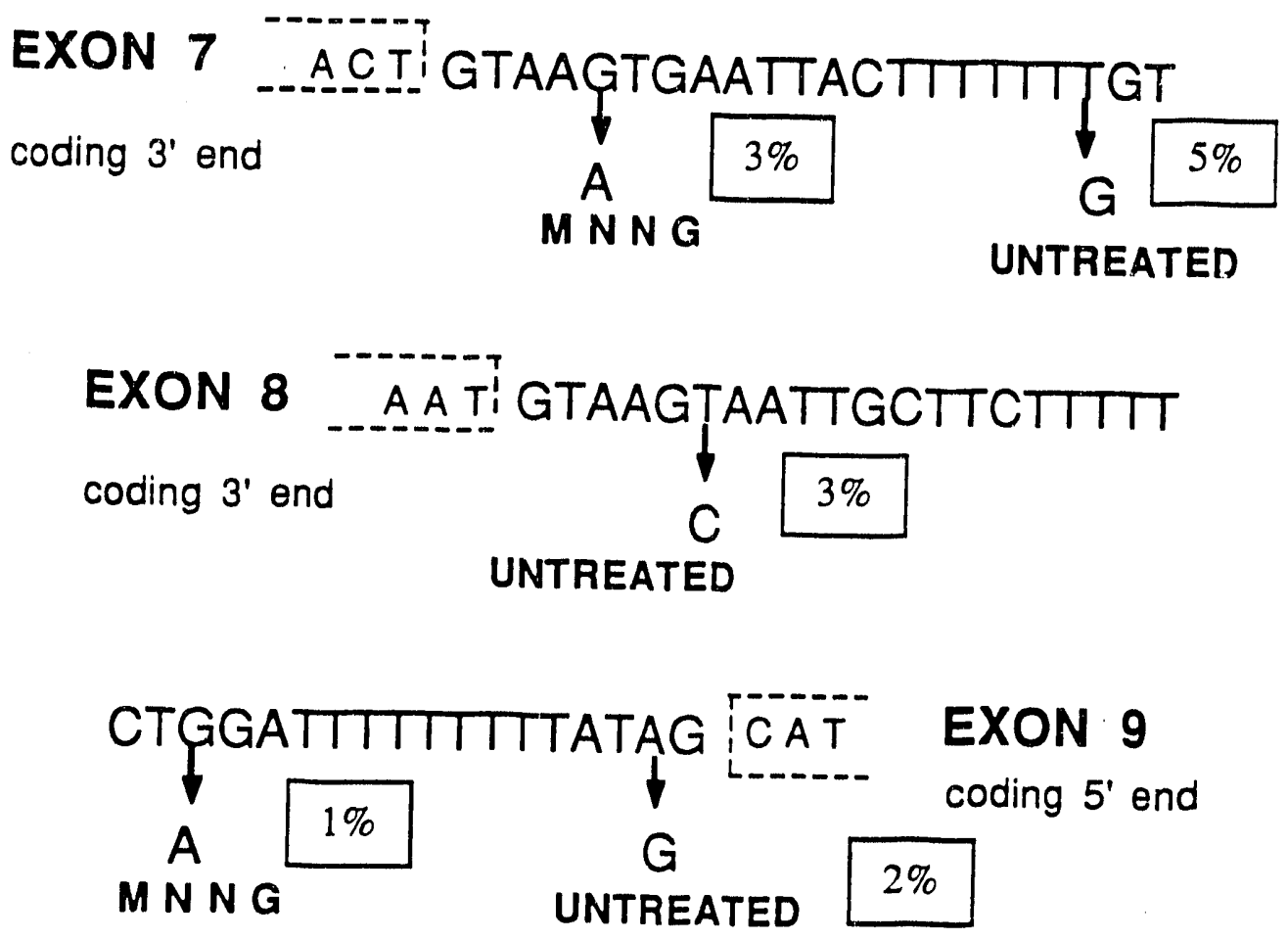


\section{MNNG SPECTRA IN HPRT EXON 3}

\section{TK6 Populations}
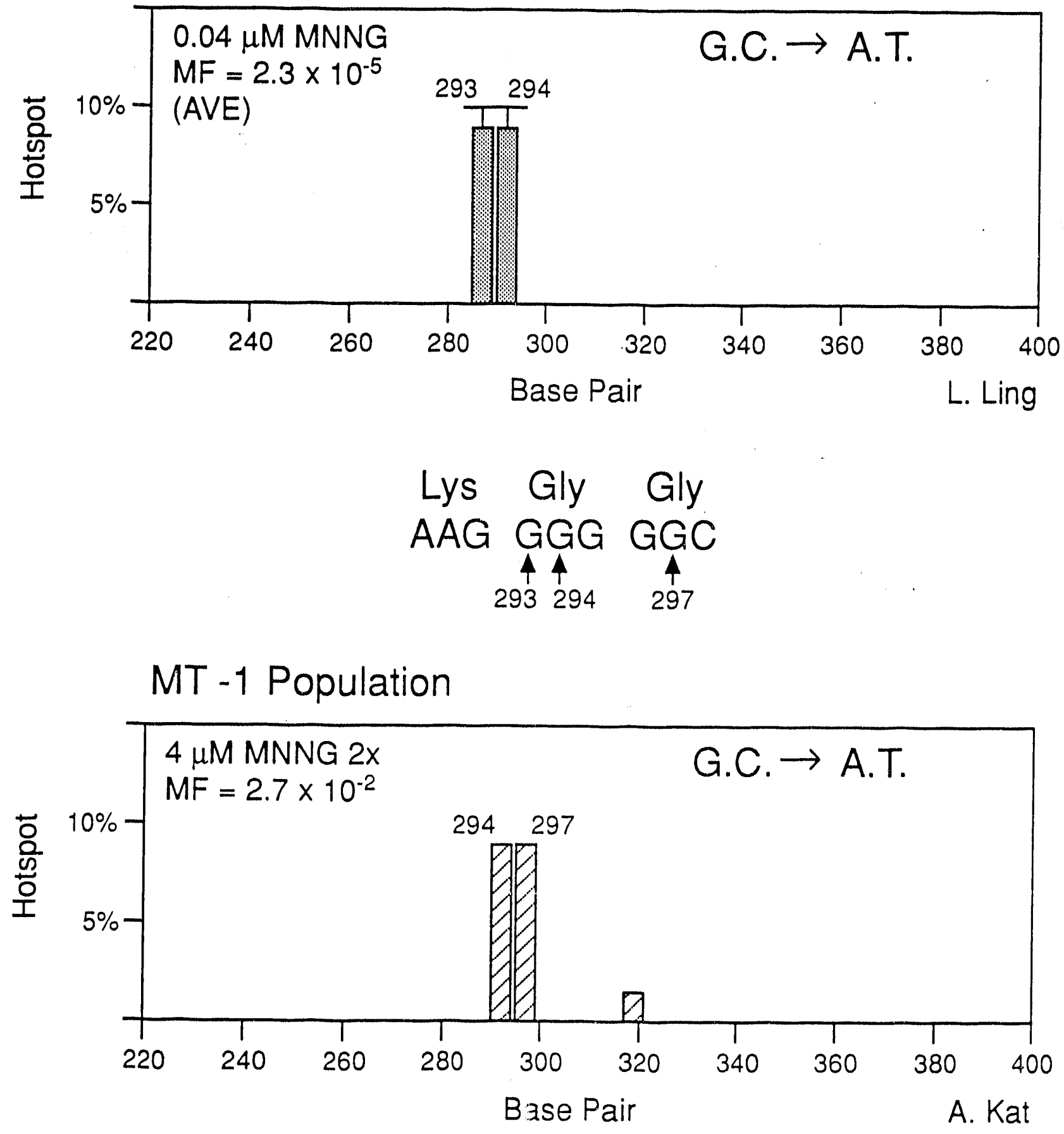

Figure 8 (II-A) 


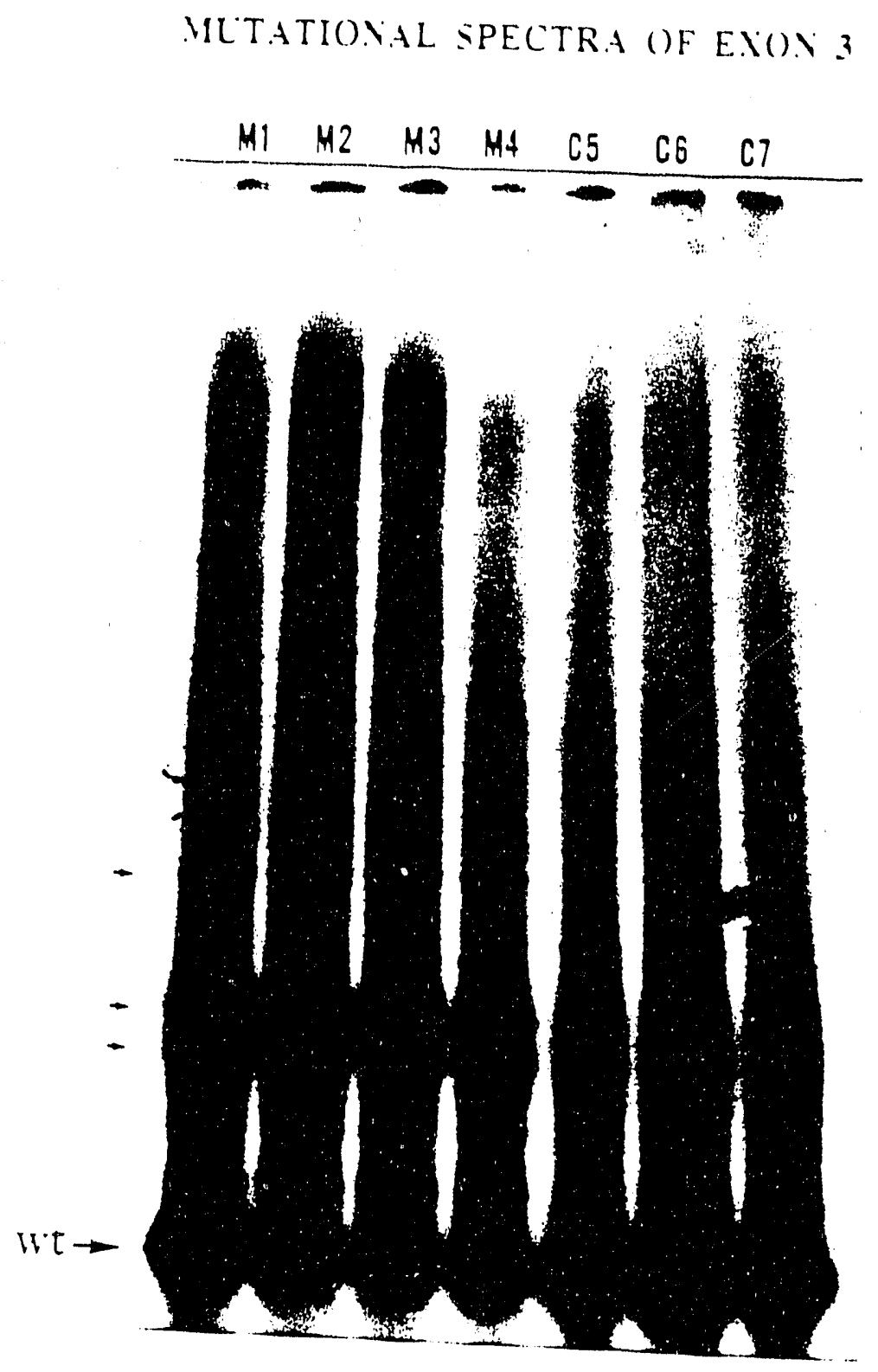

Figure 9 (II-A) 
MLTATIONAL SPECTRA ()F EAOIS

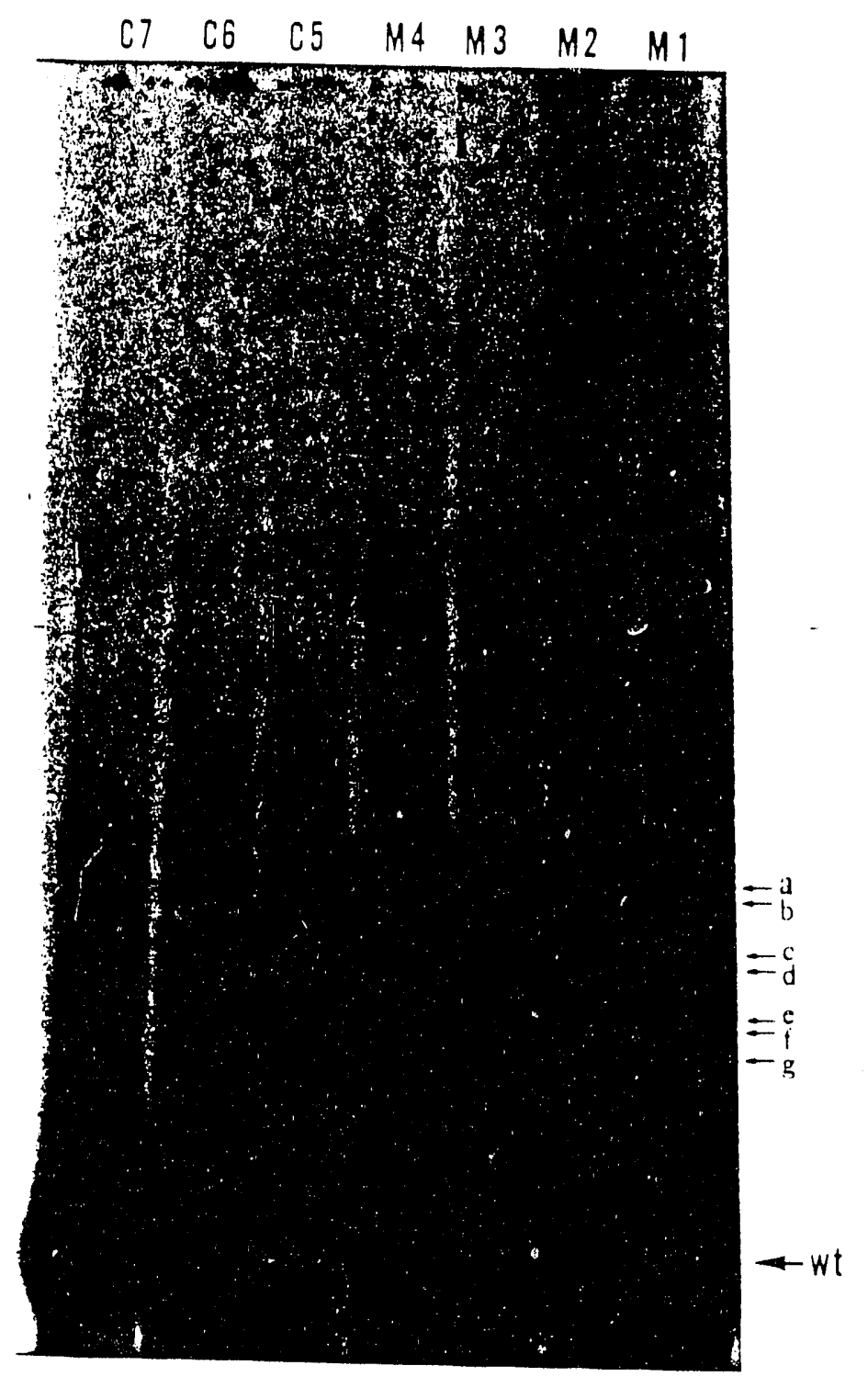

Figure 10 (II-A) 


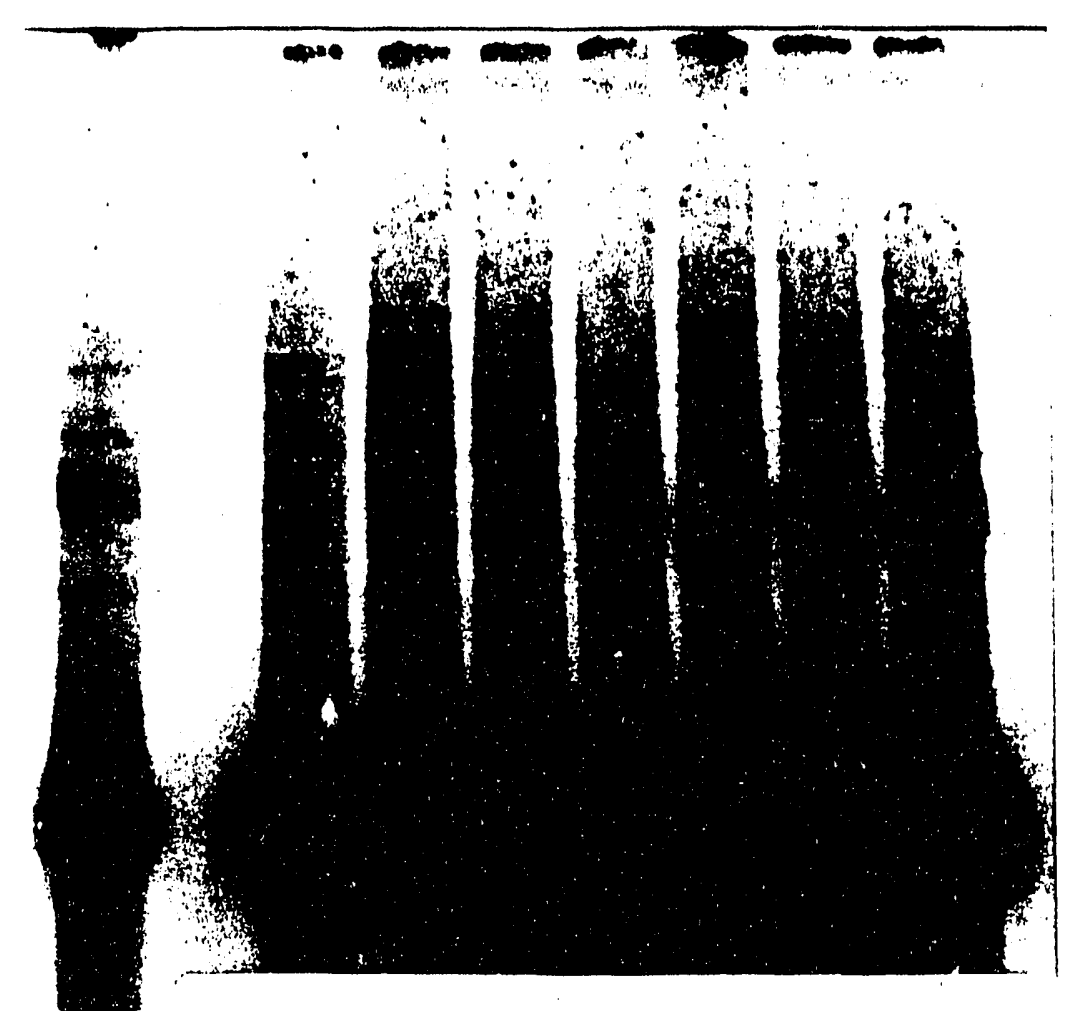

MUTATIONAL SPECTRA OF EXON 8

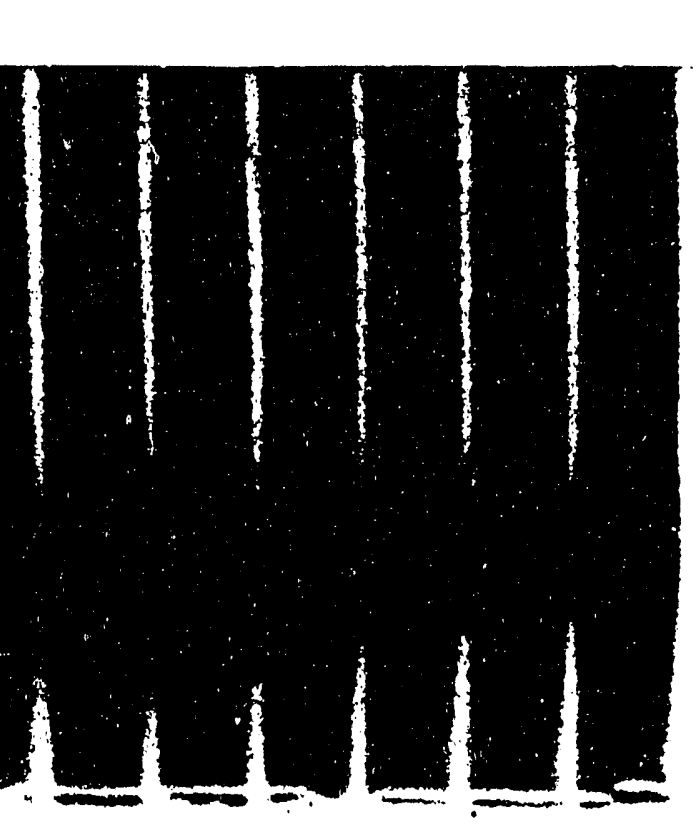

$$
\text { Figure } 11 \text { (II-A) }
$$


of allelic preference also exists. We first described this phenomenon in our studies with $\mathrm{T} 4$ and Klenow fragment DNA polymerases (Keohavong et al, 1989). To date we have seen no hint of allelic preferences with the heat stable DNA polymerases Taq, Vent, Deep - Vent and Pfu but we keep looking.

RESEARCHER REPORTS

\section{Mutation Spectra of Benzo [ $\alpha]$ Pyrene in Human cells Competent in Xenobiotic Metabolism}

\section{Dr. M. Ahmad Chaudhry \\ Postdoctoral Associate}

The studies on the mutation spectra of BPDE have been extended in an effort to understand and correlate the demage of polycyclic aromatic hydrocarbons to cellular macromolecules like DNA and proteins to the ultimate induction of mutation. The $B[\alpha] P$ induced DNA adducts, protein adducts and the induction of mutation were measured simultaneously in human MCL-5 cells ( Crespi et al., A metabolically competent human cell line expressing five cDNAs encoding procarcinogen-activating enzymes: application to mutagenicity testing. Chem. Res. Toxicol. 1991, 4, 566-572 ) engineered to be competent in xenobiotic metabolism in a short term, high dose experiment. The cell culture medium also contained human RBCs to measure the adducts of hemoglobin to the metabolites of $\mathrm{B}[\alpha] \mathrm{P}$. An $1 \mu \mathrm{g} / \mathrm{ml}$ dose of $\mathrm{B}[\alpha] \mathrm{P}$ over a period of 28 hours resulted in $50 \%$ survival and a mean mutant fraction of $5 \times 10^{-5}$ at the hprt locus which was 20 times higher than the background mutant fraction of $2.5 \times 10^{-6}$. The DNA adducts adducts were found to be $2,8 \times 10^{-6} \mathrm{~B}[\alpha] \mathrm{P}$ adducts per $\mathrm{bp}$. The analysis of globin prepared from recovered $\mathrm{RBCs}$ and digested with Pronase revealed $500 \mathrm{pg} \mathrm{B}$ [a]P adducts per $\mathrm{mg}$ of $\mathrm{RBC}$ hemoglobin. The treatment of $5 \times 10^{8}$ cells in this experiment generated 1,850 hprt mutants. These mutants were analysed en masse to find mutation hot spots in exon 3 of the gene using the combination of hi-fi PCR and DGGE. In the low melting temperature domain of exon 3 sequence, six mutation bands were found [ see Figure 1 (II-A)]. These bands are in the process of being analysed to determine their DNA sequence to discover the mutations. What is already apparent however is that the set of $\mathrm{B}[\alpha] \mathrm{P}$ mutations arising in the human MCL-5 cells are not identical to those seen when TK- 6 human B cells were treated with benzo pyrene diol epoxide ( see Appendix 1 (A-I). 
Mutational Spectra of Benzo $[\alpha]$ Pyrene Treated 6TGR Human Cells HPRT Exon 3 ( Low Melting Domain)
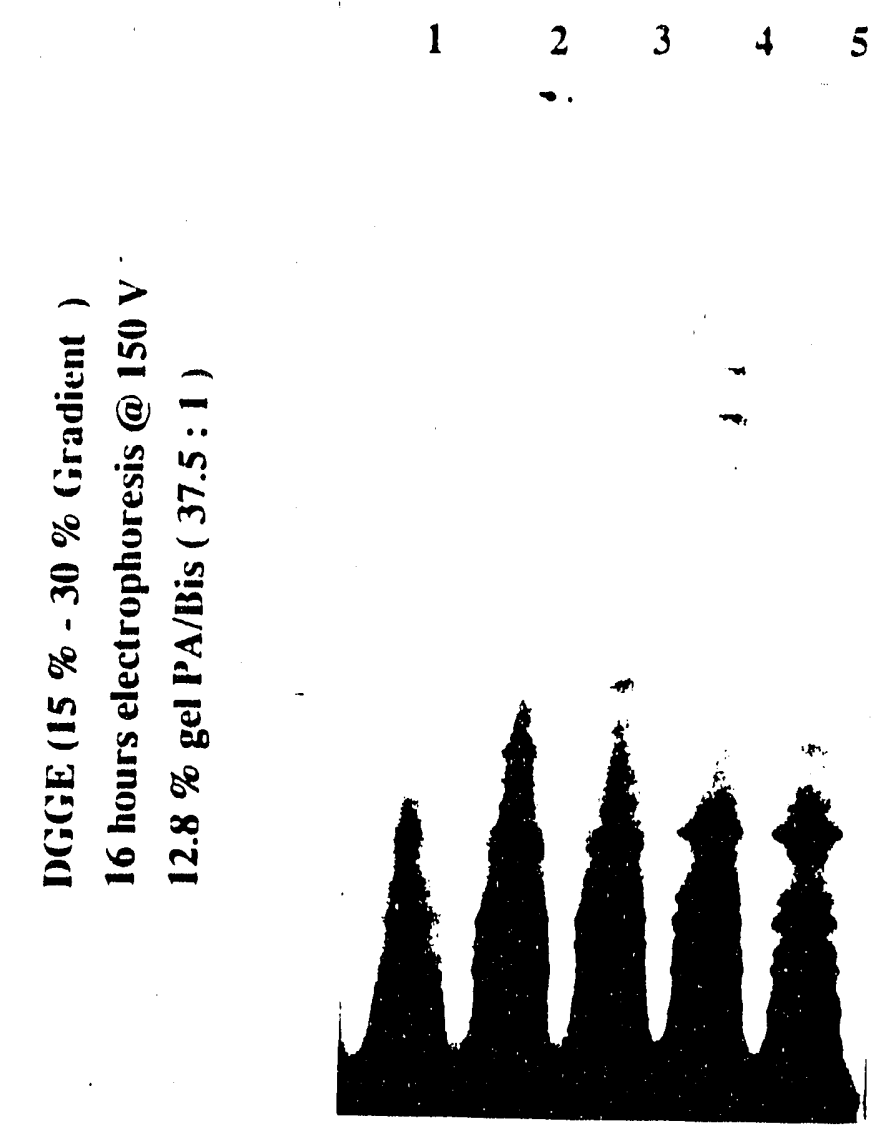

] Wild Type Homoduplex

\footnotetext{
Lanes

1 MCL-5 ( untreated ; unselected )

$2 \operatorname{MCL}-5\left(6 T^{R}\right)$

$3 \mathrm{MCL}-5$ ( $6 \mathrm{TG}^{\mathrm{R}}$ )

4 MCL-5 (B $[\alpha]$ P treated ; 6TGR )

5 MCL-5 (B $[\alpha]$ P treated ; $6 \mathrm{TG}^{\mathrm{R}}$ )
} 


\section{Mutational Spectra of Flworanthene diol epoxide in TK6 cells}

\section{Peter Southam \\ Research Assistant}

Fluoranthene is a ubiquitous polyaromatic hydrocarbon arising from incomplete combustion processes. It is introduced into the air from engine emissions and has been found in food that is cooked by grilling or frying. Thus it is a chemical to which we are all exposed on a continuous basis throughout our lifetimes. Studies of environmental mixtures, such as combustion samples, have shown that fluoranthene consistently comprises a significant portion of the mutagenic activity. (Barfnecht, Hites et al. 1982) It is primarily for this reason that we have decided to study the mutational spectra of this compound.

Along with the importance of fluoranthene as a mutagen in the environment in and of itself, a comparison of the data generated by the fluoranthene study and the benzo(a)pyrene work is important in determining our ability to discriminate between the spectra of two closely related compounds. This will be critical in the future in allowing us to decide whether a person's mutational spectra will indicate exposure to one individual agent, or to a whole class of related agents.

Studies done by our group show that fluo anthene produces a mutant fraction in human lymphoblast cells of approximately half as large as that produced by benzo(a)pyrene. However, in combustion samples that have been analyzed, it has been present in larger amounts than the benzopyrene. (Barfnecht, Hites et al. 1982)

Fluoranthene is metabolized to a number of different potentially mutagenic forms by enzymes in the human body. Work by our lab has suggested that the 2,3 dihydroxy $1,10 \mathrm{~b}$ epoxide is the most mutagenic of these metabolites, (Babson, Russo-Rodriguez et al. 1986) thus we chose this for determination of mutational spectra.

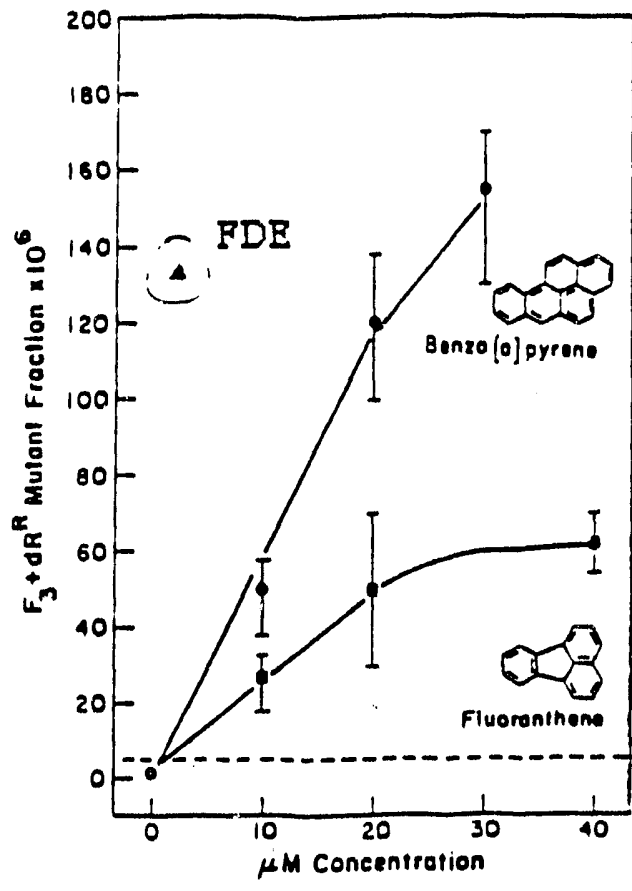

Mutant fraction versus dose for Pluoranthere - Benzo(a)pyrene and Fluoranthene diol epoxide. 493

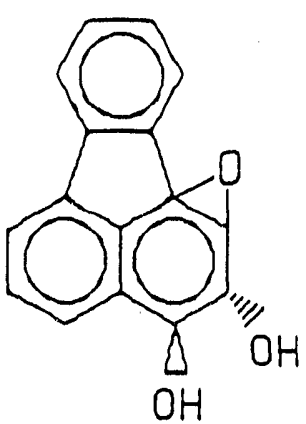

Fluoranthene 2,3 dihydroxy $1,10 \mathrm{~b}$ epoxide 
Three independent cultures of the lymphoblastoid cell line, TK6, containing $1 \times 10^{9}$ cells each were treated with single doses of $375 \mathrm{ng} / \mathrm{ml}$ of FDE. This resulted in a mean surviving fraction of $48 \%$. After an appropriate number of generations to allow for full phenotypic expression, both FDE treated and untreated cultures were selected with 6-thioguanine (6TG) which gave rise to $6 \mathrm{TG}^{\mathrm{R}}$ mean mutant fractions of $1.36 \times 10^{-4}$ for treated and $6.6 \times 10^{-6}$ for untreated cultures.

DNA samples from the treated and untreated cells have been isolated and are currently being analyzed using the PCR/DGGE protocol to determine the mutational spectra. in the high and low melting domain regions of exon 3 of the HPRT gene. Benzo(a)pyrene diol epoxide induced 12 separate hot spot mutations in this sequence so it is expected that this particular sequence will be particularly informative for FDE and other polycyclic aromatic hydrocarbons.

\section{References}

Babson, J. R., S. E. Russo-Rodriguez, et al. (1986). "Microsomal Activation of Fluoranthene to Mutagenic Metabolites." Toxicology and Applied Pharmacology 85: 355-366.

Barfnecht, T. R., R. A. Hites, et al. (1982). Human Cell Mutagenicity of Polycyclic Aromatic Hydrocarbon Components of Diesel Emissions. Toxicological Effects of Emissions from Diesel Engines. Elsevier Science Publishing Co. 277-294. 


\section{Mutational spectrum of styrene oxide in TK6-cells}

\section{Dr. Konstantin Khrapko \\ Postdoctoral Associate}

Preliminary does / response experiment. $100 \mathrm{ml}$ cell cultures were treated for 20 hours with $0,9,14$ and 21 micrograms of styrene oxide per $\mathrm{ml}$ of culture. The survival was $1,067,025$ and 0.014 correspondingly. The fractions of cells bearing a function-disrupting mutations in hprt gene were determined from the results of plating with and without 6-thioguanine, which selects for the absence of hprt activity, after 8 days of phenotypic lag. Thus defined mutant fractions in these cultures were found to be $2.0 \times 10^{-5}, 2.8 \times 10^{-5}, 4.5 \times 10^{-5}$ and $7.5 \times 10^{-5}$ correspondingly. The results are presented in Figure 1 (II-A).

The main experiment included styrene oxide treatment of $4 \times 10^{9}$ cells (4-liter culture) in a large 6-liter fermenter. The treatments were performed in triplicate, with 15 micrograms styrene oxide per $\mathrm{ml}$ of culture. The cells were derived from a single clone about 50 generations old. Mutant fractions of treated cultures were $1.3 \times 10^{-5}$, while the background mutant fraction of the control (nontreated) culture was $0.4 \times 10^{-5}$.

The mutant cells were selected with 6-thioguanine after 8 days of phenotypic lag. All the procedures were performed with sufficient number of cells so that the total number of induced mutants never decreased below about $10^{4}$.

The DNA was isolated from both treated and non-treated selected cells and a portion of hprt exon 3 was amplified approximately $10^{5} \times 10^{2}$-fold and $32 \mathrm{P}$ end-labeled in a two-stage PCR procedure with nested primers. The resulting DNA fragments, consisting of a low - and a highmelting domain, were boiled and reannealed to convert mutant homoduplexes into mutant / wild type heteroduplexes and run on a DGGE, $15 \%$ to $35 \%$ of denaturant.

The autoradiograms of the DGGE are presented in Figure 2(II-A). In "control" lane the bands above the major wild type band represent previously determined base substitutions generated by polymerase during PCR procedure. The bands present in the "treated", but not in the "control" line, correspond to mutations, induced by styrene oxide. Duplicate cultures showed the same bands as seen in Figure 2. 


\section{Dose/response experiment}

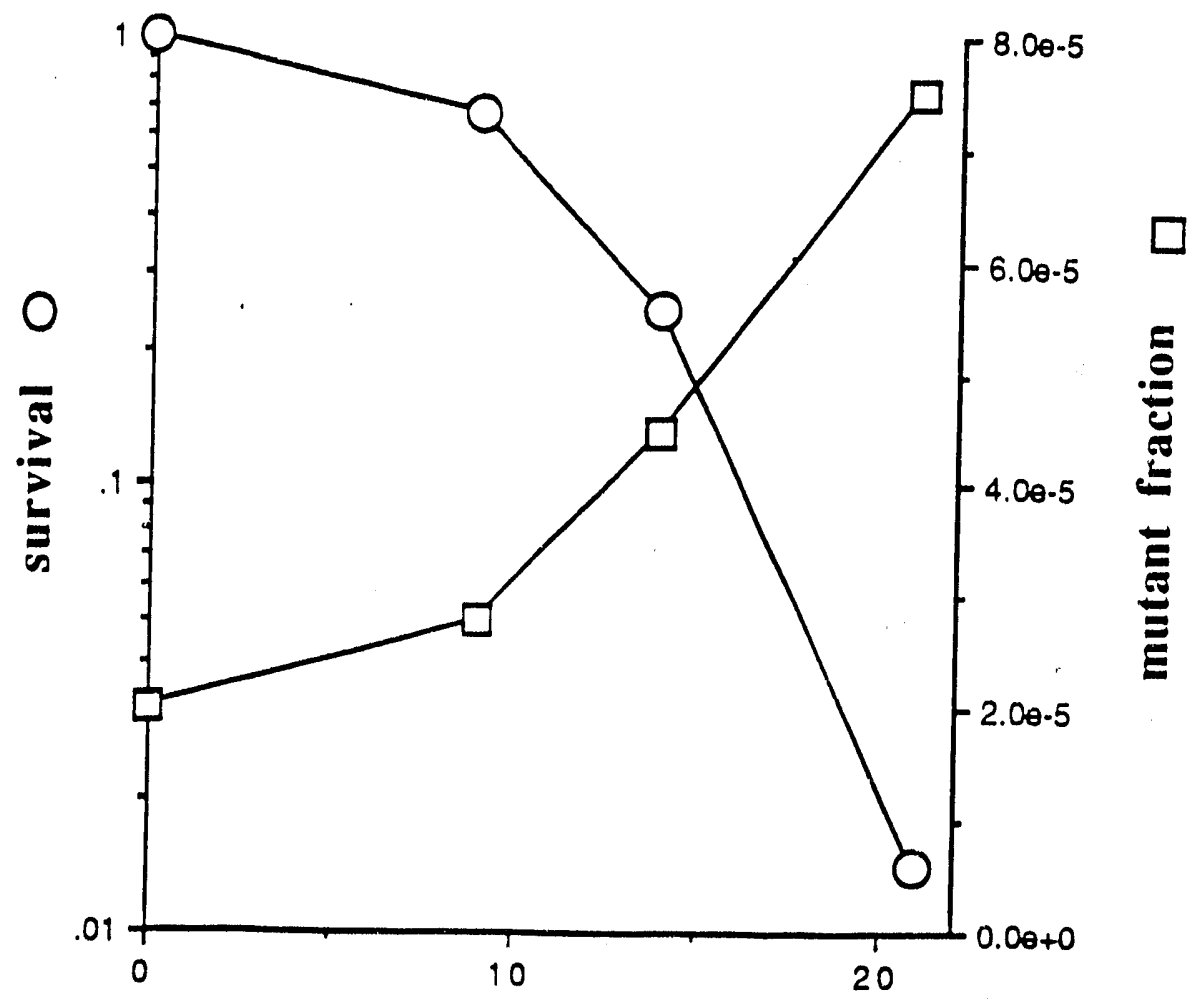

styrene oxide miin,rogram/ml

Figure 1 


\section{UV and fluorescent light modification spectra of hprt exon 3 low melting domain}

\section{$15 \%$}

$20 \%$

$30 \%$
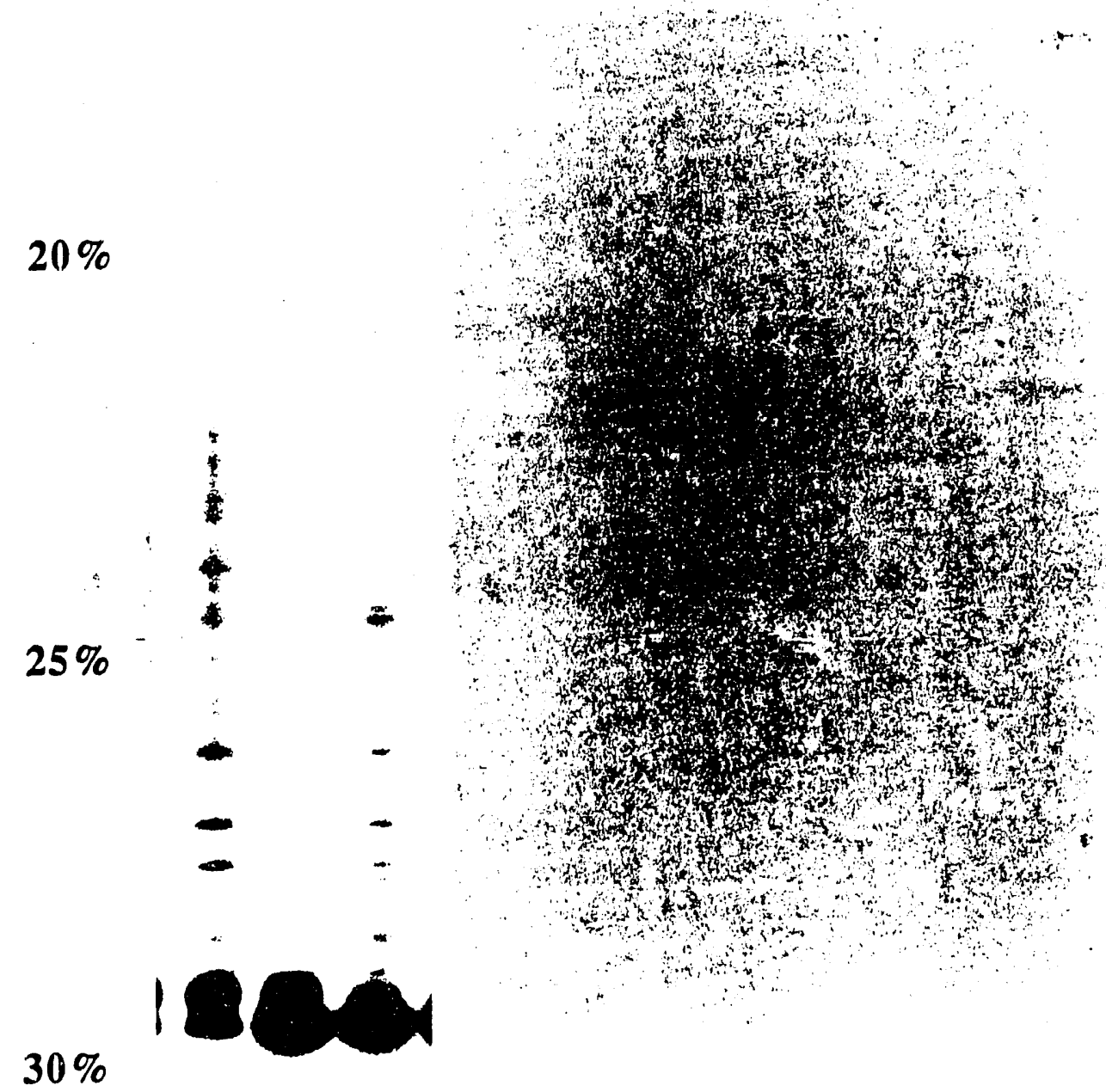

1- uv light

2- fluorescent white light, uv-filtered out

3- fluorescent white light

$35 \%$

$\begin{array}{lll}1 & 2 & 3\end{array}$ 


\section{Mutational Spectrum of Ethylene Oxide in TK-6 Cells}

\section{Hilary Coller \\ Research Assistant}

Ethylene oxide (EtO), a highly reactive gaseous epoxide and direct alkylating agent, is a well-characterized mutagen and carcinogen. It is used as an intermediate in the production of chemicals and as a sterilant of foods, medical equipment, pharmaceuticals, and spices. The National Institute for Occupational Safety and Health estimates that approximately 270,000 workers in the United States are exposed to ethylene oxide. Occupational exposure to EtO in humans has been associated with an increased frequency of sister chromatid exchanges, chromosomal aberrations and micronuclei in peripheral blood. Some epidemiological data have suggested that exposure to EtO may increase the risk of leukemia and stomach cancer in exposed workers. We are involved in an international collaboration to examine chemical and genetic EtO markers in heavily exposed workers from the former German Democratic Republic.

In order to determine the mutational spectrum of ethylene oxide on the hypoxanthineguanine phosphoribosyl transferase (hprt) locus, I first determined that a dose of 20 micrograms/milliliter would maximize the number of independently created mutants. Based on a projected survival of $31 \%$ and an expected mutant fraction of $3.5 \times 10^{-5}$ as shown in the accompanying graph, I calculated that $1.8 \times 10^{9}$ cells must be treated in order to obtain 20,000 surviving mutant cells.

Ethylene Oxide Survival and Mutant Fraction Curves

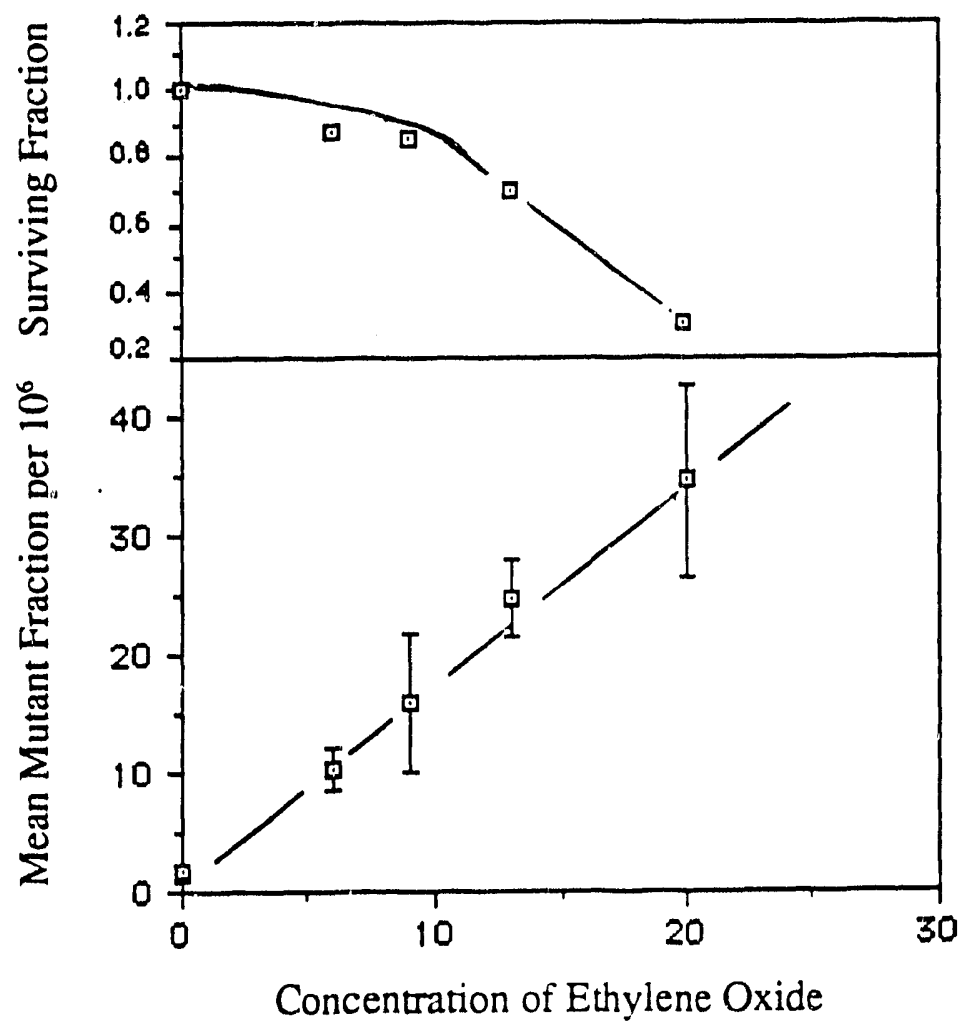


TK6 cells were treated with either ethylene oxide dissolved in ethanol or ethanol alone, grown for seven doublings to allow for phenotypic lag and selected for hprt mutants with the purine analog 6thioguanine. The treated cultures were also grown for an extra ten days after 6-thioguanine growback in order to discern whether any hprt mutants were associated with a growth advantage.

DNA from treated and control cells was isolated and the third exon of hprt was selectively amplified using Vent DNA polymerase. The DNA was then reamplified with internal primers, one of which was labeled with P32. The PCR products were analyzed on a denaturing gradient gel in order to determine the spectrum of mutations induced by ethylene oxide in the exon 3 low melting domain. Ethylene oxide induced no additional mutations that could be detected in the low melting domain of exon 3, while a presumed jackpot mutation in one of the control cultures is clearly present. This result is similar to that ascertained for MNNG, a methylating agent, in this sequence but contrasts with the hotspots observed for styrene oxide, a "bulkier" epoxide than ethylene oxide. A similar analysis of the high melting domain of exon 3 is currently being performed. 


\section{In Vitro Mutational Spectrum Of Cr (Vi) In Human Lymphoblast Cells Jia Chen Research Assistant}

Chromium $(\mathrm{Cr})$ is widely used in metal industry, pigment production and leather tanning. It is shown to be related to the respiratory diseases among the workers who are exposed to various forms of $\mathrm{Cr}$ compounds. $\mathrm{Cr}$ is listed as mutagen and carcinogen by IARC Monographs.

\section{Qbjectives}

To characterize the mutational spectrum of human lymphoblast cells (TK6 cells) treated with chromium, a common contaminant in local areas with history of tanning industry.

\section{Approach}

In order to determine the mutational spectrum of $\mathrm{Cr}(\mathrm{VI})$, the cytotoxicity of $\mathrm{K}_{2} \mathrm{Cr}_{2} \mathrm{O}_{7}$ on TK6 cells was assessed (Fig. 1). The dose of 2 uM was selected to carry out the in vitro experiment. 6 liters of suspended TK6 cells were treated in duplicate cultures with $2 \mathrm{uM} \mathrm{K} 2 \mathrm{Cr}_{2} \mathrm{O} 7$ for $5 \mathrm{hrs}$. Immediately after the treatment, cells were plated for the determination of chemically induced mutant frequency. In this experiment, the induced mutant frequency is $1 \times 10^{-5}$. Cells were allowed to grow for 10 generations after the treatment for phenotypic expression. Mutant cells with altered HPRT gene were then selected with 6-thioguanine. Thus from 6 liter cultures with $10^{6}$ cells $/ \mathrm{ml}, \mathrm{C}\left(10^{6} \times 6 \times 10^{3}\right) \times$ S $(0.33) \mathrm{X} \mathrm{MF}\left(1.2 \times 10^{-5}\right)=2.4 \times 10^{4}$ surviving mutant cells were generated. The amount of mutant cells allows us to obtain a good quality hprt mutational spectrum.

Cellular DNA were isolated from harvested mutant cells. Exon 3 of HPRT gene was PCR amplified with thermostable Vent polymerase and analyzed by gradient denaturing gel electrophoresis. Mutation hotspots in low melting region of exon 3 are clearly visualized in Fig. 2. The mutational spectrum of $\mathrm{K}_{2} \mathrm{Cr}_{2} \mathrm{O}_{7}$ is distinctly different from those of MNNG, $\mathrm{O}_{2}$ and $\mathrm{H}_{2} \mathrm{O}_{2}$. Sequencing of the hotspots is currently in progress.

\section{Significance}

From the data we obtained so far, it is interesting to see that human lymphoblast cells is much more sensitive ( $\sim 100$ fold) to both the toxicity and mutagenicity of $\mathrm{K}_{2} \mathrm{Cr}_{2} \mathrm{O} 7$ compared to the hamster cells (Table 1). These data may be important in establishing the regulatory standards for $\mathrm{Cr}$ compounds. 
TK6

\begin{tabular}{|c|c|c|}
\hline Dose (UM) & Survival (\%) & MF \\
\hline 0.1 & 85 & \\
\hline 0.5 & 63 & \\
\hline 2 & 33 & $1.2 e \times p-5$ \\
\hline 10 & 2.7 & \\
\hline 50 & 0 & \\
\hline
\end{tabular}

CH. V-79*

\begin{tabular}{|c|c|c|}
\hline Dose (UM) & Survival $(\%)$ & MF \\
\hline 50 & 65 & $7.9 e \times p-6$ \\
\hline 100 & 48 & $5.5 \theta \times p-6$ \\
\hline 150 & 39 & 9.1 exp-6 \\
\hline 200 & 41 & $1.5 \theta \times p-5$ \\
\hline
\end{tabular}

- Data irom A. Hartwig and D. Beyersmann (1987) Toxicological and Environmental Chemistry, 14: $33-42$

Fig. 1. Toxicity and Mutagenicity of $\mathrm{Cr}(\mathrm{V})$ at the hprt Locus in TK-6 Cells

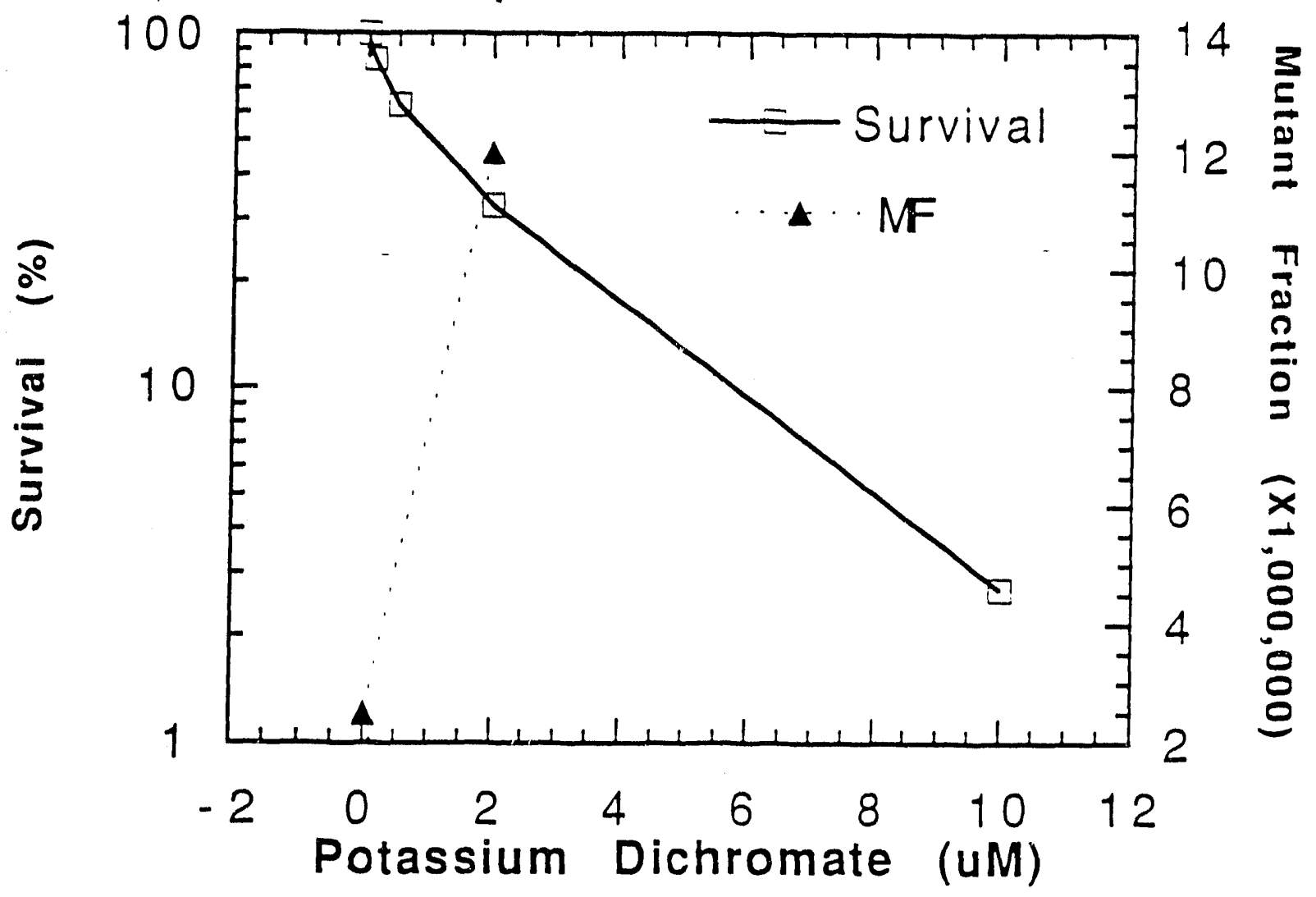


Figure 2

HPRT SELECTED SPECTRA OF $\mathrm{K}_{2} \mathrm{Cr}_{2} \mathrm{O}_{7}$ Treated TK6 CELLS

LOW MELTING DOMAIN OF EXON 3

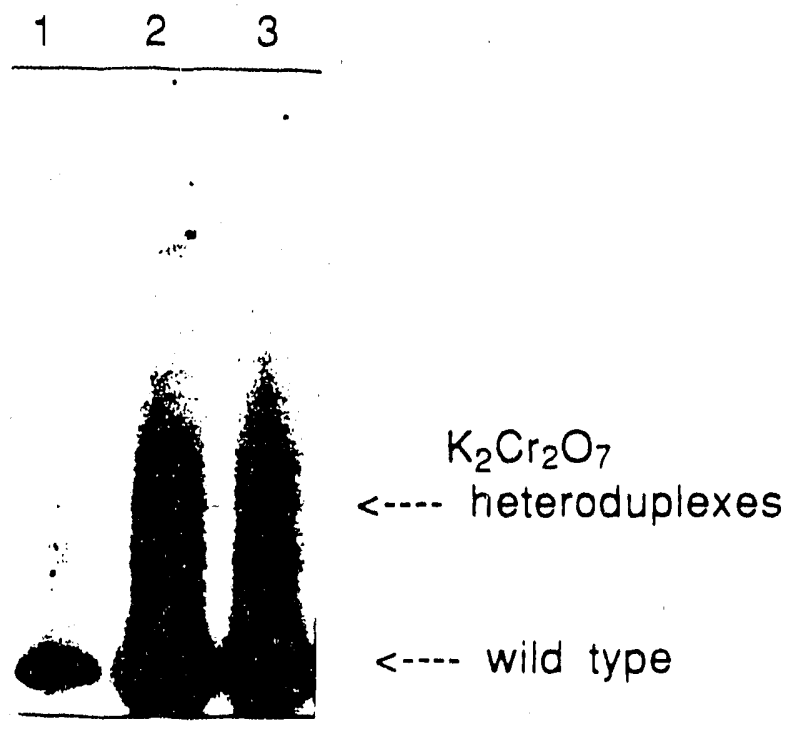

1. $P C R$ noise

2-3. duplicates of a $\mathrm{K}_{2} \mathrm{Cr}_{2} \mathrm{O}_{7}$ treated culture 


\section{Mutational spectra of radon in TK6 cells}

\section{David Katz \\ Research Assistant}

An $L$ derstanding of the effects of high-LET radiation is critically important. The National Council on Radiological Protection (NCRP, 1987) has estimated that by far, the largest single contributor of our annual effective radiation dose equivalent is due to radon and its decay products. This contribution accounts for 55\% of our yearly background dose and is furthermore estimated by the Environmental Protection Agency to be responsible for 21,600 lung cancer deaths per year (15\% of the total) in the United States (US-EPA, 1989).

That high doses of ionizing radiation are both mutagenic and cytotoxic to mammalian cells is well-known. Less understood is the nature of the mutations induced by radiation. Are these mutations unique as are chemically-and UV-induced mutations or do they reflect simply an increased frequency of spontaneous mutations, or even a set of random DNA reactions? In order to assess high-LET's capacity to induce DNA damage, we have decided to address the question "Does high-LET radiation produce a spectrum of identifiable unique hotspot mutations?"

Initially, work focused on the design of an experimental system that could be used to deliver radon gas to a suspended culture of TK6 cells. Subsequently, a preliminary experiment was conducted, exposing TK6 cells to radon, in order to determine whether radon is sufficiently mutagenic (in this system) to determine its mutational spectrum.

\section{Experimental design}

This is a working description that will serve as the basic design for radon exposure experiments conducted in our lab (Figure 1). TK6 cells are grown in suspension in the flask depicted. The cells are maintained at $37^{\circ} \mathrm{C}$ by recirculating heated water $\left(39^{\circ} \mathrm{C}\right)$ through tubing (designated by the horizontal dashed lines) wrapped around the flask. Air flows in the direction of the arrows. Only during the periods of irradiation is the air pumped through the radon generator before being delivered into the flask via the sparger. Air pumped over the Ra salts is recirculated (closed system) throughout the irradiation period. Before and after irradiation the radon generator is bypassed with a fresh supply of air and the system is left open. Cell samples are taken through the cell sample port to determine the daily cell density. Cell dilutions are conducted daily by pumping cells/medium through the output tube and pumping fresh media through the input tube. These are the only directions fluids are moved. At all times during the experiment, except for daily sampling and dilution, these tubes are clamped shut. After irradiation, cells are allowed to pass through "phenotypic lag" with subsequent hprt- mutants being selected for with 6-thioguanine.

A preliminary experiment has been conducted in order to establish the appropriate conditions needed to determine the mutational spectra of radon (high-LET radiation) in TK6 cells. Radon was pumped through this system for 20 hours at a rate of $1.75 \mathrm{ml} / \mathrm{min}$ resulting in a mutant fraction of $3 \times 10^{-5}$. The actual dose to the cells (particles/cell) has yet to be determined. Due to the $20 \%$ survival, it can be assumed that there were between 1 and 2 lethal events per cell. 


\section{Mutational Spectra: Expectations for High-LET Radiation}

Low-LET irradiations of human cells results in chromosomal breaks and rearrangements, large deletions eliminating all or part of a gene and point mutations which, so far, appear to be small deletions of one to ten base pairs. Richard Okinaka (1992, personal communication) has recently detected two X-ray-induced hotspot mutations in hprt exon 3 in TK6 cells. Using denaturing gradient gel electrophoresis (DGGE), both of these hotspots were determined to be one base pair deletions in either a run of four T:As or a run of three A:Ts.

Our basic model is that low-LET energy deposition produces a small number of chemically reactive intermediates (one $\mathrm{OH}$ radical for example) which creates one or zero reaction products in DNA. This single reaction product leads to a low probability to a gene mutation. In the case of high-LET we envision that the energy deposition event creates many chemically reactive intermediates ( $100 \mathrm{OH}$ radicals for example) within a small unit volume. If that unit volume includes a section of chromatin, many DNA reactions would occur and lead to destruction of informational sequences of both strands. This would result in a double strand break with loss of one to perhaps a dozen base pairs. Structural rejoining of the separated ends would create small deletions which (so long as $n=3,6 \ldots$, etc.) would constitute a phenotypically detectable frameshift mutation. However, not all high-LET energy depositions need engulf DNA in this cloud of reactive species. Some events arising from one or two reactions would still be expected at the "edge of the cloud". Thus, we expect a mixture of mutational outcomes peculiar to high-LET radiation and events common to both high-LET and low-LET irradiation when the full mutational spectrum is at last determined.

Our above theory addresses the small point mutations and does not address large deletions or chromosomal-level damage. It is believed that radon, like X-rays or other high-LET emitters, causes a signif icant amount of partial or large deletions. Southern blot hybridization studies with genomic DNA isolated from individual clones have showed that $30 / 43(70 \%)$ alpha-particleinduced and 11/15 (73\%) gamma-ray-induced V79 (hamster) hprt mutants (Thacker, 1986) and 12/19 (63\%) of radon-induced TK6 hprt mutants (Evans 1992 personal communication) contained partial or large gene deletions. To investigate the proportion of radon-induced deletions from our preliminary experiment, a PCR based assay was developed to probe for exon 3 of hprt. This technique takes advantage of the fact that one must plate a treated culture of cells in order to obtain a mutant frequency. Once individual hprt mutants arise in the microtiter plate, PCR is used to amplify a 224 bp region of exon 3 directly from cells. An internal control for the amplification reaction is provided by also amplifying another nuclear gene, thymidine kinase (140 bp region of tk exon 4). Deletions can be detected by the absence of the $224 \mathrm{bp} \mathrm{hprt} \mathrm{band} \mathrm{and} \mathrm{presence} \mathrm{of} \mathrm{the}$ 140 bp tk band (Figure 2, lanes 4 and 10). The presence of both bands (Figure 2, lanes 1-3 and 59 ) indicates that amplification was successful and that there is no hprt exon 3 deletion. Using this technique, results can easily be obtained from multiple (up to 100) clones within 48 hours. 11/80 (14\%) clones from our preliminary experiment did not contain an exon 3 that could be amplified; a number significantly different from previously reported data. Thus, radon in our system, does not induce a significant amount of what appears to be at least partial gene deletions. Additional experiments are planned to confirm our preliminary results.

\section{Citations}

National Council on Radiation Protection and Measurements (1987) lonizing Radiation Exposure of the Population of the United States. Bethesda, MD: NCRP Publications; NCRP Report No. 93. 
Thacker, J (1986) The nature of mutants induced by ionising radiation in cultured hamster cells, III. Molecular characterization of HPRT-deficient mutants induced by gamma-rays or alphaparticles showing that the majority have deletions of all or part of the hprt gene. Mutat. Res. 160: 267-275.

United States Environmental Protection Agency. ORP, Memorandum from Margo Oge. Current ORP estimates of annual Radon-induced lung cancer deaths in the general population. August 17 , 1989.

\section{System used for treating TK6 cells with radon}

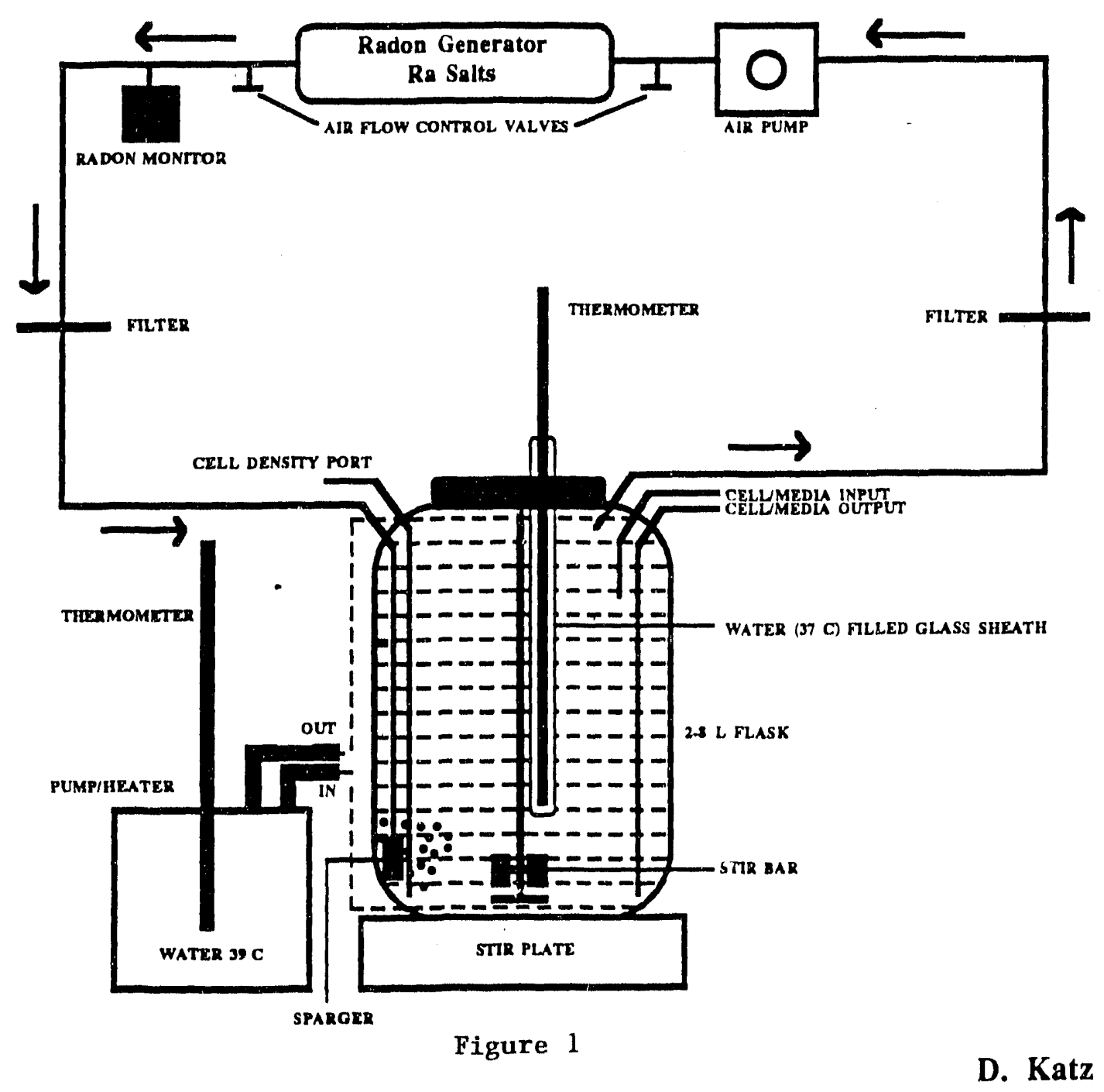




\section{Radon-induced deletions in hprt exon 3}

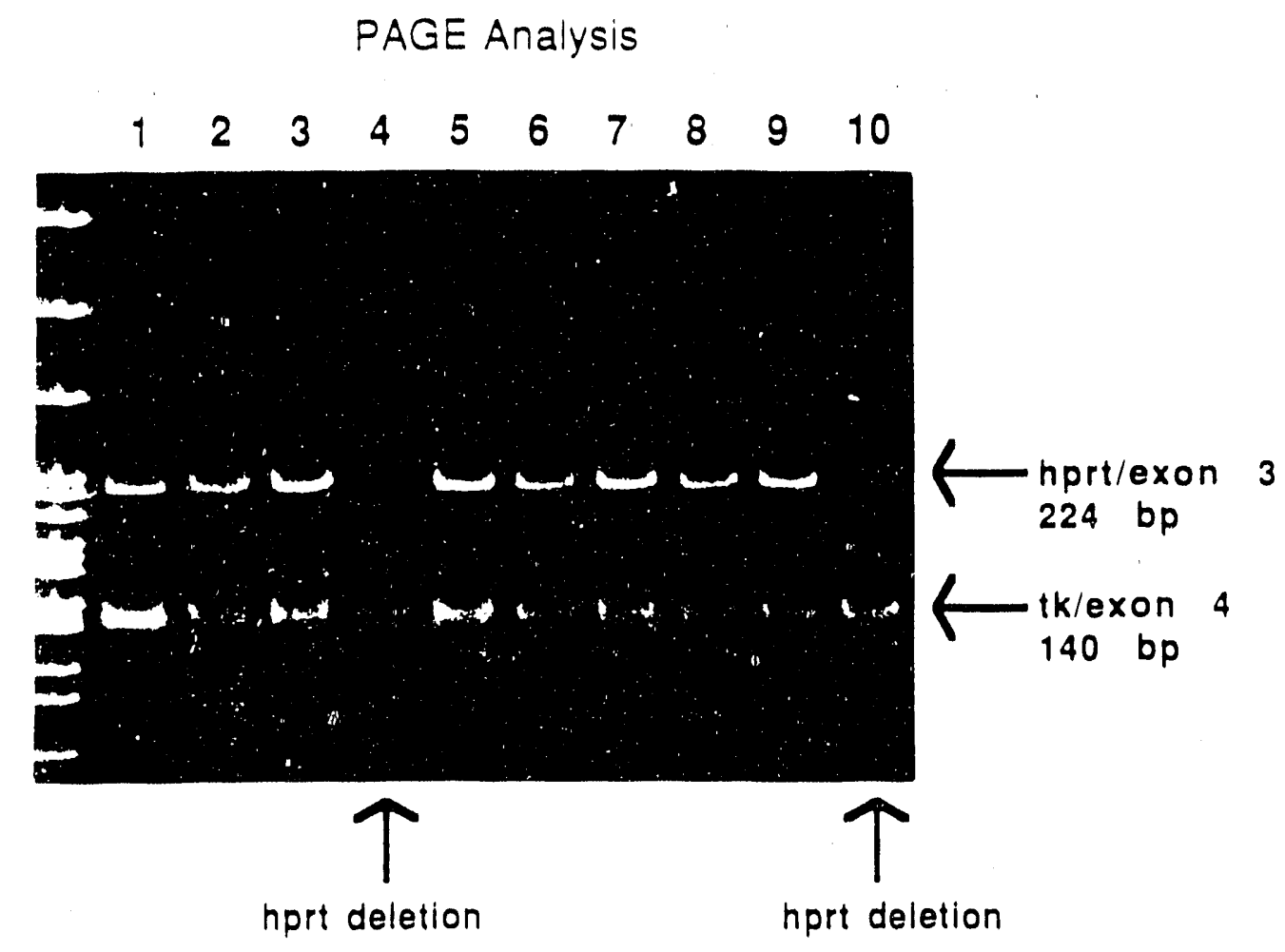

Lane 1: Genomic DNA control

Lanes 2-8: Radon hprt- clones

D. Katz

Figure 2 


\title{
Mutational Spectra of a Complex Mixture : Smokeless Tobacco (6TG Selected Phenotype Exon 3 HPRT)
}

\author{
Dr. Lata Shirname-More \\ Research Scientist
}

\section{Objective}

To charecterize the predominant point mutations arising in indepentently treated cultured human B cells namely TK6 treated with aqueous extracts of smokeless tobacco. Chewing of this complex mixture has become increasingly popular among teenagers in this country and is responsible for higher incidence of oral cancer .

\section{Relevance to human health}

The predominant point mutations produced in these cell cultures by this and other complex mixtures to which humans are exposed in their day to day life would help us to observe a point mutational spectra in human cell cultures and human cell samples. This could then ultimately be used to discover the causes of point mutations in humans.

Based on our earlier work to study quantitatively the formation and destruction of mutagens during the process of combustion using bacterial system, It is our belief that a mutational spectra for a complex mixture does exist and that one or more important chemical mutagens in this mixture may be responsible for the mutational spectra of whole mixture.

Using a jet-stirred/plug-flow reactor which mimics real life combusters such as aircraft gas turbines, home heating units, large furnaces, and electric utility boilers, it was found that only two compounds (cyclopenta(cd)pyrene and flouranthene) among nineteen major polycyclic aromatic hydrocarbons accounted for the total mutagenicity of the sample in the presence of exogenous metabolizing system, at higher doses and that the effect was additive (Lafleur, et.al., 1990).

This was also supported by earlier work done on kerosene soot sample where mutagenic activity of the whole polycyclic aromatic hydrocarbon fraction accounted for in terms of additive mutagenicity of its individual components (Kaden, et. al.,1979).

\section{Approach}

To observe point mutational spectra, independent cultures large enough so that at least 100 surviving individual point mutants arising at initial fractions of $10^{-7}$ would be present among $10^{9}$ surviving cells were treated wih water extracts of smokeless tobacco.

Cultures were treated in triplicate in six litre stirred fermentors with daily dilutions for 7 days to permit expression of 6TG R phenotype. An untreated culture served as a control. 6TG was then added to the cultures and some 14-20 days elapsed before exponential growth of 6TG R cells was detected by particle counting. An average of $1.5 \times 10^{-5}$ 6TG resistant mutants were created per treatment and the kinds and positions of the most frequent mutants were examined. DNA was isolated from the 6TG $\mathrm{R}$ population, high fidelity amplification, with thermostable Vent polymerase was carried out and the products were boiled and reannealed en masse to create heteroduplexes between mutant and wild type hprt exon 3 sequences. 


\section{h \\ Accomplisments}

In the 100 base-pair low melting region of exon 3 , smokeless tobacco extracts did not give any mutant bands when compared with untreated culture. Similar null spectra have been observed for MNNG, ethylene oxide and molecular oxygen in this sequence.

In the 79 base-pair high melting region, smokeless tobacco extracts induced four hot spots. The same set of bands appeared at the same position in two independent studies.

Currently separation, isolation and sequencing of mutant bands produced in the high melting region of exon 3 is in progress.

Figure 1 shows the hot spots induced in two idependantly treated cultures in the high melting region of exon 3.

\section{References}

Lafleur, A.L., Longwell, J.P., Shirname-More, L., Monchamp, P.A., Peters, W.A., and Plummer, E. F. Chemical Characterization and Bacterial Mutagenicity Testing of Ethylene Combustion Products from a Jet-Stirred/Plug-Flow Reactor, Energy and Fuels, 4, 307-319, 1990.

Kaden, D.A., Hites, R.A., and Thilly, W.G. Mutagenicity and Soot and Associated Polycyclic Aromatic Hydrocarbons to Salmonella typhimurium, Cancer Res., 39, 4152-59, 1979. 
Mutational Spectra of a Complex Mixture

HPRT Exon 3 (High Melting Domain)

(6TG selected)

Lane

$\begin{array}{lllll}1 & 2 & 3 & 4 & 5\end{array}$

Lane

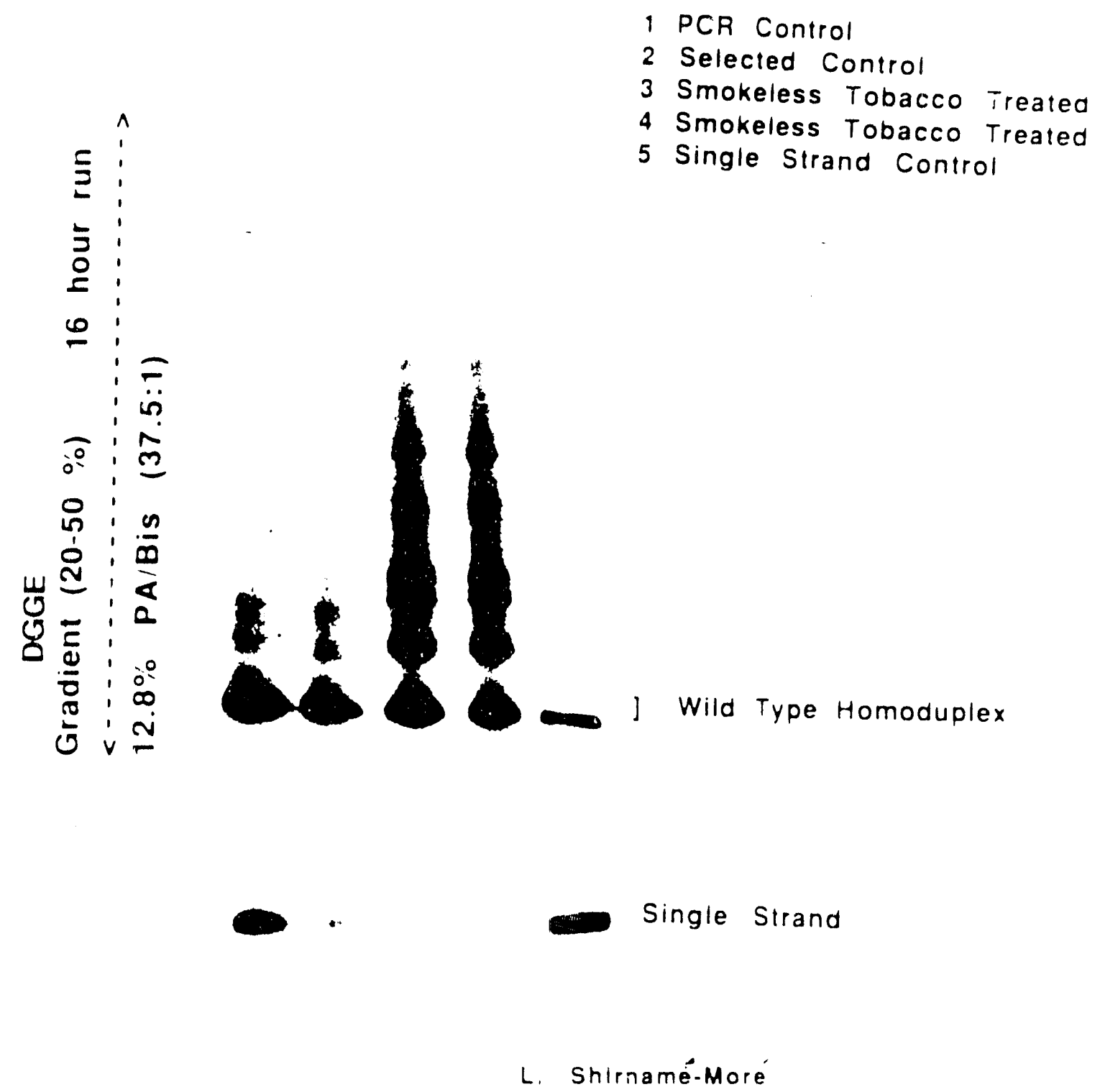

Figure 1 


\section{B. MITOCHONDRIAL GENES}

We have two compelling reasons to want to study mutations in the mitochondrial DNA.

1. Mitochondria are present at some $10^{4}$ copies per somatic cells. Thus a small blood or tissue sample suffices to provide the $10^{9}$ copies of the same sequence which we require for a mutational spectrum of useful precision.

2. We are persuaded that the ideas of Otto Warburg implicating heritable changes in mitochondrial function as necessary to the cancer phenotype were essentially correct and discarded in the 1950's for reasons not scientifically related to their merit.

Figure 1 (II-B) shows what we know about somatic mutations in human mitochondria.

\section{Figure 1 (II-B)}

However, the entire 16,569 bp of the human mitochondrial DNA has been sequenced and we have calculated $\mathrm{Tm}$ for the entire sequence. The general organization of the mitochondrial genome is shown in Figure 2 (II-B). Although PCR clamping would allow examination of any of the 16,569 base pairs by DGGE naturally occurring clamps are still useful (and cheaper). Figures $3 a, b, 4 a, b$, (II-B) show two particularly useful sequences' melting maps (a) and their focussing behavior on DGGE (b). The first sequence comprises the replication origin and membrane attachment site. This site we have chosen to help test hypotheses regarding lipid peroxidation and spontaneous mutation put forward by Professor Spencer Farr of our M.I.T. Center and the Harvard School of Pubiic Health. The second comprises tRNA glycine and a piece of NADH dehyrogenase (sub III). In this sequence using DGGE we have already found several blood donors to carry a point mutational polymorphism relative to the consensus wild type. Five useful mitochondrial sequences are shown focussed in Figure 5 (II-B). Of especial interest (lane 9) is a sequence containing $12 \mathrm{~S}$ rRNA which Dr. Gengxi Hu has found is imbedded in mutated form at several nuclear genome positions. This sequence may be useful in the research of Mr. Peter Southam who wishes to define the quantitative and qualitative differences in mutational pathways between nuclear and mitochondrial sequences. Obviously, having this sequence already in both genomes will be a big help. 
Map Human Mitochondrion

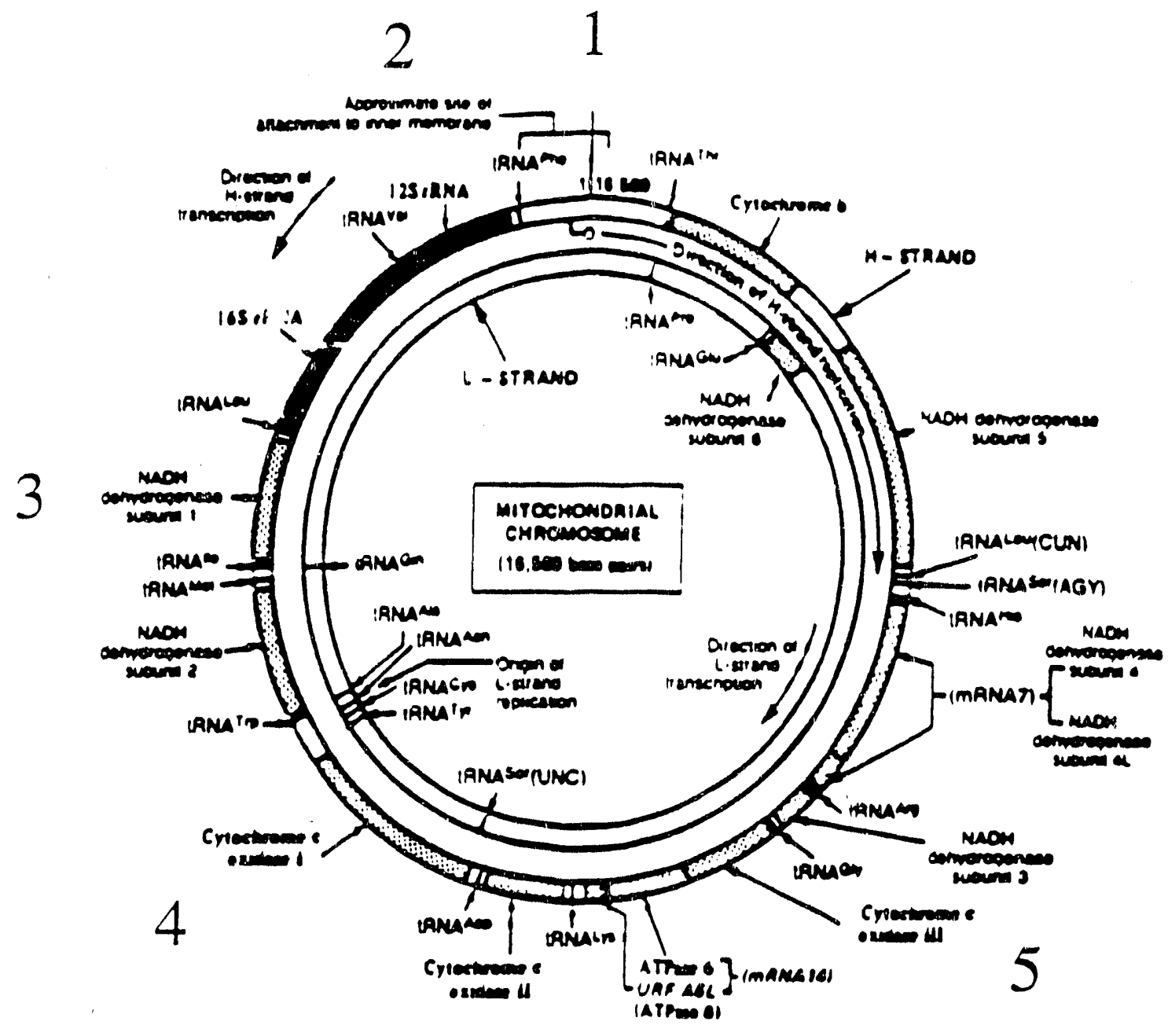

J. Hanekamp

1) Origin/membrane attachment site
a) $267 \mathrm{bp}(16,457-154)$, J8, J9

2) $12 \mathrm{~S}$ rRNA

a) 170 bp $(1,338-1,507), \mathrm{J} 17, \mathrm{~J} 18$

3) $\mathrm{NADH}$ dehydrogenase I

a) $283 \mathrm{bp}(3,843-1,125), \mathrm{J} 11 . \mathrm{J} 13$

4) Cytochrome C Oxidase I

a) $241 \mathrm{bp}(6,510-6.750), \mathrm{J} 14, \mathrm{~J} 16$

5) tRNA glycine/ NADH dehydrogenase III

a) $314 \mathrm{bp}(9,913-10,226), \mathrm{J} 1, \mathrm{~J} 2$

b) $304 \mathrm{kp}(9,913-10,216), \mathrm{J} 1$. J3

c) $219 \mathrm{bp}(10.011-10.226), \mathrm{CW} 7 . \mathrm{J} 2$

d) $209 \mathrm{bp}(10.011-10.216), \mathrm{CW} 7 . \mathrm{I3}$ 
Mitocnondria (16, 457-154)

MNLI Restriction cuts

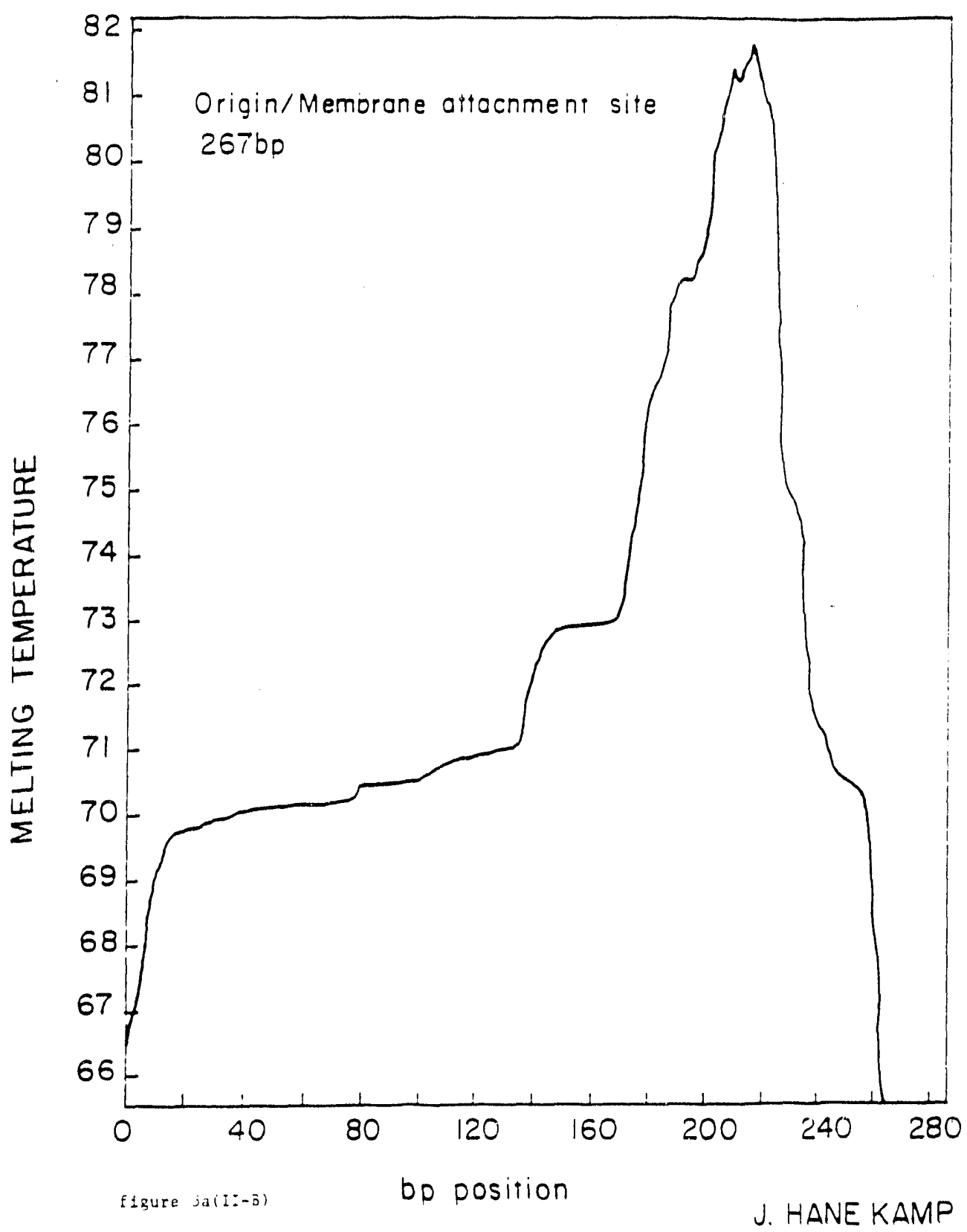

Figure $3 a$ (II-B) 


\section{Origin/Membrane Attachment Site (Base Pairs 16,457 - 154) J8, J9}

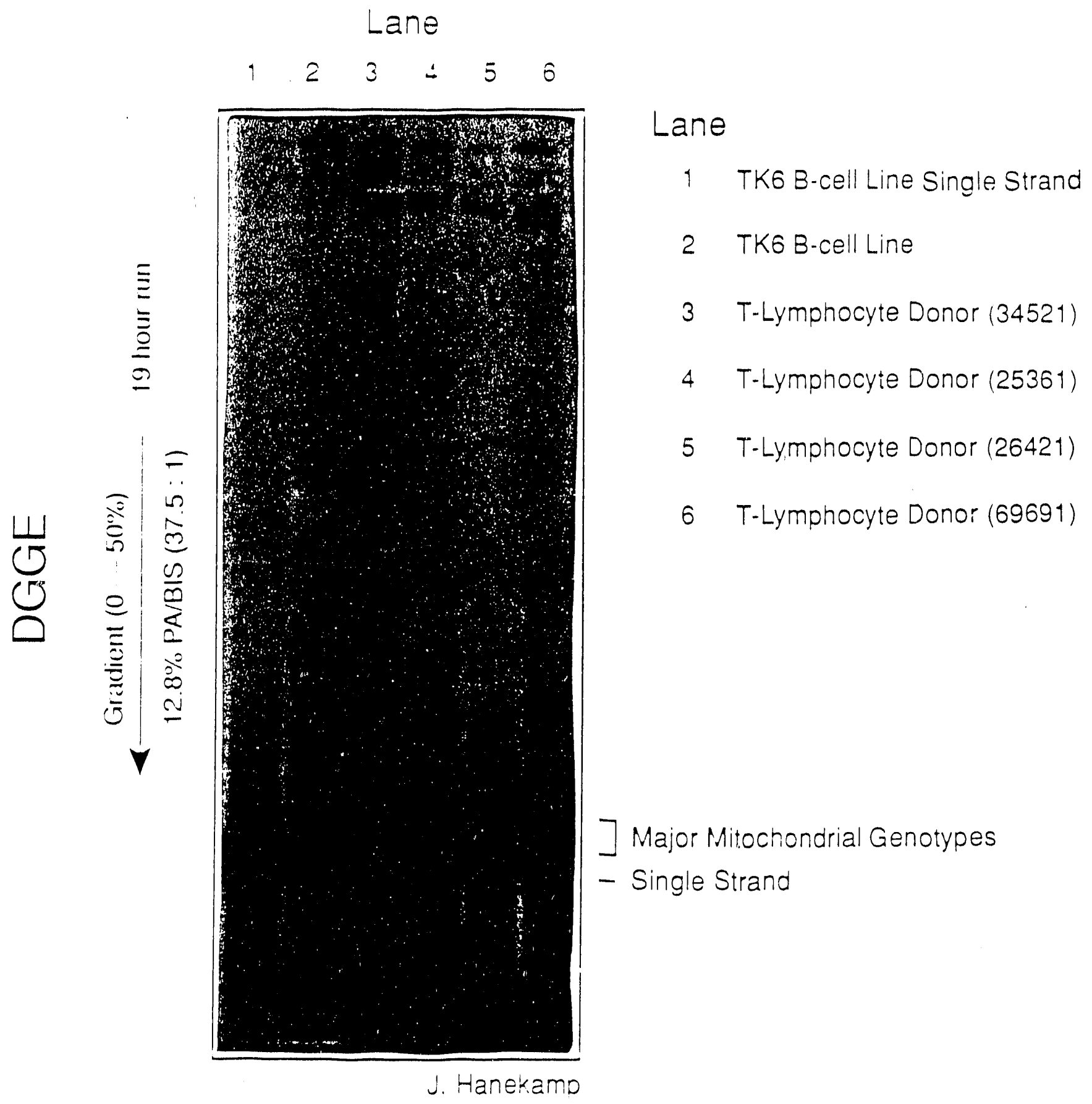

Figure $3 b(11-B)$ 


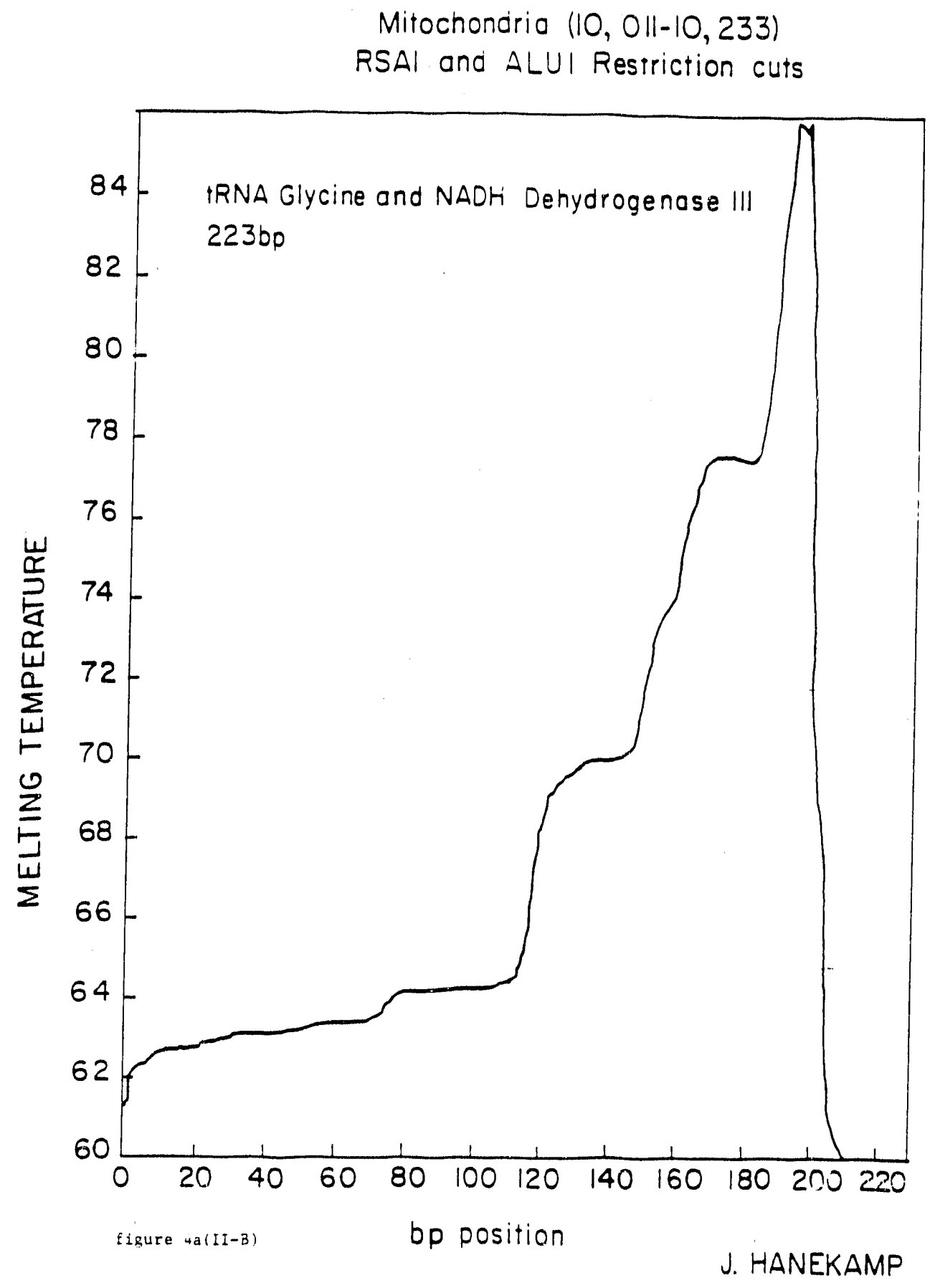

Figure 4a (II-B) 

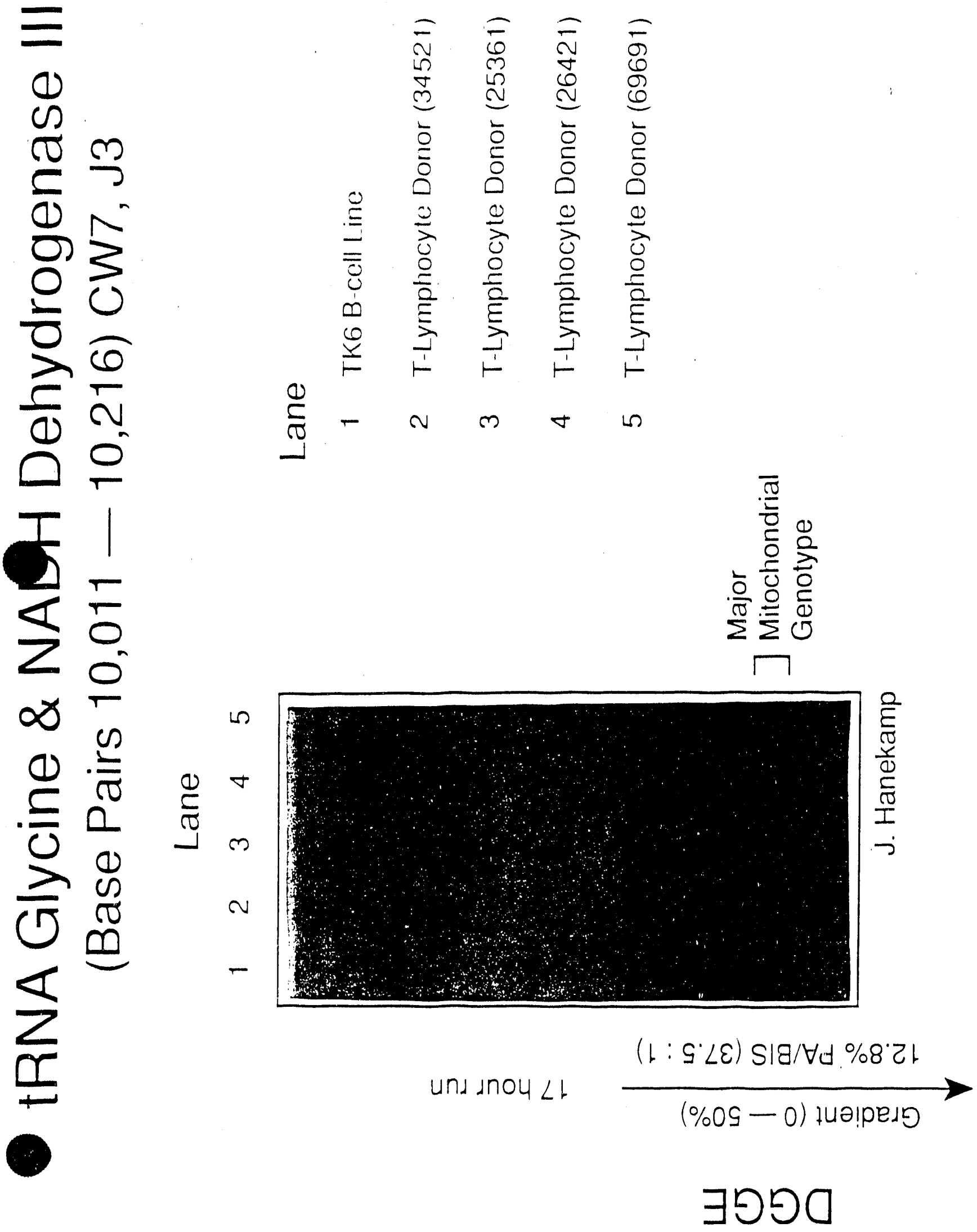

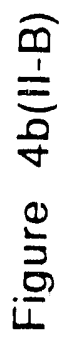

$\infty \div$

(1) $\frac{1}{\pi}$

i) a

$>0$

$\bar{\pi} \pi$

$\infty$

$<$

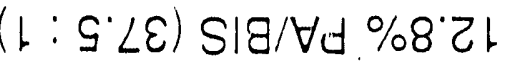

(\%0s - 0) fuə!pedg

$\exists ९ ९ 0$ 


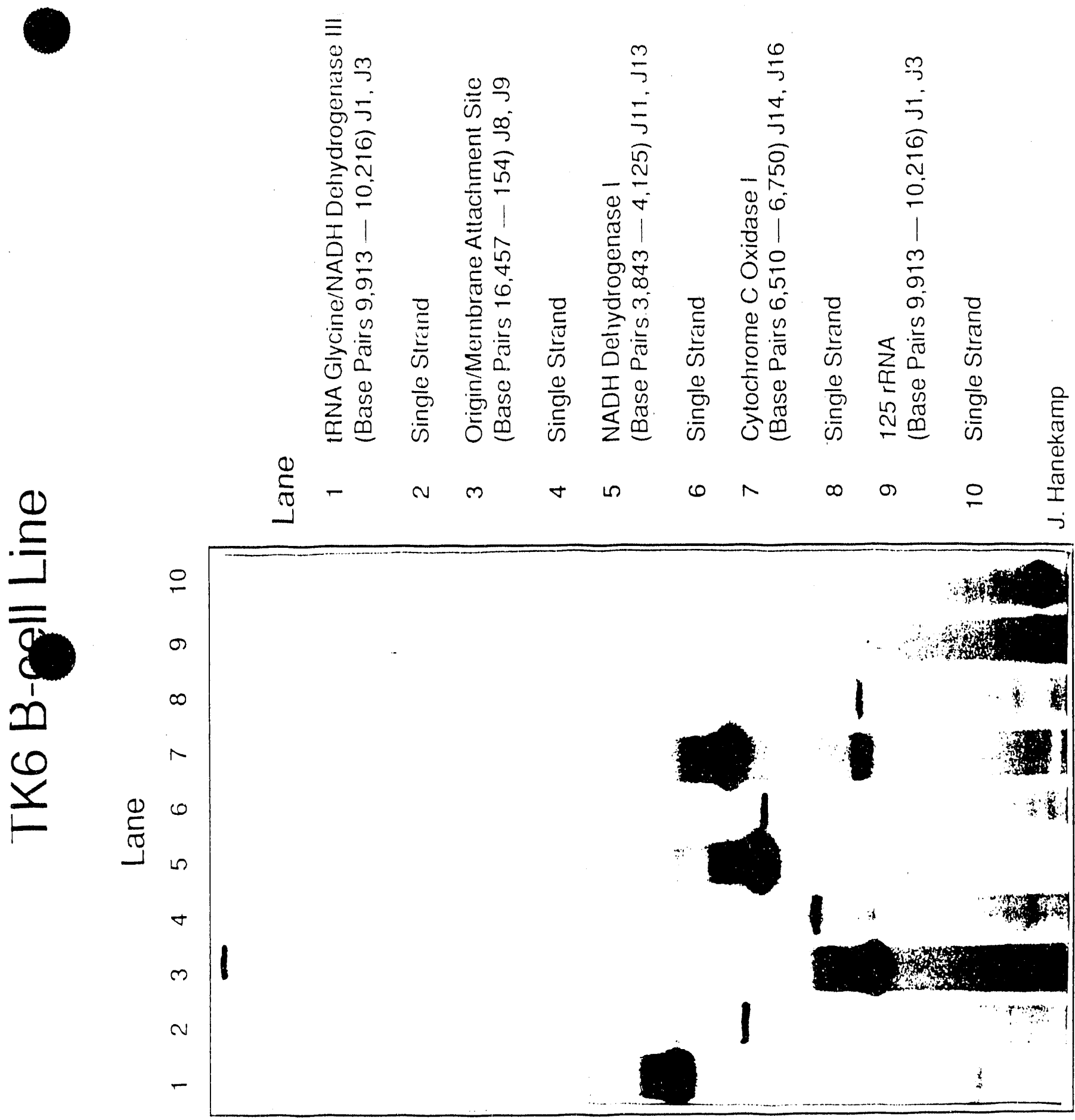

$\frac{0}{1}$
$\frac{1}{n}$
0
$\frac{0}{5}$
$\frac{0}{1}$

und Jnou 9 เ

( $\left.: S^{\circ} \angle \varepsilon\right) \operatorname{sig} / \forall d \% 8^{\prime} 乙$ เ

(\%os - 0) дuә!pedo

$\exists ९ ९ 0$

Figure 5 (II-B) 
Screening and sequencing of the mitochondrial DNA mutations using DGGEPCR-DGGE: Protocol for unselected mutations.

\section{Dr.Gengxi Hu \\ Postdoctoral Associate}

Since the development of PCR and DGGE, it has become possible to detected low frequency mutations and establish mutational spectra for them. The technique of DGGE has been improving during the past years and recently significant progress has been made by John Hanekamp in reducing the systemic noise.

I have used the technique of DGGE-H1F1 PCR-DGGE before Hanekamp's improvements to isolate a mutant-enriched fraction of human TK6 cell mitochondrial DNA bearing mutations between bp 9945 and 10,195. Seven mutations were identified by cloning and sequencing.

$\begin{array}{lclc}\text { bp } & \text { \# of cloned isolates } & \text { mutaton } & \text { estimated freque } \\ 9959 & 1 & \text { T to A } & \\ 9966 & 6 & \text { G to A } & 5 \times 10^{-3} \\ 9984 & 7 & \text { G to A } & 5 \times 10^{-3} \\ 10047 & 1 & \text { C to G } & --- \\ 10088 & 1 & \text { C to T } & -- \\ 10184 & 1 & \text { C to G } & -- \\ 10194 & 1 & \text { C to A } & \end{array}$

PCR errors has been carefully controlled though the whole experiment. It appears that spontaneous hotspot mutations frequently arise at mutant fractions of $5 \times 10^{-3}$ to $5 \times 10^{-4}$, which is somewhat higher than our a priori expectation of $5 \times 10^{-6}$ to $5 \times 10^{-7}$. These early observations will require more experiments to confirm their validity. Now we can use MAMA to measure them directly.

\section{ONTOONCOLOGY : STUDY OF THE KINDS, ORDER AND RATES OF ONCOMUTATIONS AS A FUNCTION OF AGE.}

\section{A. THE JACKPOT THEORY OF HUMAN CANCER.}

Several years ago on the occasion of Lars Ehrenberg's retirement symposium I suggested that the form of the curve for the occurrence of first mutations in a growing cell population closely resembled the age dependent cancer death curve in humans. (Thilly, 1988) (See Appendix 1 (IIIA) a figure from this paper is reproduced here: 
Age distribution of liver and biliary cancer incidence and relationship between fraction of persons with a mutation necessary for tumour formation and cell generations during organ growth

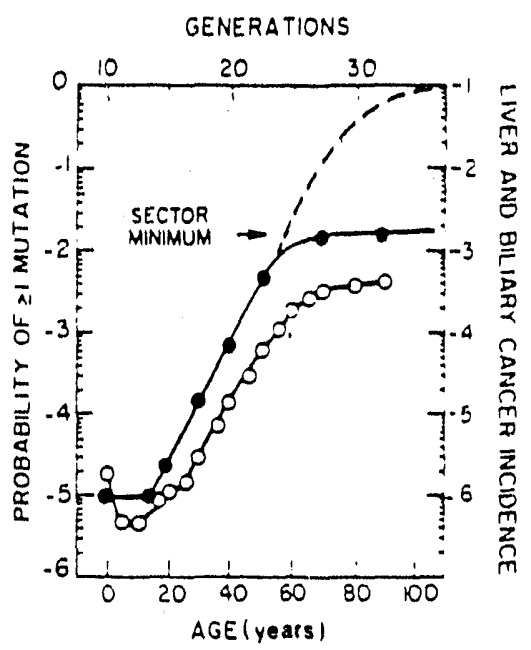

A background hereditary mutant fraction of $10^{-5}$ is assumed and sector minimum of 4000 mutant cells in a $10^{11}$ cell organ is shown as an illustration.

Figure 1 (III-A)

This curve compares the death rates from liver and biliary cancer as a function of age $(0-$ 0 ) to the probability of a growing cell population having one or more specific mutations as a function of cell generations beginning with a single cell (- - - ). Shown also is the effect of imposing a maximum cell number on the growth of such a population $(-0)$.

For a single mutation the probability of having at least one mutation as a function of $g$ is:

$$
P_{1}(\geq 1)=1-e \frac{1}{\ln 2} r_{i} 2^{8}
$$

which for low values of $P$ is just $P_{1}(\geq 1)=1-e \frac{1}{\ln 2} r_{1} 2^{8}$

Equation 2(III-A)

where $r_{i}$ is the rate of mutation per cell division for mutation $i$. The general case for a cell to arise containing $n$ different mutations is just

$$
\begin{array}{ll}
P_{n}(\geq 1)=\frac{n}{\ln 2} r_{i} r_{j} \ldots r_{n} g^{n-1} 2^{8} & \text { Equation } 3 \text { (III-A) }
\end{array}
$$

Human organs are so large, however, that even mutations arising with rates as low as $10^{-}$ 11 mutations per cell division will have occurred multiple times by birth or late adolescence. Thus every organ of an adult will have an expected number of cells carrying any oncomutation. If one looked at a particular base pair substitution in a $10^{12}$ cell organ like the liver a mutation rate of $10^{-}$ 10 mutations per cell division would give 50 cell mutations in the last cell division $\left(1 / 2 \times 10^{12} \times\right.$ $10^{-10}$ ) and thus 50 new mutant cells. The expected number of mutants per average person would just be the sum of the expected number of mutants arising from mutation at the average rate back to an organ size when no mutations would be expected. In this case some eight cell generations 
would suffice and the expected total number of mutant cells would be 400 . The key point is that everybody would have these 400 oncomutant cells but some people would have many more due to the chance occurrence of an earlier oncomutation "jackpot" giving rise during organ growth to a sector containing a number of oncomutant cells much larger than 400.

Other events necessary for cancer would occur within this jackpot sector and the people with the most oncomutants (small fraction of population) would die of cancer early in life. Eventually time permits other events to have occurred in average persons. Thus a higher fraction of persons would die of a particular cancer later in life. This of course is what is observed.

\section{BUT}

A significant failure in this level of model development is that while the forms of the jackpot mutation and cancer death curves have remarkable similarities the time scales are seemingly unrelated. The generations, $g$, for organ cell exponential expansion are essentially complete at the end of adolescence. Thus we added the cell turnover known to occur in organ maintenance. Cell turnover divisions would also permit a second oncomutation to complement a first oncomutation. However, in a cell turnover model (with or without stem cells) the requirement for additional mutations would lead to an arithmetic transform between the jackpot curve and the cancer death curve which is time dependent. For a single additional mutation this transform would be a linear function of time, $t$. A model involving two additional mutations would make this hypothetical relationship a function of $t^{2}$ and so forth. The relationship observed is however neither a $t$ nor a $t^{2}$ nor a $t^{n}$ transform of the probability of 2 or $3 n+1$ mutations arising in the same cell. It is a $t^{0}$ transform. It appears to be totally independent $t(!)$. (See Figure 1 (III-A).

Now we and our reviewers know that real tumors show various combinations of mutations ranging from very specific ras or neu point mutations, through any of a set of p53 mutations to particular chromosome rearrangements or losses. Surely, accumulation of these mutations must be a function of time. But where does time begin for this process? Even a small tumor of one gram $\left(\sim 3 \times 10^{8}\right.$ cells $)$ represents about 29 cell divisions from a single precursor cell. So long as a cell can escape the rule of "constant cell number" for its progeny it will give rise to a growing colony of cells among which will arise any particular mutation. If such a mutation creates faster cell growth, permits vascularization of the tumor etc. then the cells found in a larger tumor could carry several mutations. Only some these would have been responsible for escape from the rule of cell turnover.

The model we are building requires us to think of the mutations that follow the initial oncomutation(s) as inexorable and not requiring anything other than the orderly appearance of new mutants in a growing cell population. This is summarized in Figure 2 (III-A). The point is that finding four or five mutations in a tumor cell does not demonstrate that all of them were required to establish the essential cancerous (growing) phenotype. Only the essential oncomutations will effect the appearance of cancer as a function of age. 


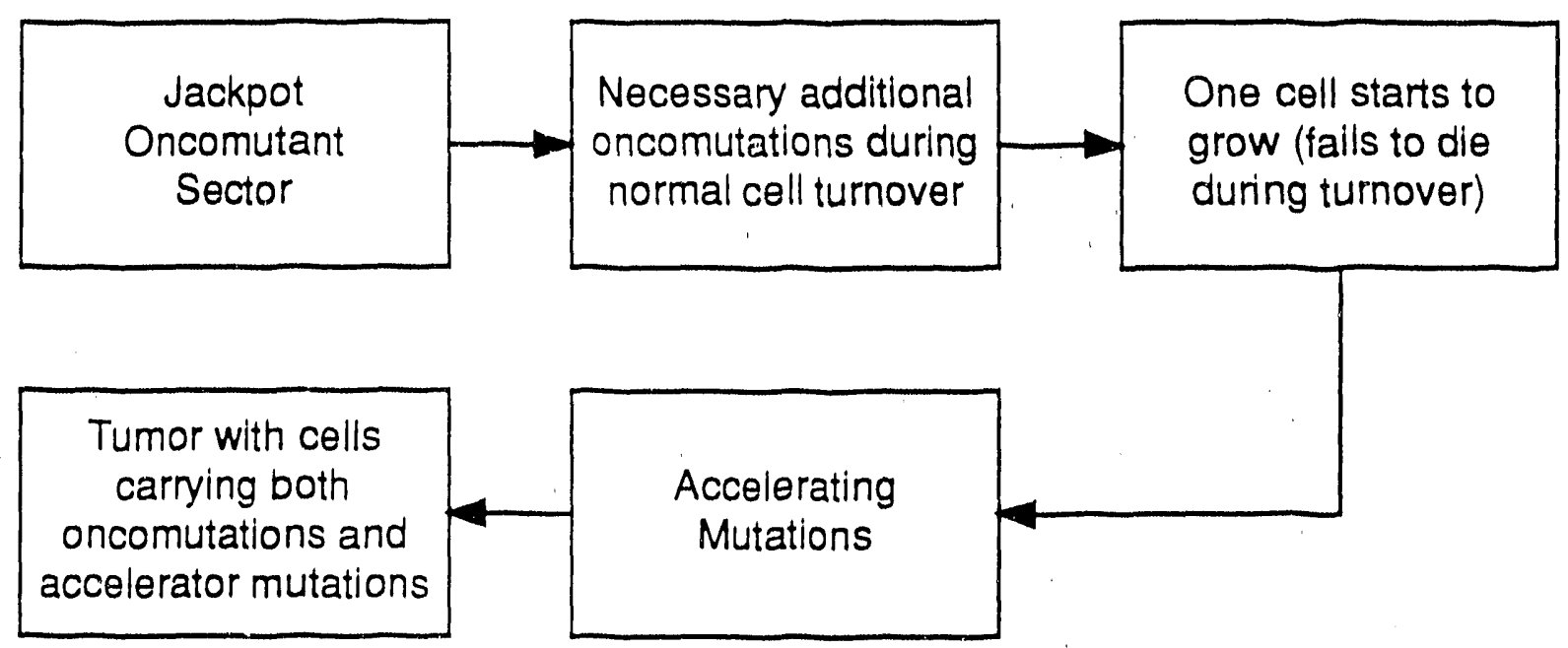

Figure 2 (III-A)

This simple model is consistent with the hypothesized relationship between fetal expected oncomutation and age dependent cancer incidence. What is missing is a link between the exponential increase in fetal oncomutants (0-9 mos.) and the observed exponential rise in cancer rates from birth to middle age. (See Figure 1 (III-A).

\section{B. THE POTENTIAL ROLE OF MITOCHONDRIAL ONCOMUTATIONS IN HUMAN CANCER.}

Our experience with a phenotypic lag of 14 cell generations to express the 6 thioguanine resistant phenotype in human cell mutation studies suggested a new way to think about this cancer delay problem (Thilly et al, 1976). It specifically offered a way to think about processes that are going on as cells divide but which don't show any result for a long time to an observer who can only see the expressed phenotype.

Just imagine that the fetal jackpot oncomutation involves modification of an $\mathrm{X}$ linked gene but that the gene produc $i$ is indestructible (stainless steel gene product). If the presence of a single molecule of unmutated gene product were sufficient to suppress the cancer phenotype then the number of cell divisions between mutation and phenotypic expression would depend on the number of the gene product copies in the cell. For instance if their were $16,000=2^{14}$ protein copies then 14 cell divisions would be required to produce descendent cells with zero original protein copies and hence phenotypic expression. In this case cancer phenotypic expression would be growth of the cell and its descendants outside the normal rules of cell turnover.

Attractive as this might seem "all that glitters is not gold". A protein that is not subject to proteolytic degradation and which in very small copy number can suppress the cancer phenotype may be possible but requires something outside of our present understanding of protein stability. So far our modelling effort has not invoked "three impossible things before breakfast". The "stainless steel tumor suppressor " remains useful only to illustrate that a time delay could arise. As a serious mechanistic hypothesis a far more attractive possibility exists: recessive mitochondrial oncomutation. 
We will now argue that the time required for phenotypic expression of recessive oncomutations in the mitochondrial genome are a sufficient delay mechanism to link a relatively rare nuclear oncomutation to the entire time dependent appearance of cancer in humans.

In so doing we echo Qtto Warburg who insisted that a change in mitochondrial function was essential in cancer (Warburg, 1924). We also argue that the long - discussed but never explained Mondal - Heidelberger in vitro carcinogenesis experiment is consistent with the induction and phenotypic expression of a mitochondrial recessive mutation (Mondal and Heidelberger, 1970). Finally we argue that non-segregation of mitochondrial sister DNA copies automatically assures that recessive mitochondrial mutant DNA sequences become numerically dominant despite beginning as one mutant copy among $10^{4}$ wild type copies in the parent cell.

Warburg showed that cancer tissue had the curious characteristic of turning glucose into lactate while simultaneously consuming oxygen and producing $\mathrm{C}_{2}$. He also showed that tumor cells carry out extensive glutaminolysis. By 1956 Warburg had integrated the discovery of "grana" (mitochondria) as independent genetic units responsible for respiration into his hypothesis that "damaged respiration" was an essential characteristic of cancer cell metabolism. "Omne granum e grano". (Warburg, 1956).

In the 1950's Warburg's ideas were seemingly discredited when it was shown that cell lines derived from normal tissues - like the NIH 3T3 lines - also showed the glucose to lactate pathway while taking up 02. (See McKeehan, 1982). The idea was that these "normal" cells behaved as Warburg said "cancer" cells behaved and therefore Warburg was wrong. I think not.

The process by which cell lines are created - particularly the NIH 3T3 lines - involves growing large populations of cells from tissue preparations through a number of passages from flask to flask. Invariably cell division slows in this growth period and most cells die. By the 3T3 regimen cells from different flasks are combined and observed until a growing cell population appears and is called a cell line. This period of slow growth and cell death is referred to as the "crisis".

I might also think of this whole process as "selection". The resulting cell line could be the descendent from mutants existing in the original tissue or arising in the first cell culture generations. The several passages would be admirable for permitting phenotypic lag to occur.

Thus I reject the rejection of the Warburg hypothesis that the changes in mitochondrial physiology were essential to the cancer phenotype. Today we know that cells in culture gain most of their ATP by glutaminolysis. The production of FADH but not NADH appears to create a major substrate for driving oxidative phosphorylation. Any change which prevented the use of NADH to produce ATP we can now see as being the kind of thing that might cause the biochemical shift. Cells in vivo oxidize fat or glucose to $\mathrm{C}_{2}$ and produce of glutamine. Cells in vitro and cancer cells convert glucose to lactate and partially oxidize glutamine to form ammonia, $\mathrm{CO}_{2}$ and either alanine or aspartate stoichiometrically.

The genetic event leading to such a phenotype need not be mitochondrial. Many elements of mitochondrial structures are encoded in the nucleus. On the other hand the key complex for NADH utilization, NADH dehydrogenase, is coded by the mitochondrial genome and involves some 6300 of the 16,569 mitochondrial bp divided among six subunit structures. 
Charles Heidelberger took advantage of the fact that some rodent derived cell lines could be established which did nor grow as fast as $3 \mathrm{~T} 3$ cells and which stopped growing at far fewer cells $/ \mathrm{cm}^{2}$ on oetri dishes despite frequent medium replenishment. When a few hundred of these cells were treated with known carcinogens like 3 - methylcholanthrene and allowed to grow to form a confluent monolayerfoci of transformed cells would erupt and continue growing. When these morphologically transformed cells were injected into a syngeneic mouse they grew to form a tumor. What Sukdeb Mondal and Heidelberger did was to separate carcinogen treated cells immediately after treatment and allow a single treated cell to give rise to a monolayer covering a Petri dish. Every cell treated with 3 - methylcholanthrene gave rise to one or more descendent transformed foci!

This experiment later repeated and explored with a cell line developed by Reznikoff and Heidelberger - C3H $10 \mathrm{~T} 1 / 2$ - has perplexed many of us for the last 24 years. Little and Kennedy showed that $\mathrm{X}$-rays produced the same essential phenomenon as polycyclic aromatic hydrocarbons. Most subsequent discussion has focused on induction of a temporarily higher mutation rate that gives rise to oncomutations as the cell population expands.

An alternate expianation is the induction of mitochondrial oncomutation.

(a) Cells contain some $10^{4}$ copies of the mitochondrial genome.

(b) The amount of polycyclic aromatic hydrocarbons or $\mathrm{x}$-rays used, would induce from 0.2 to $2 \times 10^{-4}$ 6TG resistant mutants in mammalian cells in culture.

(c) In the only studies comparing nuclear and mitochondrial mutation rates in single cells (yeasts) mitochondrial mutation occurred some 17 times more frequently.

(d) The late Alan Wilson using restriction fragment length polymorphisms estimated about a tenfold higher evolutionary rate of mutation for mitochondrial relative to nuclear DNA sequences.

Thus my hypothesis to explain the Mondal - Heidelberger experiment is simple:

$10^{4}$ mitochondrial copies / cell

$\sim 10^{-4}$ induced mutants for an average nuclear gene (hprt)

$\sim 10$ fold higher rate of mutations in mitochondia

$\sim 10$ mutations per cell inactivating an average mitochondrial gene of $10^{3} \mathrm{bp}$

I think that Mondal caused multiple mitochondrial oncomutations per cell. Thus every treated cell gave rise eventually to a small number of transformed cells. The probability of not doing so in this present example would be $\mathrm{e}^{-10} \approx 0$.

The reason that multiple cell divisions were required to permit neoplastic expression also seems clear: mitochondrial sister copies do not segregate like nuclear sister chromatids. It is likely that mitochondrial sister copies will pass to the same cell at cell division. With $10^{4}$ original wild type copies and one mutant it would take at least 14 cell divisions to achieve a single cell with only mutant copies. With some "mixing" either stochastic or by mitochondrial partition it would require $>14$ cell divisions to achieve a cell with only mutant copies. In the Mondal experiments one cill 
gave rise to about $10^{7}$ cells which is equivalent to 27 cell doublings. The simultaneous presence of as few as 100 original cells was enough to partially suppress the appearance of transformed foci (Haber et al, 1977; Haber and Thilly, 1978 among others). The growth of $100\left(\sim 2^{7}\right)$ cells to $10^{7}$ $(\sim 227$ ) cells involves 20 cell generations indicating that a $\geq 20$ cell division phenotypic lag effected the expression of morphologic and neoplastic transformation.

Thus like Warburg (1924), Mondal and Heidelberger (1970) point toward the existence of a mitochondrial oncomitation in cancer.

\section{MODEL OF HUMAN CANCER ARISING FROM A RECESSIVE} MITOCHONDRIAL ONCOMUTATION COMBINED WITH NUCLEAR
ONCOMUTATIONS.

\section{Mitechondrial_Mutation}

The probability a growing cell population will experience at least one mitochondrial mutation as a function of cell divisions is of the same form as the relationship for nuclear mutations

$$
P_{1}(\geq 1):=\frac{1}{\ln 2} r_{m} 2^{8} \quad \text { Equation } 3 \text { (III-C) }
$$

when $I_{m}$ is the rate of mitochondrial mutation per cell division.

However, the assumption of nonsegregation of sister copies leads to the expectation that the number of cells containing mutant mitrchondrial copies will remain constant until one cell has all mutant copies. Then as this cell undergoes divisions its descendants increase in number exponentially with all the other cells in the population.

We will let the number of cell divisions necessary to go from one cell with one mitochondrial mutant copy to one cell with all mutant mitochondrial copies be $\Delta$ generations. This makes it easy to write the equation for the probability of having at least one cell in a population to have all mutant mitochondrial copies. For the sake of argument we will postulate that having all copies mutant is necessary and sufficient to express a related phenotypic change.

$$
P_{m \exp }(\geq 1)=\frac{1}{\ln 2} r_{m} 2^{(8-\Delta)} \quad \text { Equation } 4 \text { (III-C) }
$$

The number of such expressed mutants in a growing population (organ) is just

$$
N_{m \exp }=r_{m}(y-\Delta) 2^{8-\Delta} \quad \text { Equation } 5 \text { (III-C; }
$$

\section{Combining One Mitochondrial and One Nuclear Mutations in the Same Cell.}

The probability that a nuclear mutation arises in the same cell that has an expressed mitochondrial mutation is the product of the nuclear mutation rate, $\mathrm{r}_{\mathrm{i}}$, and the number of expressed mitochondrial mutants: 


$$
=\left(r_{i}\right)\left(r_{m}(g-\Delta) 2^{g-\Delta}\right) \quad \text { Equation } 6(\mathrm{IM}-\mathrm{C})
$$

The probability that a mitochondrial mutation is expressed in a cell which already has a nuclear mutation is the product of the rate of experiencing a mitochondrial mutations, $\mathrm{r}_{\mathrm{m}}$, times the number of existing nuclear mutants at the time of that mitochondrial mutation, $\mathrm{r}_{\mathrm{i}}(\mathrm{g}-\Delta) 2 \mathrm{~g}-\Delta$, which is

$$
\left(r_{m}\right)\left(r_{i}(g-\Delta) 2^{8-\Delta}\right) \quad \text { Equation } 7 \text { (III-C) }
$$

Thus the probability of new double (expressed) mutants, $\mathrm{P}_{2} \exp$, is the same regardless of which came first and the sum is:

$$
P_{2 \exp }(\geq 1)=2\left(r_{i}\right)\left(r_{m}(g-\Delta) 2^{g-\Delta}\right) \quad \text { for all } g \geq \Delta . \text { Equation } 8 \text { (III-C) }
$$

Of course peoples' organs do not increase as exponential cell populations. As an approximation we have calculated that the cells of an organ undergo gmax divisions to reach a maximum organ size containing 2 gmax cells. At some time early in life cell turnover begins and the rules of turnover we have modeled as: one cell divides, one of its daughter cells dies maintaining a constant 2 gmax cells.

To facilitate this presentation we have assumed a newborn first doubles its cell number without cell turnover and then undergoes four turnover divisions simultaneously with four growth divisions.

$\begin{array}{llcc}\text { Age } & \text { Cell Number } & \text { Turnover Gencrations } & \text { Body Weigh } \\ \text { birth } & 2 \text { gmax-5 } & 0 & 6 \mathrm{lbs} . \\ <1 \mathrm{yr} . & 2 \text { gmax }-4 & 0 & 12 \mathrm{lbs} . \\ 18 \mathrm{yrs} . & 2 \text { gmax } & 4 & 192 \mathrm{lbs} .\end{array}$

After age 18 we assume only constant turnover generations throughout life. $\mathrm{r}_{\mathrm{i}}$ and $\mathrm{rm}_{\mathrm{m}}$ are for simplicity assumed to remain constant. (We intend to return soon to this point because McGinness et al. have reported very low $\mathrm{T}$ cell hprt mutation rates in fetuses relative to adults). Both growth and turnover generations are equivalent in permitting mitochondrial mutant copies to segregate into one cell expressing the mutant phenotype. This gets slightly hairy but really is just the statement for expresssed double mutants for each cell generation before and after reaching gmax.

Early in life the probability of observing an expressed mitochondrial + nuclear double mutant is dominated by events occuring during growth of the organ and have the general form

$$
P_{2 \exp }(\geq 1)=r_{i} r_{m}(g-\Delta) 2^{g-\Delta} \quad \text { Equation } 9 \text { (III-C) }
$$

which is dominated by the term $2 \mathrm{~g}-\Delta$. For human organs with $10^{11}$ to $10^{12}$ cells the term (g- $\Delta$ ) increases by a relatively small factor as the organ approaches maximum size. 
What about later in ife?

Between 0 and 18 years we have applied the logic that about four exponential cell divisions and an unknown number of cell turnover divisions. For the case where we assume the turnover divisions are equal in number 9 and probability of growth generations (4) in this period we expect

$$
\mathrm{P}_{2 \exp }(\geq 1)=\mathrm{k}_{1} \mathrm{r}_{1} \mathrm{rm}(\mathrm{g}-\Delta) 2(\mathrm{~g}-\Delta) \quad \text { Equation } 10 \text { (III-C) }
$$

when the organ reaches full size, $2^{g m a x}$ cells, this leads to the expectation

$$
\mathrm{P}_{2 \exp }(\geq 1)=\mathrm{k}_{1} \mathrm{r}_{1} \mathrm{rm}(\mathrm{g}-\Delta) 2(\text { gmax }-\Delta) \quad \text { Equation } 11 \text { (III-C) }
$$

Assuming $\mathrm{q}=4$ yields

$$
=\mathrm{k}_{1}(\mathrm{~g}-\Delta) \mathrm{ri}_{1} \mathrm{r}_{2}(\mathrm{gmax}-\Delta) \quad \text { Equation } 12 \text { (III-C) }
$$

where $\mathrm{g}$ is the sum of growth and turnover divisions. (This still needs work. W.G. Thilly)

Eventually all the mitochondrial mutations arising before the organ reached fullsize will have passed through $\Delta$ divisions and be phenotypically expressed. Now calculating the probability of an expressed double mutant is simply based on a constant cell number 2 gmax constant mutation rates $\mathrm{r}_{\mathrm{i}}, \mathrm{r}_{\mathrm{m}}$ and a constant number of cell divisions for mitochondrial phenotypic expression, $\Delta$. $2 \operatorname{gmax}$

The number of nuclear oncomutants arising during turnover generations, $g$, is just $r_{i} g$

The probability of a new double expressed mutant is

$$
\begin{aligned}
& P_{2 \exp }(\geq 1)=\left(r_{m}\right) r_{1}(g-\Delta) 2(g m a x-\Delta) \\
& \left.+\left(r_{1}\right) r_{m}(g-\Delta) 2^{(g m a x}-\Delta\right)(\Delta) \\
& =r_{1} r_{m}(g-1) 2(g m a x-\Delta)(\Delta+1)
\end{aligned}
$$

which has the form as shown in Figure 2 (III-C) 


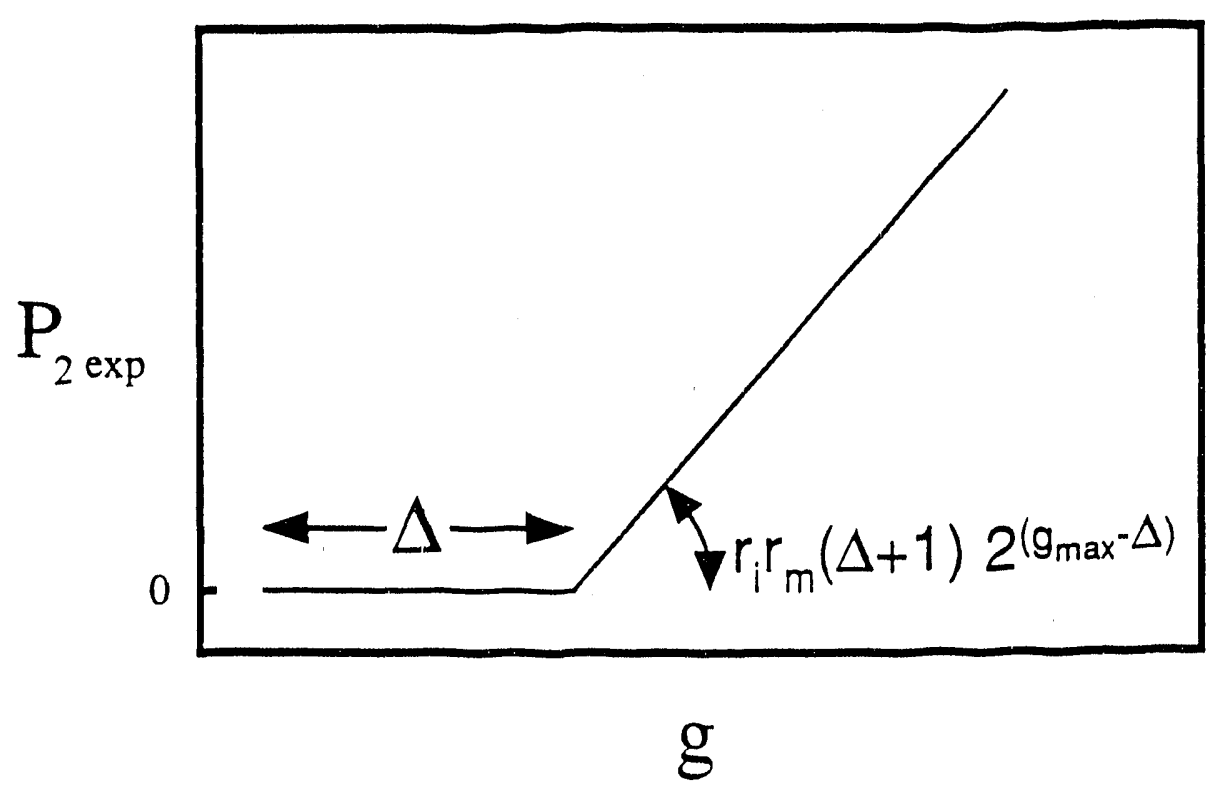

Figure 2 (III-C)

Figure 3 (III-C) shows the data (death rate) for liver and esophageal cancers and lymphosarcoma in white males as a function of age [Atlas of Cancer Mortality for US Counties 1950 - 1969, DHEW Publication NIH 75-780].

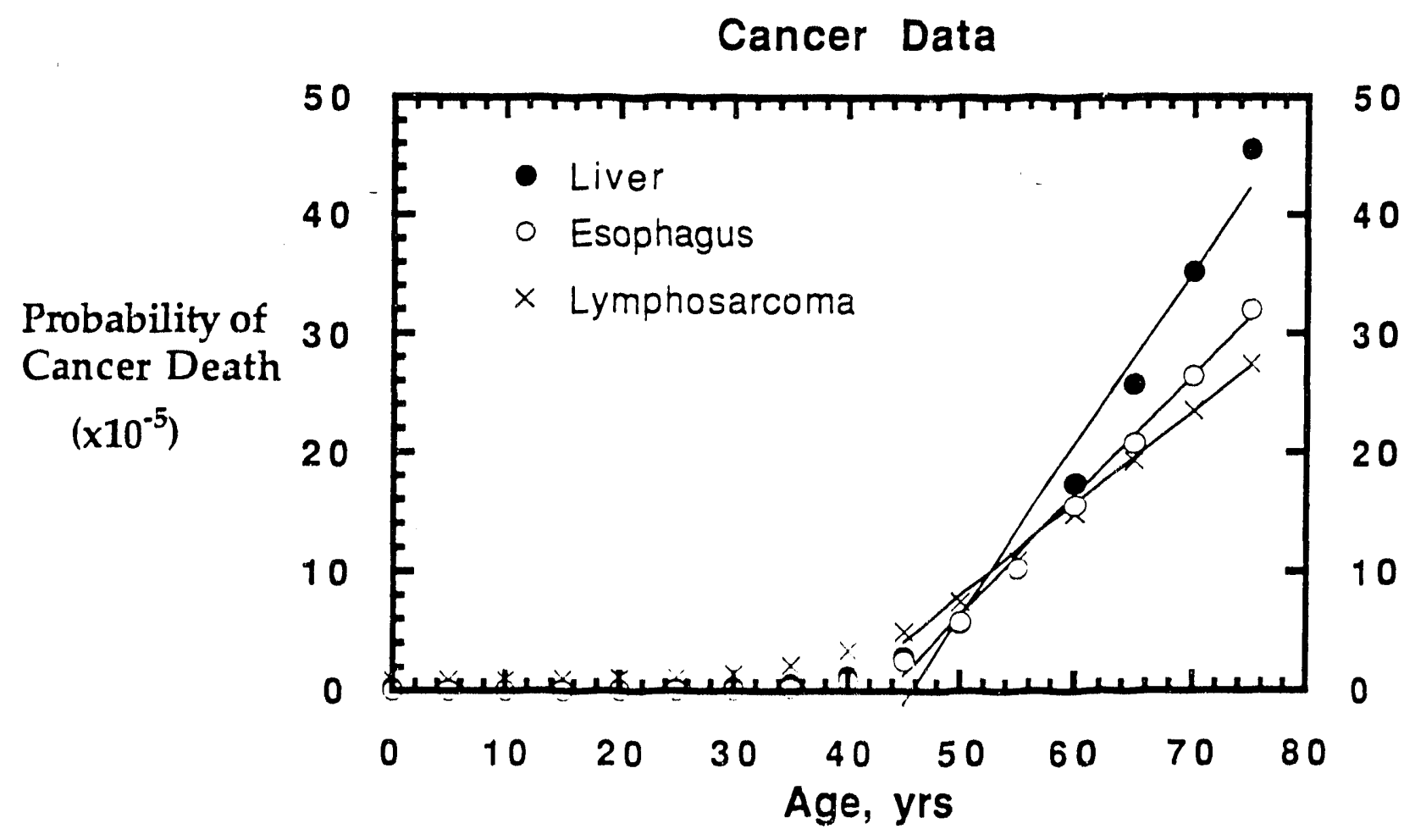

Figure 3 (III-C)

The similarity of form of cancer deaths as a function of age with the predicted time dependence of $\mathrm{P}_{2} \exp (\geq 1)$ is so striking as tu challenge credulity. The same essential relationship 
is found for pancreatic cancer and leukemia. The age intercept of these many cancer death curves is approximately 47 years. Why should $\Delta$ be a constant for many forms of cancer?

$\Delta$ would depend seemingly on the number of mitochondrial copies per cell. But it is also possible that just as cells in different organs have somewhat different turnover rates they may also have somewhat different numbers of mitochondria. The number or fraction of stem cells would enter into this statement as a constant, too. (Model under development.) Has evolution selected for people who don't rise appreciably in cancer rate till age 47? Could organs with high turnover rates have compensatory conditions such as high mitochondrial copy numbers to increase the number of necessary turnover divisions to express mitochondrial recessive mutants?

The medieval "law of parsimony" lays the philosophical basis for such a premise. If evolution is selecting for improved homo sapiens it would confer no selective advantage by delaying pancreatic cancer if everyone were already dead of liver cancer.

Isn't this too simple? Maybe. But it is a clean testable hypothesis in a laboratory which specializes in measuring genetic change without reference to phenotype.

In quantitative terms our hypothesis is that in humans the number of mutants rises linearly as a function of age. As noted earlier, this is not really an untested hypothesis. Hprt, glycophorin $A$, and HLA mutants in circulating red and white blood cells all appear to rise linearly with age. We are just pointing out the inexorable arithmetic consequences of constant mutation rate in a cell population in which constant cell number is maintained via cell turnover.

Mr. Peter Southam and I are continuing to refine the model which has peculiarities due to simultaneous generational and turnover divisions between birth and adulthood. Since our calculations predict a slower but linear increase in $\mathrm{P}_{2} \exp$ for some turnover divisions prior to attaining the maximum rate of increase in $\mathrm{P}_{2}$ exp. Our present data set uses 5 years cancer death rate averages. We are in the process of obtaining the U.S. rates on a year by year basis in order to compare them more closely the details of the specific model.

\section{The Case of Two Nuclear Oncomutations and One Recessive Mitochondrial Oncomutation.}

Arithmetically the case of three required nuclear mutations arising in a single cell in an exponentially growing population has a probability

$$
P_{3}=\frac{3}{\ln 2} r_{i} r_{j} r_{k} g^{2} 2^{8}
$$

where $r_{i}, r_{j}$, and $r_{k}$ are the mutation rates for mutations $i, j$ and $k$ respectively. (Thilly, 1990).

Applying this to the case of a cell population in which constant cell number is maintained by cell turnover is a simple extension of our prior model. Incorporating the hypothesized recessive mitochondrial mutation for mutant $\mathrm{k}$, the expression for $\mathrm{P}_{3} \exp$ is straight forward:

$$
\left.P_{3 \exp }(\geq 1)=k_{2} \operatorname{rirji}(g-\Delta)^{2} 2^{(g m a x}-\Delta\right) \quad \text { for all } g>\Delta
$$


As $g$ increases this leads to an expectation that $P_{3} \exp$ will rise as a function of $g^{2}$. This expectation is shown in Figure 4 (II-C).

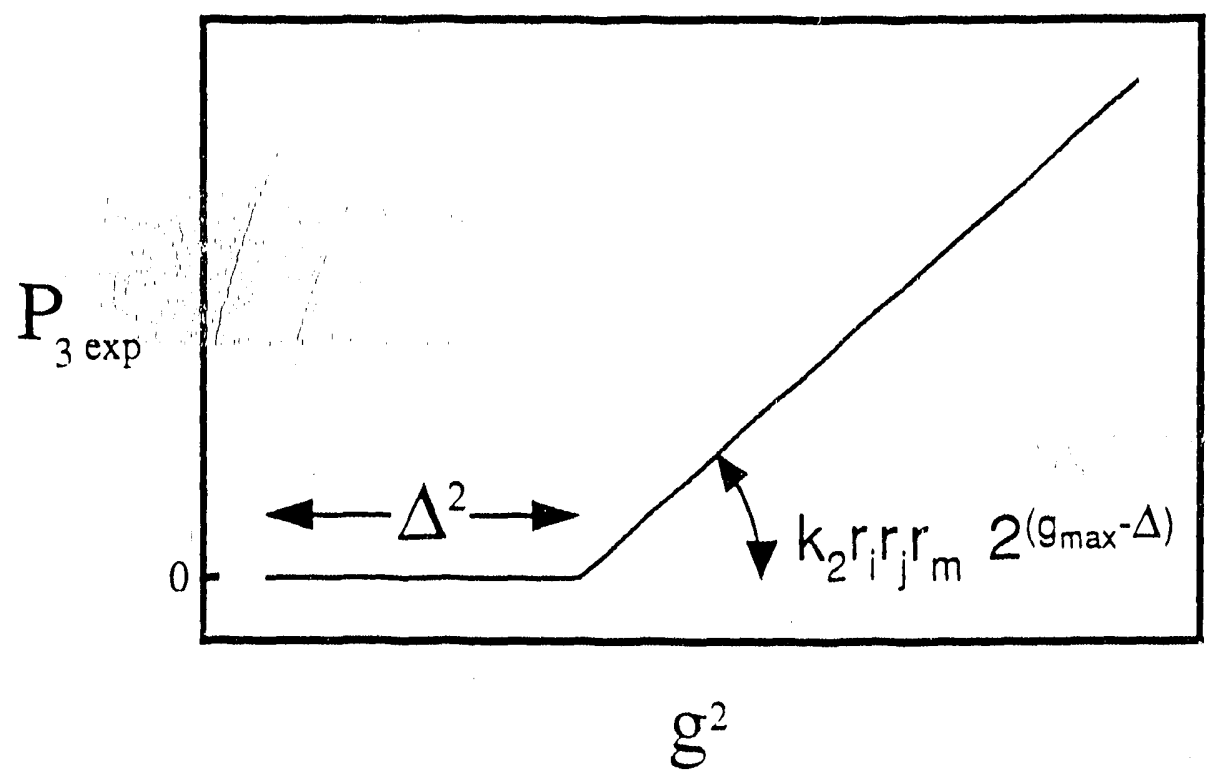

Figure 4 (III-C)

This expectation may now be compared to the actual (age $)^{2}$ dependence of probability death by cancer of certain organs. Shown in Figure 5 (III-C) is the result of plotting these data for stomach and lower intestinal cancer.

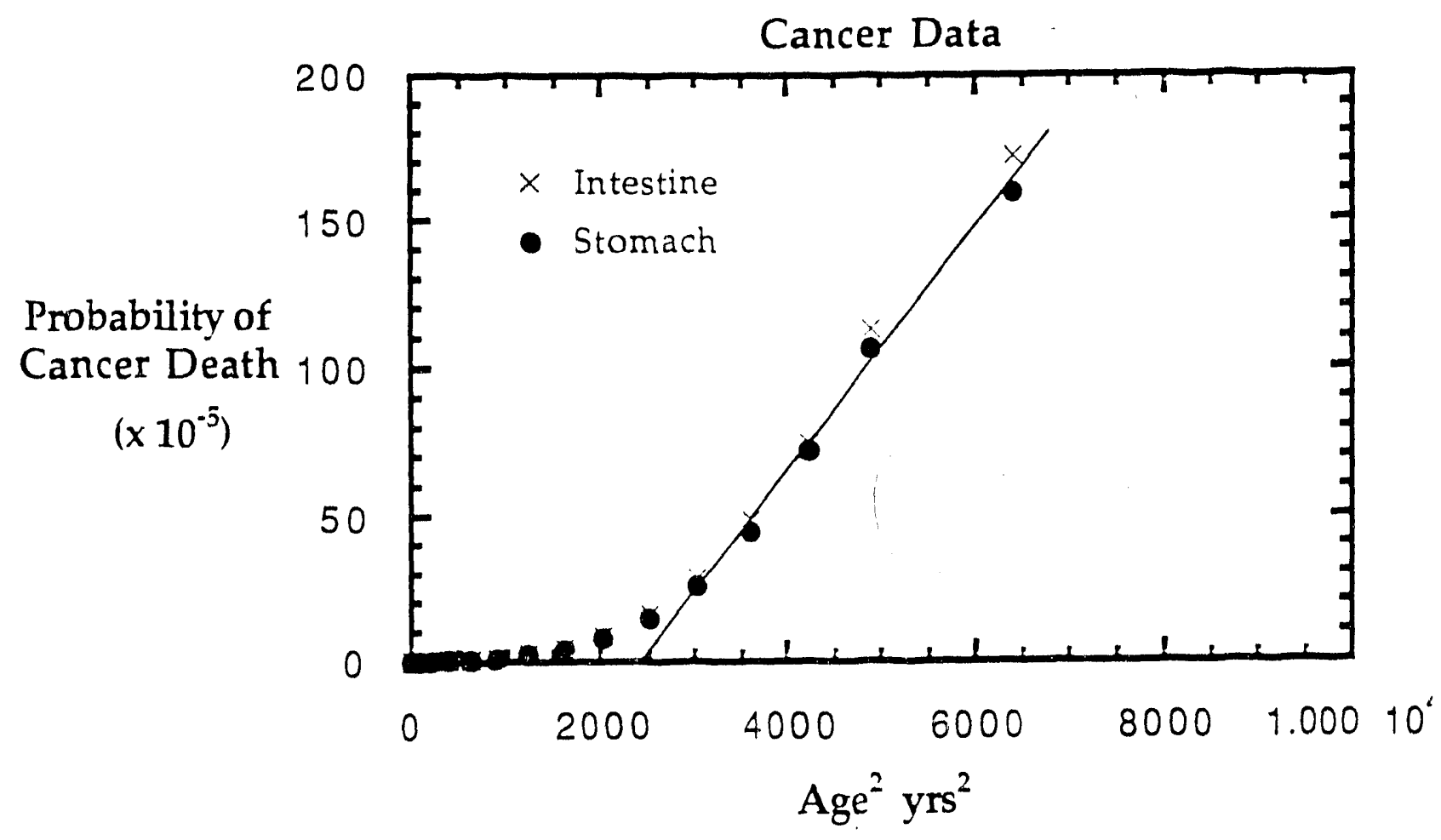

Figure 5 (III-C) 
The same relationship is obtained with bladder cancer. For these organs cancer rates remain low until (age $)^{2}$ is about $(50)^{2}$ and then rises as a simple function of (age - 50) ${ }^{2}$. Once again the fit of these data drawn from the U.S. population of white males from 1950 - 1969 to the expected behavior of a constant rate of mutation for one recessive mitochondrial oncornutation and two nuclear oncomutations is remarkable.

We continue to search the mutagenesis and carcinogenesis literature but so far we have found no earlier comparable statement of this hypothesis. We have discussed our approach to a mitochondrial oncomutation hypothesis with Eliczer Huberman, Alfred Knudsen, and our colleagues at M.I.T. Professors Tannenbaum, Wogan and Zarbl. No one is acquainted of with any earlier statement of a mitochondrial oncomutation hypothesis based on the delay function in cancer expression. We also have discussed the general problem of mitochondrial segregation with Douglas Wallace (Emory University) and confirined our impression from the literature that most workers regard segregation as random as opposed to "unmixed" or "partially mixed". This is important because the latter possibilities but not the former permit expression of recessive phenotypes by continuous cell division alone, given a large number of mitochondrial genome copies. It should be added that cell cybrid studies tend to support the general notion of a recessive mitochondrial oncomutation (Howell and Sager, 1978; Ziegler, 1978; Koura et al, 1982 and Hayashi et al, 1986). However, we can not argue that these reports could not have other reasonable interpretations.

Whether our hypothesis is original or not, it is a clear and testable in a laboratory that can measure mutations in DNA.

\section{LIMITATION ON THE HYPOTHESIS OF MITOCHONDRIAL RECESSIVE ONCOMUTATION}

Df course, the form of the cancer delay function might not be due to a recessive mitochondrial oncomutation. There might be a "stainless steel gene product" which must be diluted by cell division before the mutant phenotype would be expressed. Another possibility comes from the recently published work of Professor Katherine M. Call formerly supported by this grart and now Assistant Professor at the Harvard School of Public Health. She showed that heavy stibstitution of TK-6 DNA with bromodeoxyuridine created a large fraction of cells which were temporarily resistant to killing by trifluorothymidine i.e. they were temporarily $\mathrm{tk}^{-/}-$. This number decreased exponentially as a function of cell generations. Her hypothesis based on effects of 5 - aziacytidine on this phenomenon was that bromodeoxyuridine incorporation created pseudo methylation sites which when methylated suppressed thymidine kinase transcription (Call and Thilly, 1991).

Without Warburg, (1956) without Mondal and Heidelberger, (1920) without the suppression of tumorigenicity in cybrids Hayashi et al, (1986) and others our arithmetic model would work just as well for any phenotype which is not expressed for $\Delta$ generations after genotypic change. Imagine that each human chromosome carries methylated sites and that if the site on any one chromosome is methylated the neoplastic phenotype is repressed. A mutation which eliminates site methylation will inexorably lead to cells with zero chromosomes with a single methylated site given continued cell division. By random distribution of sister chromatids this process would require about 6 generations to accomplish, $46 \times 2^{-6}<1$. 
But such a mutation would be a nuclear mutaion. It might produce the "damaged respiration" phenotype of Warburg. It would not give rise to treated cells each of which gives rise to a small fraction of transformed cells as in Mondal and Heidelberger.

\section{MUTATIONS OF THE H-RAS GENE IN SOMATIC CELLS OF THE RAT.}

Using the MAMA for the GGA ...-> GAA mutation of the c-H-ras gene of the females Fischer rat we have measured mutations as a function of age in liver and mammary cells. Studies of ten other organs are in progress.

The description of this work is under review by Science and is included as manuscript in the Appendix (Cha et al, 1992). The key findings are:

(a) In mammary epithelial cells, h-ras G --.-> A mutations arise at an average rate of $\mathrm{r}_{\mathrm{i}}=2 \times 10^{-8}$ mutations / cell division.

(b) The process is continuous through mammary development as evidenced by the number of mutant cells distributed among sectors of the organ. The number of mutants rises as expected:

$$
N_{h-\text { ras }}=\frac{1}{\ln 2} g^{2}
$$

(c) A similar continuous process occurs in the liver but the average rate is significantly lower with $r_{j}=2 \times 10^{-9}$.

(d) Treatment of these animals with methylnitrosourea results in breast tumors carrying the specific h-ras mutation. However, methylnitrosourea does not increase the number of mutants among the mammary epithelial cells.

(e) We conclude that, however attractive, the hypothesis that methylnitrosourea induced the specific $\mathrm{G} \mathrm{-...>>} \mathrm{A} \mathrm{mutation} \mathrm{found} \mathrm{in} \mathrm{the} \mathrm{induced} \mathrm{breast} \mathrm{tumors} \mathrm{is} \mathrm{disproved.} \mathrm{MAMA}$ offers all researchers a convenient and accurate means to test such hypotheses in the future.

(f) Recognizing that MNU must have done something to induce the tumors and that there were only 200 pre-existing h-ras mutants in which to do it, we conclude that this effect arose with a probability of $5 \times 10^{-3}$.

Could there be a relation between these observations of a known nuclear oncomutation and the theoretical state of expressed mitochondrial oncomutants? Could treatment kill off copies of mitochondrial DNA so that a large fraction of surviving copies would be mutant? Could these repopulate the cell rapidly and lead to the expressed mitochondrial phenotype without intervening cell turnover?

(g) We hypothesize that the h-ras tumor cells contain mutant mitochondria. Since this mutation must lie in the 16,569 bp genome testing the hypothesis is straightforward if arduous. 
The submitted manuscript Cha et al, 1992 with primary data and discussion are included in the Appendix.

\section{E. STUDIES OF MITOCHONDRIAL FUNCTION IN NORMAL AND CANCER CELLS.}

If we are going to take the mitochondrial oncomutation hypothesis seriously biochemistry will have to be joined with our genetics studies. Last year we worked with Dr. Sam Singer in the National Magnet Laboratory at MIT to provide the first means to study live, healthy mammalian cells in an NMR spectrometer. Our contribution was the high density cell culture technology described in Section I-A. By allowing the NMR researchers to achieve $\geq 10^{7}$ healthy growing cells per $\mathrm{ml}$ in their $20 \mathrm{ml}$ probe volume, the technology allowed direct in vitro measurements for ${ }^{13} \mathrm{C}$ and ${ }^{31} \mathrm{P}$. A manuscript under review by Cancer Research (Singer et al, 1992) is included in the Appendix.

The key finding for our future work was that cultured human colonic cells showed identical biochemical dynamics as found in perfused tumors grown in nude mice. We anticipate using NMR with primary human cell cultures to note the effect of a series of decouplers of oxidative phosphorylation to test the hypothesis that cancer mimics to some extent an NADH dehydrogenase deficient cell.

\section{SPECIFIC AIMS AND MILESTONES}

1. Perfect the technology for measuring specific mutation and mutational spectra in human and animal tissues. This goal will be achieved by improvements and combinations of techniques herein described as :
a. DGGE + HiFi PCR
b. MAMA
c. HUMA
[Mr. John Hanekamp, Dr. Gengxi Hu and others]

2. Apply the technology in present and improved form to test the following hypotheses:

a. That human $\mathrm{T}$ cell mutations are induced by exogenous mutagens. This will be performed by determining and comparing the mutational spectra in several mitochondrial sequences in fresh $T$ cell samples and in $T$ cells expanded for 15 generations in vitro from the same donors. [Mr. John Hanekamp].

b. That the causes of mutation in human and animal tissues are essentially constant throughout life. This will be done first by examining the mutational spectra in the mitochondrial sequences of various organs of Fischer rats from early fetal life to old age. The process will then be repeated for humans, pending review by the Committee on the Use of Humans as Research Subjects, in T cells and other tissues obtained as surgical specimens. [Ms. Rita Cha. Ms. Hilary Coller, Mr. Eric Larson].

c. That nuclear and mitochondrial mutagenesis proceed by nearly identical pathways reflecting the similarity observed between E.coli and human cell mutational spectra. Here 
we will use mitochondrial sequences and nuclearly encoded mitochondrial pseudogenes to compare spectra of closely related DNA sequences [Dr. Gengxi Hu, Mr. Peter Southam].

d. That mitochondrial mutations (chloramphenical or oligomycin resistance) are expressed via non segregation of sister DNA copies in successive cell divisions [Mr. Peter Southam].

e. That the probability of two mutations arising in the same cell in arithmetic product of the probabilities of each of the two mutations. This is a key assumption in all of our models for multiple mutations in cancer. We will treat large human cell population with mutagens, isolate all hprt- mutants and within that population assay for simultaneous t $k^{-1-}$ mutants.

f. That cancer arises by virtue of complementary nuclear and mitochondrial oncomutations. Our model predicts that human cancers must express and, therefore have, many copies of, a recessive oncomutation. There is no reason to imagine a common oncomutation such as h-ras, so each tumor might well have a different point mutation in a mitochondrial "suppressor gene" inactivated by mutation. We propose to examine mitochondria from untransformed and transformed C3H $10 \mathrm{~T} 1 / 2$ cells Fischer rat tumors and a series of human tumors from surgery or autopsy.

This is a major undertaking. The hypothesized mutation could theoretically be anywhere since its activity may well reside in some unknown role of a gene product in nuclear - mitochondrial coordination. Our specific hypothesis concerning NADH dehydrogenase is not sufficiently compelling to focus on those $\sim 6300 \mathrm{bp}$ alone. Nor could we rely on the hypothesis that sooner or later a restriction site change would be an oncogenetic change. Furthermore there is no reason to believe that tumors would bear the same mitochondrial oncomutation. Mutations inactivating NADH dehydrogenase, for instance, could arise within any of its six subunit genes. Our tactics, imperfectly laid out at this time, could encompass a method as simple as $S_{1}$ nuclease digestion of a 50/50 hybridization mixture of different restriction digests of isolated tumor and non tumor mitochondria from the same cell line, animal or person.

Alternately one could use DGGE iteratively. Checking all 16,569 bp by this approach would require the expensive process of synthesizing a large $(\geq 1000)$ series of suitable PCR primers containing high melting clamps. A more likely approach would be to prepare complementary RNA fragments and recognize mutant heteroduplexes with RNase.IDr. Gengxi Hu, Ms. Hilary Coller, Mis. Jackie Griffith. Mr. David Katz, Mr. Eric Larson and others. 
Our overall experimental tree is represented here:

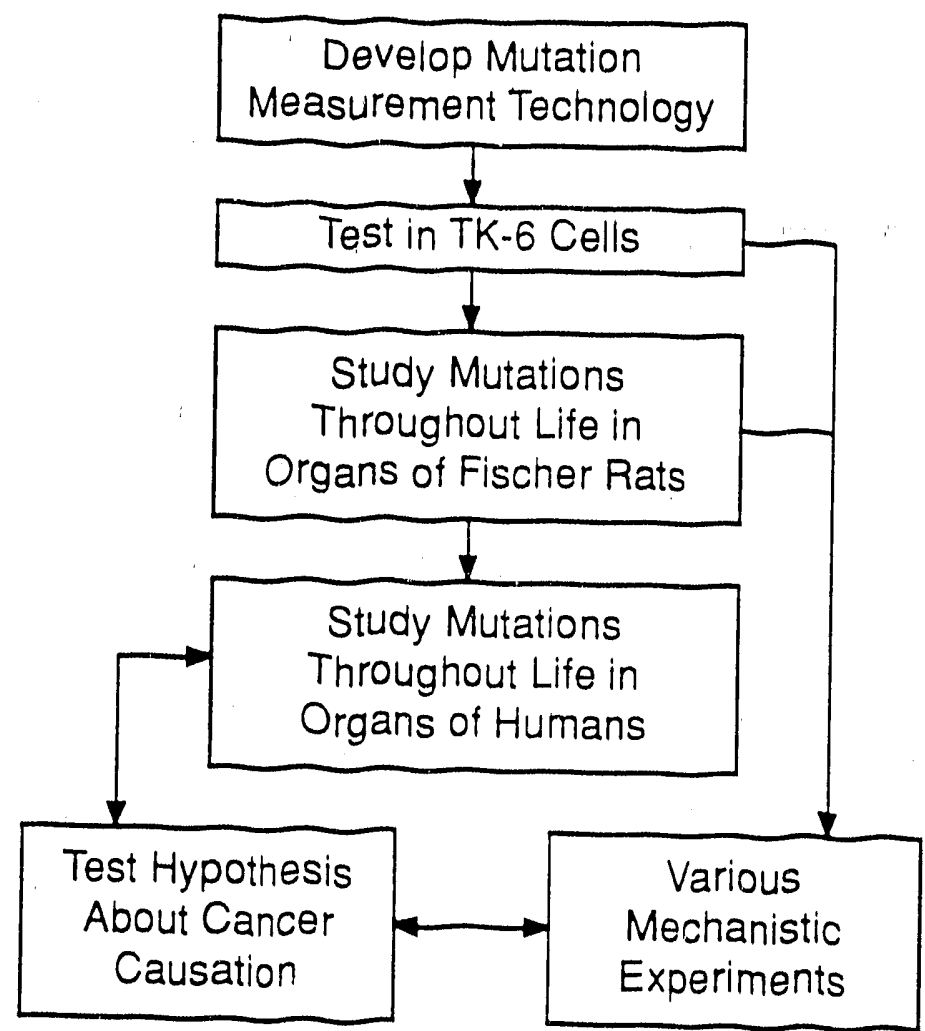

\section{Milestones}

\section{Specific Aims Completion Dates}

Nov 1992

Nov 1993
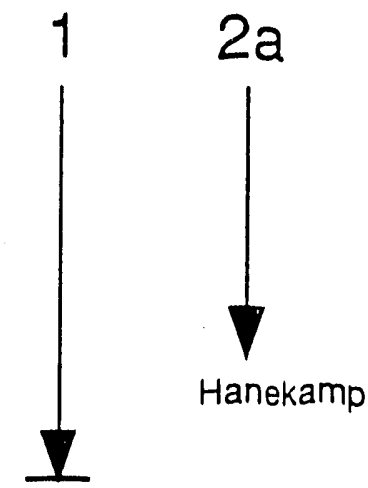

Hanekamp

$\mathrm{Hu}$

Nov 1994

Cha

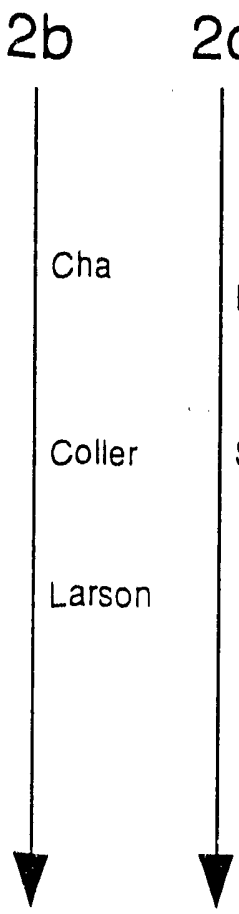

$2 d$

$2 e \quad 2 f$

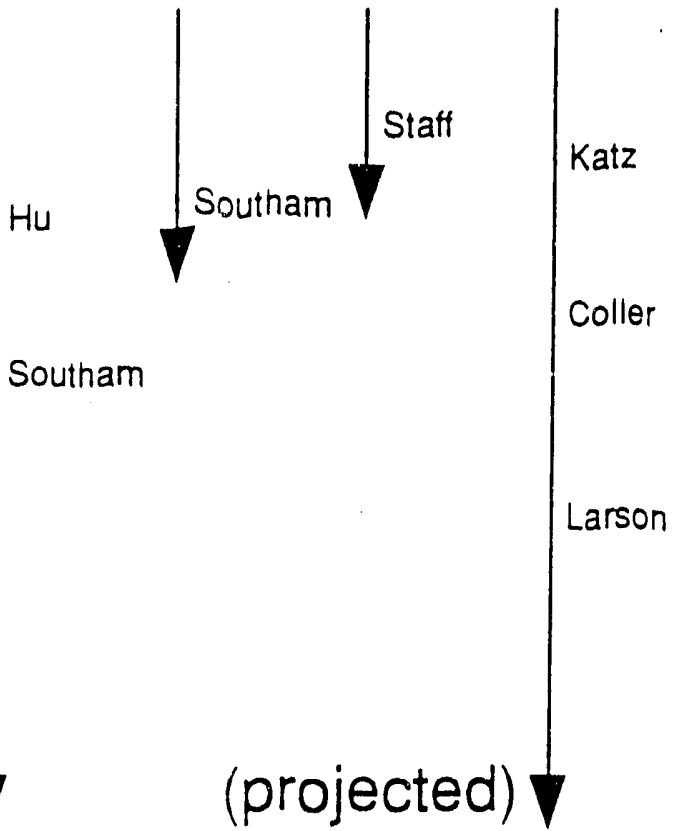

Nov 1995 


\section{Citations:}

Albertini, RJ, Castle, KL, and Borcherding (1982) T-cell cloning to detect the mutant 6thioguanine-resistant lymphocytes present in human peripheral blood, PNAS 79: 66176621 .

Brown, WM, George, M, Jr., and Wilson, AC (1979) Rapid evolution of animal mitochondrial DNA. PNAS 76:1967-1971.

Cariello, NF, Keohavong, P, Kat, AG, and Thilly, WG (1990) Molecular analysis of complex human cell populations: Mutational spectra of MNNG and ICR-191. Mutat. Res. 231:16576.

Cariello, NF, Keohavong, P, Sanderson, JS, and Thilly, WG (1988) DNA damage produced by ethidium bromide staining and exposure to ultraviolet light Nucleic Acids Research: 16(9):4157.

Cariello, NF, Scott, JK, Kat, AG, Thilly, WG, and Keohavong, P (1988) Resolution of a missense mutant in human genomic DNA by denaturing gradient gel electrophoresis and direct sequencing using in vitro DNA amplification: $\mathrm{HPRT}_{\text {Munich. }}$ Am. J. Hum. Genet. 42:726-34.

Cha, RS, Zarbl, H, Keohavong, P, and Thilly, WG (1992) Mismatch Amplification Mutation Assay (MAMA): Application to the $\mathrm{c}-\mathrm{H}-\mathrm{ras}$ gene. PCR Methods and Applications. Cold Spring Harbor Laboratory Press. (In press).

Coulondre, C, and Miller, JH (1977) Genetic studies of the lac repressor. IV. Mutagenic specificity in the lac I gene of Eschenchia coli J. Mol. Biol. 117: 577-606.

Danheiser, SL, Liber, HL, and Thilly, WG (1989) Long-term, low-dose benzo(a)pyrene-induced mutation in human lymphoblasts competent in xenobiotic metabolism. Mutat. Res. 210:143-7.

Devasagayam, TP, Steenken, S, Obendorf, MS, Schultz, WA, and Sies, H (1991) Formation of 8-hydroxy (deoxy)guanosine and generation of strand breaks at guanine residues in DNA by singlet oxygen. Biochemistry 25:30:6283-9.

Devasagayam, TP, Sundquist, AR, Kaiser, S, and Sies, H (1991) Activity of thiols as singlet molecular oxygen oxygen quenchers J Photochem Photobiol B 9:10516.

Furth, EE, Thilly, WG, Penman, BW, Liber, HL, and Rand, WM (1981) Quantitative assay for inutation in diploid human lymphoblasts using microtiter plates. Anal. Biochem. 110:1-8.

Gentil, A, Bourre, F, and Sarasin, A (1989) Carcinogen-induced mutagenesis in the simian virus 40 genome. Ann 1st Super Sanita 25:171-6.

Goldmacher, VS, Cuzick, RA Jr, and Thilly, WG (1986) Isolation and partial characterization of human cell mutants differing in sensitivity to killing and mutation by methylnitrosourea and N-methyl-N'-nitro-N-nitrosoguanidine. J. Biol. Chem. 261:12462-71.

Grist, SA, McCarron, M, Kutlaca, A, Turner, DR, and Morley, AA (1992) In vivo human somatic mutation: frequency and spectrum with age. Mutation Res., 189-196. 
Hayashi, JI, Werbin, H, and Shay, JW (1986) Effects of normal human fibroblast mitochondrial DNA on segregation of HeLa TG mitochondrial DNA and on tumorigenicity of HeLa TG cells. Cancer Research 46:4001-4006.

Held, KD, and Awad, S (1991) Effects of polyamines and thiols on the radiation sensitivity of bacterial transforming DNA. Int J Radiat Biol. 59:699-710

Howell, N, and Sager, R (1978) Tumorigenicity and its suppression in cybrids of mouse and Chinese hamster cell lines. PNAS 75:2358-2362.

Imamura, I, Crespi, CL. Thilly, WG, and Brunengraber, H (1982) Fructose as a carbohydrate source yields stable $\mathrm{pH}$ and redox potential in microcarrier cell culture. Anal. Biochem. 124: 353-358.

Kennedy, AR, and Little, JB (1984) Evidence that a second event in x-ray - induced oncogenic transformation in vitro occurs during cellular proliferation. Radiat Res. 99:228-248.

Keohavong, P, and Thilly, WG (1989) Fidelity of DNA polymerases in DNA amplification. PNAS 86:9253-7.

Keohavong, P, and Thilly, WG (1992) Mutational spectrometry: A general approach for hotspot point mutations in selectable genes. Proc. Natl. Acad. Sci. USA.(In press).

Keohavong, P, and Thilly, WG (1989) Fidelity of DNA amplification in vitro. In: HA Erlich, R Gibbs and HH Kazaziam Jr, eds., Polymerase Chain Reaction, Cold Spring Harbor Laboratory Press, New York, pp. 19-24.

Keohavong, P, Liu, VF, and Thilly, WG (1991) Analysis of point mutations induced by ultraviolet light in human cells. Mutat. Res. 249:147-159.

Koura, M, Isaka, H, Yoshida, MC, Tosu, M, and Sekiguchi, T (1982) Suppression of tumorigenicity in interspecific reconstituted cells. Gann. 73:574-580.

Kwok, S, Kellogg, DE, McKinney, N, Spasic, D, Goda, L, and Sninsky, JJ (1990) Effects of primer-template mismatches on the polymerase chain reaction: human immunodeficiency virus type 1 model studies. Nucleic Acids Research 18:999-1005.

Langlois, PG, Bigbee, WL, and Jensen, RH (1985) Measurements of the frequency of human erythrocytes with gene expression loss phenotypes at the glycophorin A locus, Hum. Genet. 74:353-362.

Leong. P-M, Thilly, WG, and Morgenthaler, S (1985) Variance estimation in single-cell mutation assays: Comparison to experimental observations in human lymphoblasts at 4 gene loci. Mutat. Res.150:403-10.

Liber, HL, Danheiser, SL, and Thilly, WG (1985) Mutation in single-cell systems induced by low-level mutagen exposure. Basic Life Sci. 33:169-204.

Matsunaga, T, Hieda, K, and Nikaido, O (1991) Wavelenghgt dependent formation of thymine dimers and (6-4) photoproducts in DNA by monochromatic ultraviolet light ranging from 150 to $365 \mathrm{~nm}$. Photochem. Photobiol 54:40,3-10. 
McGinniss, MJ, Falta, MT, Sullivan, LM, and Albertini, RJ (1990) In vivo hprt mutant frequency in T cells of normal human newborns. Mutation Res. 240:117-126.

McKeehan, WL (1982) Glycolysis, glutaminolysis and cell proliferation. Cell Biol. Int. Rep. $6: 635-650$.

Mitchell, DL, Jen, J, and Cleaver, JE (1992) Sequence specificity of cyclobutane pyrimidine dimers in DNA treated with solar (ultraviolet $B$ ) radiation. Nucleic Acids Research $25: 20: 225-9$.

Mondal, S, and Heidelberger, C (1970) In vitro malignant transformation by methylcholanthrene of the progeny of single cells derived from C3H mouse prostate. PNAS 65:219-225.

Morley, AA, Cox, S, and Holliday, R (1982) Human lymphocytes resistant to 6-thioguanine increase with age Mech. Age. D。velop. 19:21-26.

Morley, AA, Grist, SA, Turner, DR, Kutlaca, A, and Bennett, G (1990) Molecular nature of in vivo mutations in human cells at the autosomad HLA-A locus. Cancer Res. 50:4584-4587.

Newton, CR, Graham, A, Heptinstall, LE, Powell, SJ, Summers, C, Kalsheker, N, Smith, JC, and Markham, AF (1989) Analysis of any point mutation in DNA. The amplification refractory mutation system. Nucleic Acids Research 17:2503-2516.

Nicklas, JA, Hunter, TC, O'Neil, JP, and Albertini, RJ (1989) Molecular analyses of in vivo hprt mutations in human T-lymphocytes. III. Longitudinal study of hprt gene structural alterations and T-cell clonal origins. Mutation Research 215:147-160.

Oller, AR, and Thilly, WG (1992) In vitro mutational spectra in human B-cells. Spontaneous, oxygen- and hydrogen peroxide-induced mutations at the hprt gene. J. Mol. Biol. (In press).

Oller, AR, Buser, CW, Tyo, MA, and Thilly, WG (1989) Growth of mammalian cells at high oxygen concentrations. J. Cell Sci. 94:43-9.

Oller, AR, Rastogi, P, Morgenthaler, S, and Thilly, WG (1989) A statistical model to estimate variance in long term-low dose mutation assays: Testing of the model in a human lymphoblastoid mutation assay. Mutat. Res. 216:149-61.

Penman, BW, Crespi, CL, Komives, EA, Liber, HL, and Thilly, WG (1983) Mutation of human lymphoblasts exposed to low concentrations of chemical mutagens for long periods of time. Mutat. Res. 108:417-36.

Rajasinghe, H, Jayatilieke, E, and Shaw, S (1990) DNA cleavage during ethanol metabolism: role of superoxide radicals and catalytic iron. Life Sci. 47(9):807-14.

Rastogi, PB, Thilly, WG, and Shirnamé-Moré, L (1991) Long term low dose mutation studies in human cells: Metanil yellow and orange II. Mutat. Res. 249: 265-273.

Reznikoff, CA, Bertram, JA, Brankow, DW, and Heidelberger, C (1973) Quantitative and qualitative studies of chemical transformation of cloned $\mathrm{C} 3 \mathrm{H}$ mouse embryo cells sensitive to post-contluence inhibition of cell division. Cancer Res. 33:3239-3249.

Scheraga, HA, and Poland, D (1970) Theory of Helix-Coil Transitions. Academic Press, New York. 
Thilly, WG (1985) Po sntial use of gradient denaturing gel electrophoresis in obtaining mutational spectra from human cells. In: E Huberman and SH Barr, eds., Carcinogeneris, Vol. 10, Raven Press, New York, pp. 511-28.

Thilly, WG, Del.uca, JG, Hoppe, H IV, and Penman, BW (1976) Mutation of human lymphoblasts by methyinitrosourea. Chem. Biol. Interact. 15:33-50.

Thilly, WG, Liu, VF, Brown, BJ, Cariello, NF, Kat, AG, and Keohavong, P (1989) Direct measurement of mutational spectra in humans. Genome 31:590-3.

Trainor, KJ, Wigmore, DJ, Chrysostomou, A, Dempsey, J, Seshadri, R, and Morley, AA (1984) Mutation frequency in human lymphocytes increases in age. Mechanism of Aging and Development 27:83-86.

Tyo, MA, and Thilly, WG (1989) "Novel High Density Perfusion System For Suspension Culture Metabolic Studies." Presented at the 1989 Annual Meeting of the American Institute of Chemical Engineers, San Francisco, CA.

Warburg O, Posener, K, and Negelein, E (1924) Über den Stoffwechsel der Carcinomzell Biochem Z. 152:309-344.

Warburg, O (1956) On the origin of cancer cells. Science 123:309-314.

Ziegler, ML (1978) Phenotypic expression of malignancy in hybrid and cybrid mouse clones. Somatic Cell Genet. 4:477-489. 
$1 \perp \ldots$

$\$$
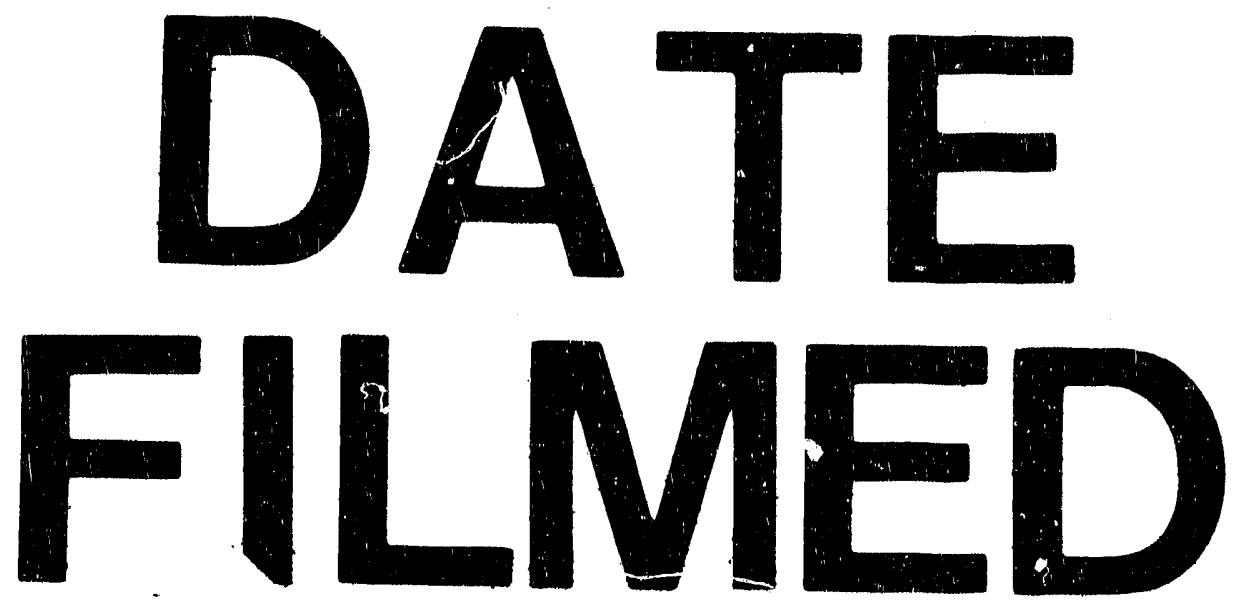

$8111 / 92$ 
